\title{
La plena colonización agraria del Valle Medio del Duero
}

\section{The full farming colonization of the Middle Duero Valley}

\author{
Germán Delibes de Castro*, Fernando Romero Carnicero** \\ Departamento de Prehistoria, Arqueología, Antropología Social y Ciencias y Técnicas Historiográficas. \\ Facultad de Filosofía y Letras. Plaza del Campus Universitario s/n. 47011-Valladolid. \\ *delibes@fyl.uva.es**fromero@fyl.uva.es
}

Recibido: 29-10-2010

Aceptado: 23-02-2011

\section{RESUMEN}

A partir de los inicios del I milenio a.C. se documentan en el valle medio del Duero huellas de la implantación progresiva de nuevas formas de vida campesina; ello da pie, junto a otros argumentos, a analizar el tránsito de la cultura de Cogotas I a la del Soto y a discutir el porqué de tales cambios. Se analizan con posterioridad las características de los nuevos asentamientos en lo que concierne, fundamentalmente, a los emplazamientos, a la arquitectura doméstica y a las estrategias de subsistencia.

Palabras Clave: Valle Medio del Duero. Cultura de Cogotas I. Cultura del Soto. Sedentarización. Aldeas campesinas.

\begin{abstract}
From the early first millenium $B C$, new forms of peasant life are gradually emerging in the Duero valley. On the basis of this and other lines of evidence, the transition between the Late Bronze Age Culture of Cogotas I and the Early Iron Age Culture of Soto is analysed here. The characteristics of the new type of settlements are examined, mainly with respect to site location, domestic architecture and livelihood strategies.
\end{abstract}

KeY words: Middle Duero Valley. Cogotas I Culture. Soto Culture. Sedentarism. Peasant villages.

Sumario 1. Escenario y protagonistas para un hecho histórico. 2. Las comunidades de la Edad del Bronce del Duero medio: ¿Itinerancia o sedentarismo relativo? 3. El Soto de Medinilla: la aparición de un hábitat definitivo. 4. Las bases económicas de la sedentarización. 5. Reflexión final. 
La Historia, en determinada perspectiva, no es más que un proceso progresivo de apropiación de la naturaleza por parte del hombre, cuyos tres primeros grandes hitos fueron la conversión de aquella en paisaje, a raíz de la irrupción en escena de los humanos; la domesticación de la tierra, a partir del Neolítico, dictada por la expansión de la agricultura; y la aparición de un paisaje monumentalizado en el que ciertas manifestaciones antrópicas, entre las que destaca la urbanización, parecen llamadas a rivalizar con las de la naturaleza. Es evidente, que los efectos acumulados de estos tres trascendentales episodios han sido muy parecidos en todas partes, pero no lo es menos que, con sólo ampliar la escala de análisis, se perciben notables diferencias zonales en el tempo de su ejecución: nada tan obvio como que la aparición del hombre no fue acontecimiento simultáneo en todos los rincones del orbe o como que el cultivo fue anterior en las llamadas "áreas nucleares" neolíticas que en los territorios de expansión.

En lo que atañe al fenómeno urbanizador, si trasladamos el ejemplo a la Submeseta Norte española tomaremos conciencia del retraso con que se incorporan a este territorio determinadas novedades que en los hábitats de otras áreas peninsulares están perfectamente arraigadas desde el inicio de la Edad de los Metales. En efecto, sin merecer todavía la consideración de auténticas ciudades en el sentido childeano, los establecimientos amurallados y con agrupaciones de casas de la Edad del Cobre, tanto en el Sureste (Los Millares), como en el curso inferior del Tajo (Zambujal), dan muestras de una considerable entidad y envergadura que los acredita como centros "protourbanos" y no constituyen sino el asomo de una tendencia hacia la complejidad y el pleno sedentarismo que se revela mucho más acusada en los poblados posteriores de la Edad del Bronce del Sureste, en la cultura del Argar. Es evidente que el hábitat en tales casos constituye la materialización de unas particulares formas de vida que, curiosamente, en la cuenca del Duero, sólo van a cuajar más de un milenio más tarde, en torno al año 1000 a.C., con la cultura del Soto.

¿Qué motivos hay para tal desfase? ¿Entraña alguna forma de "retraso" cultural? ¿No merecen, por esta razón, ser consideradas las de la
Edad del Bronce de la cuenca del Duero sociedades complejas? Todas estas preguntas, que se repiten invariablemente en cualquier síntesis sobre la Prehistoria Reciente de la Meseta, van a reaparecer una vez más en estas páginas, pues es nuestra intención analizar en ellas tanto las circunstancias que pudieron obstaculizar el avance del proceso urbanizador en las tierras centrales de la Península, como las soluciones, de tipo adaptativo, arbitradas por las gentes del Primer Hierro para su neutralización.

\section{Escenario y protagonistas para un hecho histórico (Figs. 1 y 2)}

El espacio al que nos remiten los acontecimientos objeto de estudio en el presente capítulo son las tierras nucleares de la cuenca del Duero; una parte muy concreta de aquel bastión de la Meseta que con tanto acierto describiera Alejandro de Humboldt y que, en rigor, constituye la planicie central de una elevada cuenca sedimentaria cuyos bordes se encrespan, al modo en que lo hacen las gradas de un anfiteatro, para formar un cíngulo montañoso (Solé Sabarís 1966). El escenario no es otro, pues, que las campiñas y páramos del valle medio del Duero, con centro casi geométrico en la confluencia de éste con el Pisuerga; un inmenso y casi ininterrumpido labrantío a lo largo de los últimos siglos, que Unamuno, con su implacable prosa, acertara a definir como tierra nervuda, enjuta y despejada.

Si cabe dar cuenta de algún rasgo físico dominante y de fácil percepción en el referido ámbito éste es la horizontalidad, la ausencia de accidentes significados, por más que sea cierto que la sensación de uniformidad se multiplica merced a la monotonía de los cultivos cerealistas - las ubícuas tierras de pan- que, por sistema durante el periodo histórico, se han desenvuelto sobre ellas. Ambos factores, a los que se añade una rala red hidrográfica, de cursos escatimosos, lentos y zigzagueantes, confieren una indudable unidad paisajística a este sector central de la cuenca del Duero, por encima de los matices de diversidad que puedan introducir unos suelos de grandes contrastes litológicos. Y es que la Castilla ancha y presuntamente homogénea de las llanuras responde, en reali- 
dad, a una yuxtaposición de distintas facies sedimentarias que, de Norte a Sur y adoptando la forma de anchas bandas horizontales, se disponen de la forma siguiente: páramos detríticos o de raña, que sirven de enlace con los pliegues secundarios de la Cordillera Cantábrica; planicies arcillosas de Tierra de Campos; el espacio campiñés, modelado sobre arenas eólicas y fluviales, de la Tierra de Pinares, ya al sur del Duero; y, actuando como límite entre las dos últimas, "la más perfecta llanura" de los páramos calcáreos — son palabras de José Ortega Valcárcel (1995: 36) —, que alcanzan a asomar en el centro de la cuenca en su penetración desde el Este, donde constituyen las formaciones dominantes al pie del Sistema Ibérico (García Fernández 1968). En todo caso, una realidad espacial en modo alguno exenta de personalidad orográfica a la que, siguiendo la tradición de los estudios de Federico Wattenberg en su ya clásica "Región Vaccea", los arqueólogos nos referimos asiduamente con el poco expresivo término de valle medio del Duero.

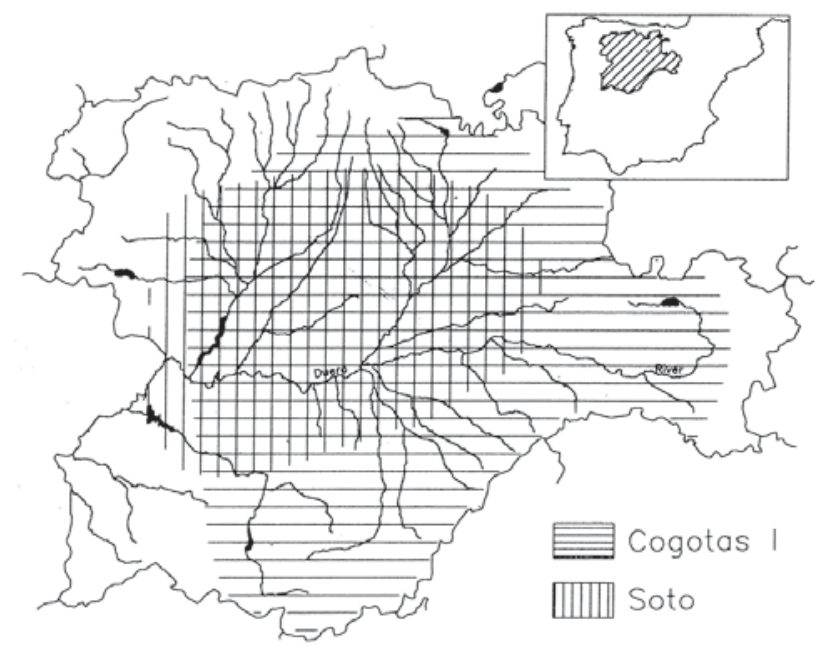

Figura 1.- Distribución geográfica de las culturas de Cogotas I y del Soto en el valle del Duero (Delibes et al. 2001).

Sobre esa despejada planicie, que tiene una extensión de varias decenas de miles de kilómetros cuadrados, que fluctúa altitudinalmente entre los 900 y los $600 \mathrm{~m}$ sobre el nivel del mar, que se vertebra en torno al eje del Duero Medio y al curso más bien bajo de sus principales afluentes de ambas márgenes -Pisuerga, Valderaduey, Cea, Esla, Cega y Adaja-, y que en distintos momentos de la Historia, como demostrara H. Hopfner (1954) a partir del análisis de la toponimia, debió contar con una cobertera enciniega importante, hoy irreconocible; sobre esos campos de horizonte sin fin a los que no cuesta mayor trabajo identificar con la Castilla casi yerma y llana cantada por los autores del 98, por oposición a aquella otra diversa en lo paisajístico y más fragosa en lo orográfico de los espacios periféricos de la cuenca; sobre esa estepa que, en mayor o menor medida, se extiende por ocho de las provincias actuales de la Comunidad de Castilla y León - el Páramo y los Oteros leoneses, las Tierras del Pan y del Vino de Zamora, la Armuña salmantina, la Moraña abulense, la Ribera de Burgos y Segovia o las tierras horizontales de Campos y Torozos en Palencia y Valladolid-; sobre ese espacio, en fin, se asiste al florecimiento, allá por el año 1000 cal a.C. y frisando el comienzo de la Edad del Hierro, de una cultura campesina de gran personalidad, la del Soto, que da al traste con las formas de vida arcaizantes, todavía caracterizadas por cierta movilidad, de las comunidades de la Edad del Bronce y que marca el punto de inflexión hacia un nuevo modelo de paisaje, con núcleos de habitación de considerable entidad y estabilidad y, sobre todo, con la aparición en torno a ellos de un ager y un saltus fuertemente antropizados, escenario de prácticas agropecuarias cada vez más elaboradas. En suma, un paso importante en la creación de ese típico espacio rural que, sin demasiadas modificaciones, ha pervivido en gran parte del agro castellano hasta su abandono hace poco más de medio siglo.

Esta es la particular circunstancia histórica que propicia nuestra participación en esta obra colectiva y que aconseja efectuemos seguidamente una presentación de los principales rasgos arqueológicos de quienes fueron sus protagonistas: los propios campesinos soteños, por supuesto, y aquellas comunidades de la Edad del Bronce que les precedieron, a las que los arqueólogos hemos bautizado con el nombre de Cogotas I en homenaje a los hallazgos producidos en el nivel inferior de tan afamado castro abulense (Cabré 1930). Comencemos por las últimas, no en vano fueron las primeras en ocupar el territorio del valle medio del Duero.

Al igual que el resto de las "culturas arqueológicas" perfiladas a mediados del pasado siglo, 
la de Cogotas I adquirió carta de naturaleza a partir del reconocimiento de ciertos rasgos distintivos en su equipamiento material, rasgos que en este caso, antes de tener claro cómo eran sus poblados, sus enterramientos o su economía, por ejemplo, vinieron dados fundamentalmente por el pintoresquismo de las decoraciones de sus cerámicas. A las gentes - o a los pastores, como aún acostumbra a llamárseles sin el debido fundamento - cogotianas se las identifica, en efecto, con una vajilla singular, todavía hecha a mano, en la que predominan unos grandes platos y fuentes de perfil troncocónico cuyas paredes, por lo común - los recipientes decorados distan mucho de ser minoritarios, como en la alcallería campaniformese adornan con abigarradas composiciones geométricas casi siempre radiales, en las que falta cualquier tema figurativo. Se trata de decoraciones sobre todo incisas e impresas, que nada raramente se extienden al interior de los bordes, pero también materializadas con dos técnicas singulares, la excisión y el "punto en raya" o Boquique, que pasan por ser los auténticos signos de identidad de Cogotas I. Apresurémonos a señalar, en todo caso, que ninguna de las cuatro es, en rigor, técnica propiamente decorativa por cuanto su verdadero objetivo es grabar - cuando todavía está el barro tiernomotivos destinados a recibir una pasta o incrustación blanca o más raramente roja creando el efecto de un vaso pintado (Maluquer de Motes 1956; Delibes, Fernández y Rodríguez 1990).

A partir de los años setenta, la multiplicación de las excavaciones constituyó el revulsivo necesario para perfilar la personalidad de Cogotas I más allá de sus productos alcalleros, permitiendo dar cuenta de otros rasgos distintivos de este horizonte prehistórico de la Meseta. La atención en este sentido se centraría en la irrelevancia constructiva de sus poblados, normalmente reducidos a chozas de postes y ramaje con un leve manteado de barro, por lo que suponían de contrapunto respecto a las arquitecturas duraderas, de piedra, de otras culturas de la Edad del Bronce peninsulares como El Argar, Las Motillas o el Bronce Valenciano. Todo ello anticipaba cierta dificultad a la hora de reconocer la planta de las unidades habitacionales, acentuada por otra circunstancia adversa: el arrasamiento sistemático de los niveles cimeros de los yacimientos - ubicados insistentemente en áreas de cultivo - bajo los efectos devastadores del arado. De ahí que, salvo en contados sitios, como el Teso del Cuerno de Forfoleda, en Salamanca, donde se lograra identificar la planta de una gran cabaña rectangular con cabecera absidal, construida con postes (Martín Benito y Jiménez González 1989), los excavadores debamos casi siempre conformarnos con registrar en los hábitats de entonces fosas y hoyos sin número que, lejos de corresponderse con los primitivos suelos de ocupación, constituyen tan sólo el extremo inferior y más profundo - por eso el único conservadode unos depósitos arqueológicos originalmente más complejos y ricos. Poblados, en suma, de no mucha entidad, construidos con materiales leznes que, como ha subrayado María Dolores Fernández-Posse (1998: 112-114), invitaban a pensar en formas de vida itinerantes y que, a la larga y al amparo del estudio de algunas colecciones faunísticas, no se vacilaría en atribuir a grupos pastoriles instalados en la movilidad.

Existe cierta controversia sobre la posición que ocupa Cogotas I en la secuencia de la Edad del Bronce peninsular, lo cual es resultado en parte de la errática tipología de los escasos materiales metálicos adscritos al grupo (Fernández-Posse 1998: 106-111). La circunstancia de que nada raramente figuren entre ellos hachas planas y puñales de roblones justifica el deseo de algunos autores de considerarla cultura del Bronce Pleno; pero la asociación no menos recurrente a las cerámicas excisas y del Boquique de otros de tipología mucho más moderna, caso de lanzas tubulares, armas pistiliformes y fíbulas de codo, denota su prolongación hasta los primeros compases del Bronce Final (Delibes, Fernández Manzano y Herrán 2007). Cogotas I actúa en este aspecto metalúrgico, por tanto, como un singular complejo bifronte, a horcajadas entre antiguas tradiciones y la renovación lo cual, junto a su condición de epígono de El Argar en algunos yacimientos del Sureste, sirvió en su día de disculpa para proponer su asimilación a un inédito Bronce Tardío, a mitad de camino entre el Pleno y el Final (Molina González 1978).

Hace algo más de medio siglo, Pedro Bosch Gimpera (1942) y Martín Almagro Basch (1939), tras reparar en la analogía de las de- 

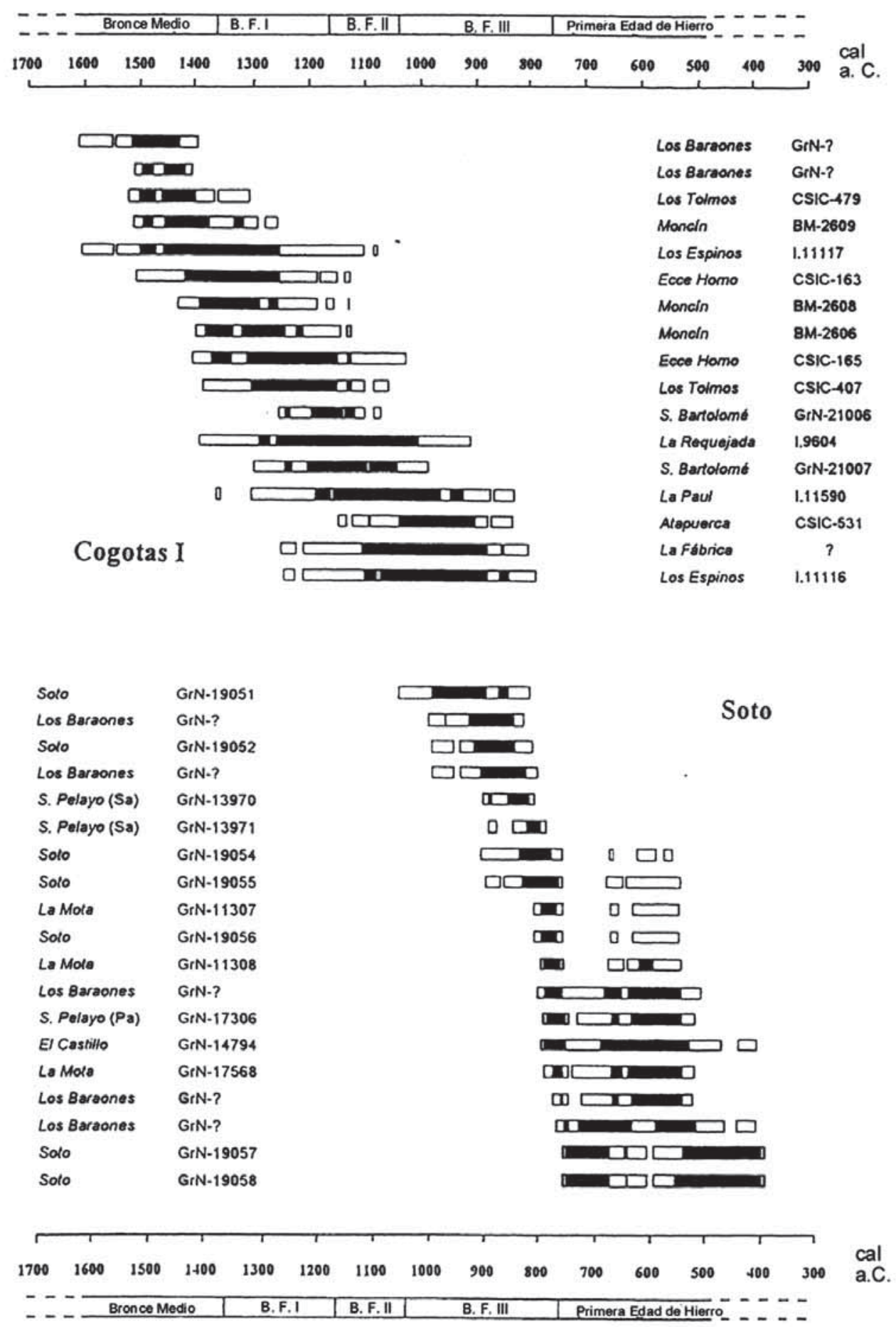

Figura 2.- Dataciones radiocarbónicas de la transición Cogotas I-Soto en la Península Ibérica (Delibes et al. 1999). 
coraciones excisas de esta clase de cerámica con respecto a las de la vajilla del Bronce Final y del Primer Hierro en Centroeuropa, atribuyeron su presencia en la Meseta a un aporte demográfico ultrapirenaico, indoeuropeo se decía, que el primero no dudaría en identificar con la primera de las invasiones de los Campos de Urnas perpetrada por los pasos pirenaicos occidentales. Maluquer, en cambio, a raíz de las investigaciones que llevara a cabo sobre los yacimientos de Sanchorreja y El Berrueco, en Ávila y Salamanca respectivamente, insistiría en la importancia del componente indígena de Cogotas I y contemplaría la posibilidad de una cultura de síntesis, aglutinadora de elementos europeos, responsables de la técnica excisa, y locales cuya huella, en este último caso, cabía rastrear, en lo que a la cerámica se refiere, en la incrustación de pasta blanca de fuerte arraigo en la Meseta desde los tiempos del campaniforme Ciempozuelos (Maluquer de Motes 1956 y 1958a: 68). Hoy, conocida la anterioridad de Cogotas I respecto a los fenómenos centroeuropeos que pasaron en principio por ser sus inspiradores, advertida también la singularidad de los rituales funerarios del grupo - inhumaciones simples en fosa dentro de los poblados, muy en línea de nuevo con Ciempozuelos y sin réplica convincente al norte de los Pirineos (Esparza 1990) — apenas si existen argumentos para dudar del indigenismo de Cogotas I (Delibes y Romero 1992; Delibes 2001).

Al igual que Cogotas I, la cultura del Soto nació, historiográficamente hablando, a partir de la identificación de un rasgo peculiar de su cultura material: la planta circular de sus viviendas; un detalle que, por encima de tal concomitancia y como tendremos ocasión de explicar a continuación, no viene sino a subrayar lo contrario, y en buena medida anómalo, de dicho proceso de gestación. El vallisoletano Soto de Medinilla, un yacimiento situado a las afueras de la capital, donde fue descubierto en los primeros años treinta del pasado siglo, fue excavado, de manera más o menos regular, entre los años cincuenta y sesenta; tal empresa terminó por sacar a la luz hasta un total de cinco poblados superpuestos que, si por algo se caracterizaban era, como decíamos, por la peculiar planta de sus casas (Palol y Wattenberg 1974: 181-195). Un hecho del que se despren- den otros varios en relación con lo apuntado en un principio.

De no ser por sus viviendas, en primer lugar, El Soto de Medinilla, aun sin haber pasado seguramente desapercibido, no se habría convertido en el unicum que terminó siendo, pues, frente a ese rasgo - cuyo origen trataba de rastrear su excavador, Pedro de Palol, en el substrato indígena del mediodía peninsular-, otros muchos, por no decir todos los demás, apenas si le diferenciaban, como se encargaba de destacar dicho investigador (Palol 1974), de otros yacimientos contemporáneos, y muy particularmente de los poblados asimismo superpuestos que, por aquellos mismos años en que se intervenía en la estación que comentamos, había dado a conocer Juan Maluquer de Motes (1954 y 1958b) tras sus excavaciones en El Alto de la Cruz, de Cortes de Navarra. Curiosamente, en tanto que este último calificaba al yacimiento navarro de hallstáttico, el primero se refería al vallisoletano como céltico.

Por otro lado y desde el primer momento, la cultura del Soto quedaba configurada, en las más de las características de su cultura material - cerámica, metalurgia, arquitectura doméstica y defensiva, patrón de asentamiento o vocación económica-, a partir de un sólo yacimiento: El Soto de Medinilla, prácticamente el único conocido del grupo y, por supuesto, el único excavado. Ello terminó por convertirlo en el espejo en el que irían reflejándose cuantos yacimientos se descubrieron en adelante y en el faro que ha guiado buena parte de la investigación posterior, lo cual, como supo ver Fernández-Posse (1998: 46-52 y 141-155), no ha dejado de constituir un profundo lastre para esta última y ha conducido, muy seguramente, al empleo de términos que, pretendidamente asépticos - tales como horizonte, grupo o facies - , han retardado hasta no hace tanto su reconocimiento como cultura arqueológica.

Conviene recordar en relación con lo dicho, por una parte, cómo la excavación del tell, que la continuada ocupación del solar a lo largo de casi medio milenio terminó por configurar en El Soto de Medinilla, desveló la superposición de cinco poblados sucesivos, de casas circulares de adobe todos ellos; y cómo, por otra, fueron individualizadas dos grandes fases en su desarrollo — Soto I y Soto II-, delimitadas 
por el potente nivel de incendio detectado entre el segundo y el tercero de aquellos. Pues bien, dicha secuencia fue determinante, durante un buen número de años, a la hora de analizar la evolución y establecer la periodización de la cultura homónima, en la medida en que las dos fases identificadas a lo largo de la vida del poblado vinieron aplicándose, por extrapolación, al desarrollo de toda la cultura. De esta manera, los cada vez más numerosos yacimientos de filiación soteña que iban descubriéndose se adscribían al Soto I o II, según sus materiales, cerámicos en lo esencial, pudieran paralelizarse, respectivamente mejor, con los recuperados en los dos niveles inferiores o en los tres más recientes del yacimiento epónimo; por idéntica razón, y dada la analogía establecida por $\mathrm{Pa}-$ lol entre el Soto II y el poblado PIIb de Cortes de Navarra, se fechaban entre el 800 y el 650 a.C. o entre esta última fecha y un momento impreciso pero anterior, en cualquier caso, al 400 a.C.

Puede decirse así, en definitiva, que los resultados aportados por las prospecciones llevadas a cabo en años sucesivos no venían sino a abundar en lo ya conocido. El escalonamiento de los asentamientos a lo largo de las principales vías fluviales seguía el patrón del propio Soto de Medinilla, localizado a orillas del Pisuerga; en virtud de ello, y como él, debieron haber basado su economía en el cultivo intensivo de las gramíneas. Frente a las vistosas cerámicas cogoteñas, las monótonas y por lo general bastante aburridas del Soto apenas si han merecido por ello una particular atención; es así cómo al día de hoy no contamos todavía con un estudio de conjunto sobre las mismas, dándose la circunstancia de que unas "notas" con las que se pretendió vislumbrar el carácter diagnóstico de ciertas formas para cada una de las dos fases mencionadas - vasitos carenados para el Soto I y vasitos ovoides de cuellos diferenciados, platos de borde almendrado y esbeltos pies anulares para el Soto II-, realizadas curiosamente a partir de dos colecciones de otros tantos yacimientos vallisoletanos (Romero 1980), han sido el punto de partida, poco menos que obligado, de ulteriores estudios. La metalurgia, salvo una escueta y un tanto incómoda referencia a la aparición de fragmentos de hierro en los niveles del yacimiento de refe- rencia correspondientes al Soto I, remitía en todos sus testimonios, ya estuvieran vinculados a la producción - caso de moldes y crisoles de fundición - o se tratara de auténticos elaborados, como algunas puntas de jabalina de corto enmangue tubular, al mantenimiento de la tradicional en bronce. Entre tanto, la muralla de adobes y empalizada del mismo Soto de Medinilla, cuya vida corrió pareja a la del poblado Soto I-2, en tanto única, no pasaba de ser una mera anécdota; y los cementerios seguían resistiéndose insistentemente a aparecer. La intensificación y sistematización de las prospecciones y la excavación de nuevos yacimientos, en las dos últimas décadas del siglo XX, y el concurso de la fotografía aérea han permitido ampliar nuestros conocimientos en muchos aspectos y, muy particularmente, en los que tienen que ver con lo que aquí tratamos, razón por la cual serán comentados en el momento oportuno.

Una última cuestión. Como hemos visto, Cogotas I se relacionó en un determinado momento con las primeras invasiones de Campos de Urnas, de ahí que al descubrirse El Soto de Medinilla y reivindicarse para sus gentes idéntica raigambre indoeuropea se planteara un problema de nada fácil solución, dadas las enormes diferencias entre sus respectivos bagajes materiales y máxime cuando, por los mismo años y a escasos metros de la estación vallisoletana, en el inmediato barrio de San Pedro Regalado, se descubría y excavaba asimismo un asentamiento cogoteño. Es así como se esgrimió una dualidad cultural - pastores de cerámicas excisas y del Boquique, de un lado, $\mathrm{y}$, de otro, agricultores de aluvión portadores de cerámicas pintadas hallstátticas-, que permitía contemplar a Cogotas I y el Soto como dos facies, diferentes y en parte contemporáneas, del Primer Hierro en el Duero Medio (Palol 1963 y 1974).

En el curso de los últimos años el problema ha sido reconducido. Así, en relación con Cogotas I y como queda igualmente dicho, al demostrarse su mayor antigüedad, ubicándose en la secuencia de la Edad del Bronce peninsular, y admitirse su indigenismo. Salvado el escollo cronológico, la investigación se interesó por el tránsito Cogotas I-Soto y la filiación de esta última cultura (Romero y Ramírez 
2001; Romero, Sanz y Álvarez-Sanchís 2008: 652-657). El primero de los aspectos mencionados se ha planteado en términos claramente rupturistas, dadas las diferencias que a todos los niveles separan a ambas culturas — de ahí sin duda que buena parte de los trabajos de síntesis sobre la del Soto, y este mismo es un nuevo ejemplo, arranquen, al objeto de apreciar el contraste, del último Cogotas I (Delibes y Romero 1992; Romero y Jimeno 1993; Delibes et al. 1995a) - , lo que ha dado pie a su vez a insistir en los presupuestos invasionistas. Así, a la ya mencionada filiación céltica del Soto, siguieron la hallstáttica o la de Campos de Urnas, hasta que, demostrada la imposibilidad de hablar de tal para las tierras del interior peninsular - ni siquiera en las versiones más matizadas de "tradición" o "influjos" (Almagro-Gorbea 1986-87)_, se volvió a llamar la atención sobre la ascendencia meridional de algunos, y cada vez más (Romero y Ramírez 1996), de sus elementos, se valoraban los componentes autóctonos y se abría camino, como posible explicación alternativa para el cambio cultural, un complejo proceso de evolución interna en el que todos los aspectos mencionados podrían tener cabida (Delibes et al. 1995a: 7982). La cuestión, por lo que a este punto respecta, no está ni mucho menos resuelta y para nada extraña que, insistiendo en esa evidente ruptura, de cuando en cuando ciertas voces no descarten o se pregunten por la llegada de gentes foráneas (Esparza 1995: 140-144; Delibes y Fernández Manzano 2000: 113-117).

\section{Las comunidades de la Edad del Bronce del Duero medio: ¿Itinerancia o sedentarismo relativo?}

\subsection{El paradigma del nomadismo pastoralista: construcción y consecuencias}

Al haber sido tantos los prehistoriadores identificados con la opinión de que las comunidades de la Submeseta Norte, antes de la Edad del Hierro, fueron pastores itinerantes, no es fácil, llegada la hora, imputar a un autor determinado la paternidad de la idea ni precisar el momento en que tuvo lugar su alumbramiento. Pero esta es orfandad propia de este y de todos los tópi- cos, en tanto se trata de realidades instaladas en el subconsciente colectivo.

De cualquier manera, los fundamentos o primeros anclajes de la hipótesis se encuentran ya en los trabajos que dedicara Maluquer de Motes, en su etapa salmantina, a la investigación de la prehistoria reciente de la cuenca del Duero. Allí se comenzaría a subrayar que las comunidades locales de avanzada la Edad del Bronce recurrieron, para la ornamentación de la cerámica, a una técnica, la excisión, que en sus efectos resultaba sensiblemente similar a las labores "a punta de navaja" (kerbschnitt) propias de la artesanía pastoril. También se anotó que los yacimientos de entonces se concentraban mayoritariamente en espacios, como el piedemonte del Sistema Central, orientados tradicionalmente a la cría de ganado (Maluquer de Motes 1956). Además, los sitios habitacionales se caracterizaban por una escasa presencia física, muy inferior a la de los poblados de gran parte de las culturas de la Edad del Bronce peninsular, lo que se atribuía a la extrema movilidad de sus moradores (Almagro-Gorbea 1986). Y, con el paso del tiempo, algunas décadas después, vendrían a redondearse los argumentos con un dato tan atractivo como polémico: los yacimientos con aquellas pintorescas cerámicas excisas y del Boquique, asimiladas, como hemos dicho, al grupo Cogotas I, además de por la Meseta, donde se reconoce su máxima densidad por lo que hablamos de un Área Nuclear, se reparten también por el País Valenciano, el Sureste y el valle del Guadalquivir, mostrando cierta superposición respecto a los viales cañariegos que, a partir de la Baja Edad Media, acotara el Honrado Concejo de la Mesta (Abarquero 1997), en lo que varias veces ha querido verse la prueba de una forma de vida trashumante de fácil y tentador acomodo a la hipótesis nomadista tradicional.

Asentamientos efímeros, en fin, para pueblos ambulantes. Este es el eslogan que ha venido a resumir hasta hoy la realidad de los hábitats del Bronce meseteño y que no deja de hacer cierta justicia a unos hechos arqueológicos insoslayables: en los poblados no documentamos verdaderas casas sino cabañas de materiales poco duraderos; los sitios rara vez presentan largas secuencias ni estratigrafías horizontales reveladoras de ocupaciones 
claramente sucesivas; no cuentan, por regla general, con fortificaciones artificiales de alcance, comparables a las de los hábitats argáricos o de Las Motillas, también de la Edad del Bronce aunque algo anteriores; y quienes moran en ellos recurren por sistema a fórmulas constructivas en las que sólo intervienen materiales efímeros -madera, ramaje, manteados de barro-, declinando el uso de la piedra o del barro a gran escala, pese a la importancia que el amasado de este último, bajo la forma de tapial, llegó a tener dos milenios antes en algunos sepulcros colectivos neolíticos de la región, como el túmulo de La Velilla, en Osorno (Delibes y Zapatero 1996: 338). De tal manera, los prehistoriadores parecemos condenados a descubrir en los yacimientos habitacionales de esta época poco más que estructuras negativas, ya se trate de las cubetas de las chozas y otros hoyos que, a partir de 1924 y por iniciativa de Pérez de Barradas (1924: 33), denominamos "fondos de cabaña", ya de las improntas de los postes utilizados para sustentar sus cubiertas, sin que en la mayoría de los casos se alcance a conocer la relación orgánica entre tales subestructuras a falta de los depósitos - normalmente desmantelados por el arado, dada la condición de agro sin límites de este territorio campiñés- que originalmente los ensamblaban y conferían sentido.

Así, el panorama que ha llegado a perfilarse es bastante desalentador y justifica la frustración de los resultados de centenares de intervenciones dedicadas en las dos últimas décadas a exhumar yacimientos de estas características, sin mayor beneficio que una reiteración de hechos, por ya sabidos, insustanciales: su asignación al horizonte Cogotas, o al anterior Proto-Cogotas, merced a la presencia en los "fondos" de los correspondientes fósiles-guía cerámicos, su datación absoluta o ciertas especulaciones sobre la funcionalidad de tales subestructuras. Escaso fruto, insistimos, para lo que tales trabajos de campo representan de erosión patrimonial y para proceder de la lectura de los únicos documentos posibles - no los hay mejores, ni peores; el "campo de hoyos" es lo que es- con vistas a reconocer la habitación de la Edad del Bronce en la Meseta castellana.
Tal despliegue de desinformación ¿no es normal que se materializara en una tesis también un tanto evanescente e inasible como la del nomadismo? Por miopía de los propios arqueólogos más que por auténtica afasia de los documentos investigados, los campos de hoyos de las comunidades prehistóricas del valle medio del Duero continúan siendo yacimientos rodeados de un halo de misterio, con una problemática en gran medida por desentrañar, pero cuanto se sabe de ellos no representa mejor aval para la hipótesis de unas ocupaciones estacionales, tan cara a los planteamientos ganaderos trashumantes o transterminantes, que para defender un régimen semisedentario compatible con prácticas agrícolas o mixtas (Jorge 1998: 249; Díaz del Río 2001: 110-125).

\subsection{Los campos de hoyos ¿hábitats de ocasión?}

Los estudiosos de estas manifestaciones, suelen ser concluyentes y bastante unánimes a la hora de responder afirmativamente a esta pregunta, por entender que el campo de hoyos es un tipo de yacimiento acumulativo en el que, sin demasiada planificación, a unas fundaciones iniciales de muy poca entidad se van agregando por yuxtaposición otras posteriores, sin que los sitios aspiren de antemano a una configuración definitiva. Realidades semovientes, por tanto, no espontáneas por completo en su desarrollo pero sí poco planificadas, de ahí que se desconozcan límites preestablecidos en los poblados de este signo o que raramente se perciban indicios de una distribución ordenada del espacio, de acuerdo con un proyecto inicial. Una circunstancia ilustrativa de que tales caseríos fueron fruto de la improvisación y de que, con alguna probabilidad, constituyeron el exponente habitacional de contingentes humanos que no contemplaban una permanencia definitiva en ellos: tal vez esos pastores trashumantes que, por las necesidades de sus ganados, apenas se detienen transitoriamente en un sitio para buscar rápidamente nuevo acomodo en otro diferente y que, por ello, ni invierten seriamente en infraestructuras ni se enredan en onerosos ritos de fundación como los que caracterizan a la mayoría de los pueblos sedentarios. No faltan apoyaturas teóricas, así, para 


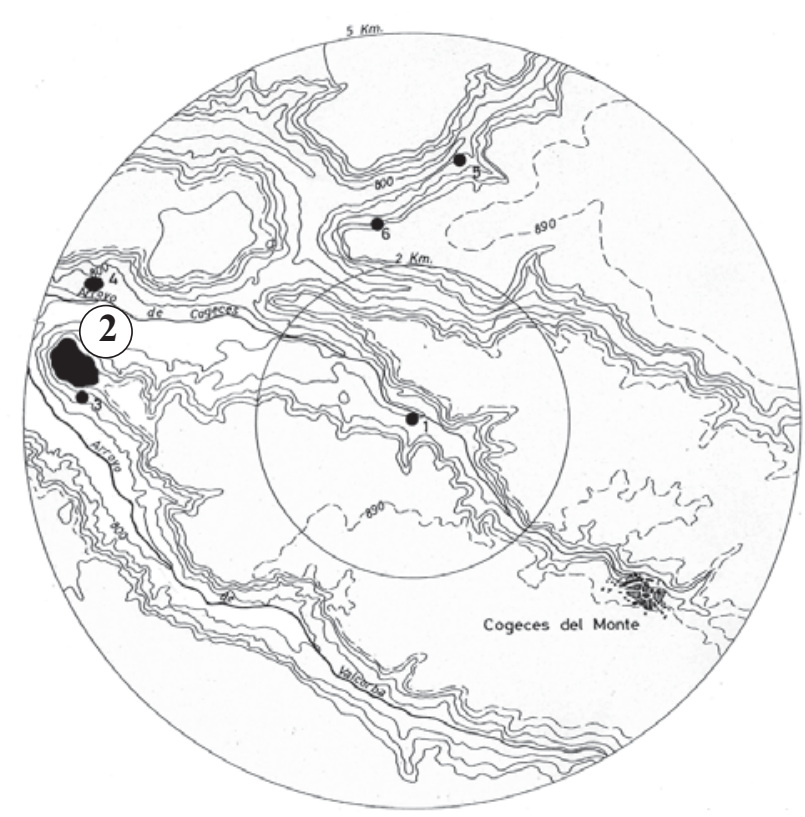

Figura 3.- Modelo de poblamiento jerarquizado Cogotas I: el yacimiento central de La Plaza ( $\left.\mathrm{n}^{\circ} .2\right)$, en Cogeces del Monte (Valladolid) y sus satélites. (Rodríguez Marcos 1993).

interpretar el campo de hoyos como la expresión arqueológica de un campamento nómada, de un aduar que aúna provisionalidad y eficacia $\mathrm{y}$ en el que se descarta una fuerte inversión en arquitectura por aquello de la brevedad de la ocupación que se anuncia.

Hasta ahora, esta lectura había intentado contrarrestarse con la evidencia de un poblamiento jerarquizado o complementario, en el que unos pocos establecimientos mayores y por lo general en alto -la Mesa del Carpio, en Salamanca (Cruz 1997: 270-271), Carricastro en Valladolid (Delibes et al. 1995a: 53) o el Ecce Homo en Madrid (Almagro-Gorbea 1986: 366-368)- actuarían como núcleos centrales de referencia para las pequeñas alquerías que se diseminan a sus pies. Sin duda, un modelo de poblamiento impropio de poblaciones no sedentarias, en el que cobran sentido como reclamos centralizadores determinadas "obras públicas", bien se trate de cercas de ganado o de murallas, como las acreditadas en los "castros" de Cogeces del Monte (Fig. 3) o Cevico Navero (Delibes y Fernández Manzano 1981; Rodríguez Marcos 1993; Rodríguez Marcos y Moral del Hoyo 2007). Aunque contadas, no deja de tratarse de evidencias en contra de la hipótesis de la provisionalidad, pero no es nuestra intención insistir en ellas sino volcar nuestro esfuerzo en la reivindicación de los clásicos poblados de llanura, esto es, de los campos de hoyos, como asentamientos surgidos de una planificación y, como tales, dotados de unos límites físicos establecidos en el mismo momento de su fundación.

Una primera aproximación a la realidad de los campos de hoyos nos obliga a recordar que no se trata de un tipo de yacimiento exclusivo y específico de la fase Cogotas I, sino representativo, por lo que a la Meseta se refiere, de toda la Prehistoria reciente anterior a la cultura del Soto. En efecto, los incontables sitios de este tipo documentados modernamente por la arqueología de urgencia en los espacios campiñeses tanto del Duero como del Tajo, autorizan a ver en el campo de hoyos un modelo de yacimiento $\mathrm{y}$, forzando algo las cosas, un elemento identitario común a todas las poblaciones del interior de la Península entre el Calcolítico precampaniforme y el horizonte de las excisas y del Boquique. Casi un hilo conductor dotado, en nuestra opinión, de cierto sabor étnico, lo que posibilita que los comentarios a que dan lugar alguno de ellos resulten aplicables a todos los de ese intervalo temporal (Díaz del Río 2001: 130).

Para mejorar la percepción de los campos de hoyos, tan obstaculizada por los estragos de la erosión y del arado y, en no menor medida, por la adopción de escalas inadecuadas en las excavaciones - las pequeñas calicatas habituales rara vez tienen efectos panorámicos sobre la totalidad de un yacimiento de estas características-, recurrimos en la actualidad a un procedimiento de registro poco habitual como es la Arqueología Aérea. Dando con las condiciones idóneas de altitud, inclinación, luminosidad, tempero, o crecimiento vegetal -lo que obliga a perseverar en el sobrevuelo de los mismos sitios-, la fotografía desde el aire aporta imágenes enormemente reveladoras sobre la configuración de los campos de hoyos, a través de las cuales queda claro que muchos de ellos responden a un esquema y a una planificación previos conforme se deduce de la precisión de sus límites. Todo muy lejos, pues, de aquel planteamiento que los suponía resultado de simples agregaciones progresivas un tanto improvisadas (Fernández-Posse 1998: 113). 
He aquí el comentario que inspira un análisis desde esta óptica de dos yacimientos que reflejan a la perfección cuanto decimos, ambos fundados en la Edad del Cobre, con reocupaciones Cogotas I: el poblado de San Miguel, en Cubillas de Cerrato, en el Sur de Palencia, y el de El Casetón de la Era, a escasos doscientos metros al este del monasterio cisterciense de Matallana, en la provincia de Valladolid. Los fotogramas aéreos permiten documentar en los dos casos unos anillos o fosos de varios metros de anchura que los circunvalan y que, aunque en distinto número - sólo uno en Cubillas y tres, concéntricos, en Matallana-, responden a la intención de acotar espacios más o menos ovales de entre una y dos hectáreas (Fig. 4). Las fotos aéreas, obtenidas a finales de primavera, cuando merma la humedad del terreno y se producen grandes contrastes en el crecimiento de las siembras, revelan también la existencia de una enorme cantidad de hoyos, mayoritariamente en el interior de los recintos pero también fuera (Cubillas), e incluso la existencia de "puertas" o zonas de acceso relativamente bien diferenciadas.

Pero ¿cuál es la contribución de estas imágenes al conocimiento de los hábitats de aquel momento de la prehistoria? Sobre todo la seguridad de que un campo de hoyos no es un sitio básicamente natural que el hombre prehistórico domestica de forma precipitada y casi involuntaria con su ocasional presencia, convirtiéndolo en apeadero, sino la plasmación de un proyecto concienzudo. Y, por añadidura, la oportunidad de comprobar que la fundación de esta clase de asentamientos exige una nada desdeñable inversión de trabajo, la excavación de cientos o miles de metros cúbicos de gravas o margas - iZanjas de drenaje imprescindibles para el saneamiento de unos hábitats siempre muy próximos de los lechos fluviales? ¿Signos de soberanía? ¿Simples defensas? (Bradley 1984: 121) - , que se nos antoja tarea desproporcionada e incompatible con la hipótesis de una mera ocupación transitoria, de tipo estacional. Nuestro sentido práctico está reñido con esfuerzos gratuitos y el hombre no se entrega al trabajo sin estar seguro de rentabilizarlo. De ahí la deducción irrebatible de que quienes pusieron tanto empeño en realizar las referidas infraestructuras preveían una estancia duradera.

En todo caso, pese a no ser poco lo avanzado, ningún problema estará definitivamente

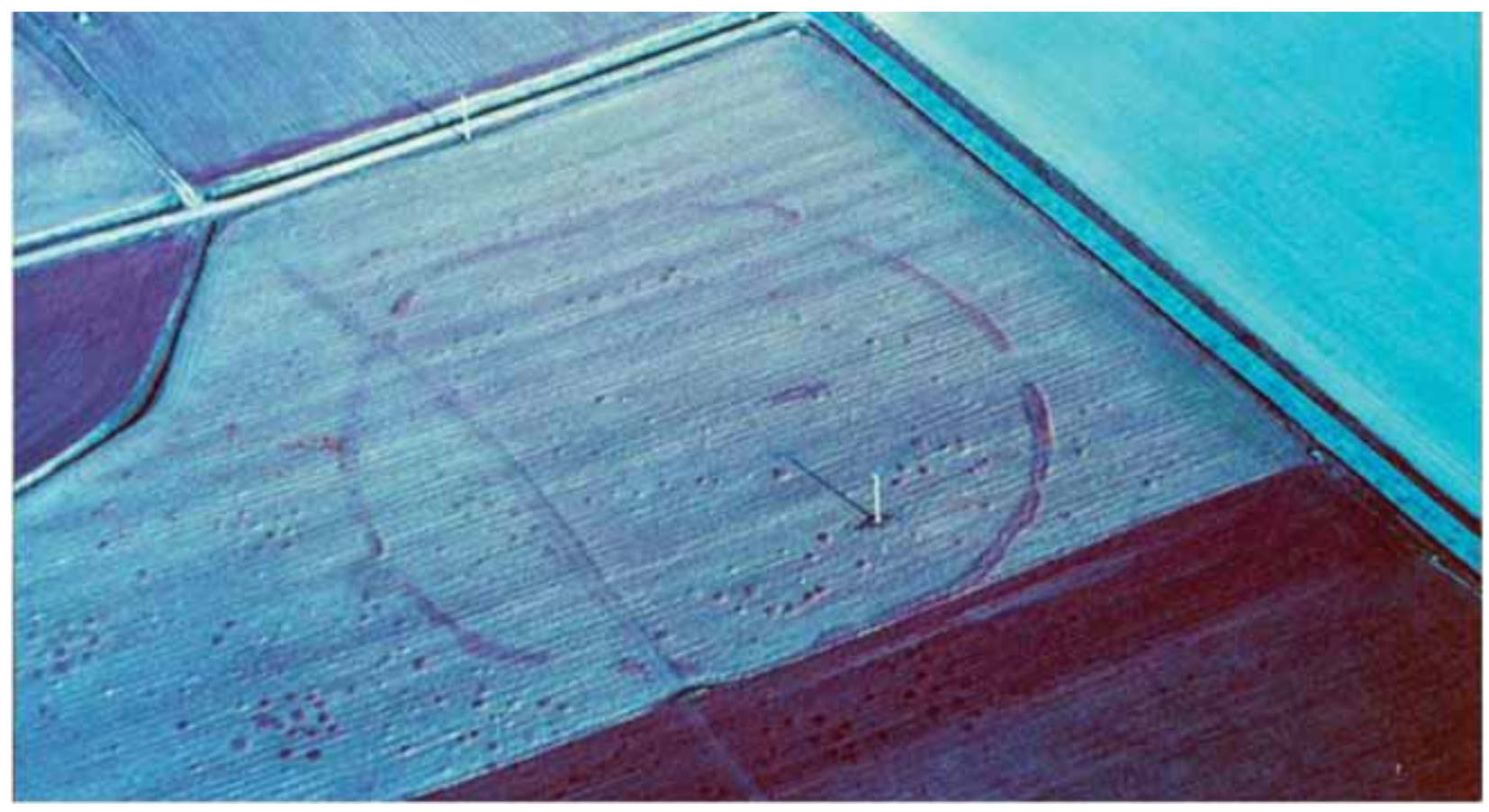

Figura 4.- Campos de silos y recintos de fosos fueron complementarios a partir del Calcolítico. Vista aérea del yacimiento palentino de San Miguel, en Cubillas de Cerrato (Palencia). Fotografía de infrarrojos de J. del Olmo. 
resuelto mientras continuemos apelando a términos ambiguos y subjetivos como "permanencia considerable", y en tanto no seamos capaces de cuantificar la duración de las ocupaciones. De nuevo la teoría y los datos relativos iluminan los problemas y contribuyen a formulaciones más exactas, pero no los resuelven enteramente. Así y todo, nos parece significativo comprobar cómo nuestros yacimientos, tan reiteradamente atribuidos - por sus, en apariencia, pobres infraestructuras- a comunidades nómadas y a ocupaciones estacionales, revelan unas características idénticas a los de la gran mayoría de sus contemporáneos de Europa occidental, cuyo sedentarismo nunca se ha puesto en duda. Las fotos aéreas comentadas de Cubillas y Matallana, en efecto, aunque no con el rigor y la exactitud con que permitiría hacerlo su excavación, acreditan poblados en nada diferentes de los ring forts británicos (Needham 1992) o de los champs fossés del Oeste de Francia (Blancquaert et al. 2000). Presentan los mismos anillos perimetrales e idéntico caos de hoyos que las excavaciones sistemáticas han revelado en un yacimiento tan emblemático del Bronce Final como el de Mucking, en Essex (Jones y Bond 1980). Pero la relación de paralelos posibles llegaría al infinito y acabaría convocando incluso, aunque suelan sustituir fosos por empalizadas, a los mismos palafitos del lago Neuchatel - ¿alguien cree honestamente que caracterizados por el uso de materiales más duraderos que los de los hábitats Cogotas? - de cuya profundidad trayectorial, pese a algunas interrupciones motivadas por las variaciones de nivel de las aguas lacustres, dan crédito las pulcras series dendrocronológicas obtenidas en ellos (Arnold 1992; David-El Biali 1982).

Conste, en cualquier caso, que nada de lo dicho supone menoscabo de la importancia que numerosos autores atribuyen a la ganadería en la Edad del Bronce (Kristiansen 1989: 70). Porque ¿acaso es posible pasar por alto que los sedimentos de la cueva burgalesa de El Mirador, por recurrir a un documento próximo al área de estudio, en vez de corresponder a ocupaciones humanas son consecuencia del uso de tales cavidades como tenadas para guardar los rebaños? (Vergés et al. 2002: 109111). La actividad pastoril, según acreditan los estudios micromorfológicos, fue notoria en el norte de la Península desde el Neolítico y no dejó de serlo en Cogotas I, a juzgar por los estudios de fauna de Moncín (Harrison, Moreno y Legge 1994) o por los más modernos de El Pelambre, en León (Fernández Rodríguez 2009). Pero ¿por qué insistir en nuestro caso en un pastoreo identificado con un nomadismo a ultranza que nadie reconoce abiertamente, ni siquiera en el problemático complejo kurgán (Neustupny 1964), en el resto del continente?

Así las cosas y habida cuenta de la similitud de los documentos arqueológicos invocados, o bien hemos errado hasta ahora al asimilar el peculiar tipo de hábitat de fondos de cabaña a una forma de vida caracterizada por la movilidad (continua o estacional), o, lo que parece menos probable, los prehistoriadores europeos no tardarán en entonar el mea culpa por la improcedencia de defender regímenes de ocupación permanentes, de carácter plurianual, en los ring forts coetáneos. Una observación ésta que, en su simplificación, no deja de rozar el absurdo al no valorar el peso de las particulares circunstancias medioambientales en la configuración del modelo paleoeconómico de cada espacio; pero más adelante tendremos oportunidad de ponderar igualmente los hechos climáticos de la Meseta - que, como reconoce Cabo (1987: 31), son, entre los físicos, los que más han condicionado históricamente en este ámbito geográfico la actividad humana- y no por ello variará sustancialmente nuestra convicción de que los habitantes de los campos de hoyos del Duero Medio bien pudieron cumplir todo el ciclo anual sobre el propio terreno, sin tener que recurrir al desplazamiento.

\subsection{Una lanza en pro de la actividad agrícola: a vueltas con la función de los "hoyos"}

La investigación ha venido apostando tan unánimemente por la opción de los "pastores" de Cogotas I y la inercia en ese sentido ha sido tan fuerte que apenas si han quedado ánimos para reivindicar otras actividades alternativas o complementarias; un auténtico contrasentido cuando no faltan testimonios, indirectos pero bastante concluyentes - por ejemplo la relativa frecuencia en yacimientos de excisión y Bo- 
quique de elementos de hoz, tallados en cuarcita y pedernal- de prácticas agrícolas. El quid de la cuestión, una vez más, estriba en aquilatar la importancia que los productos de cultivo llegaron a alcanzar en la balanza económica y alimentaria de entonces y, en algunos casos, en ponderar si los mismos resultaron directamente de la actividad de las propias comunidades locales o dependieron - es objeción posible, aunque rebuscada - de abastecimiento externo. Demasiadas incógnitas, sin duda, pero no un escollo por completo infranqueable, pese a que la documentación para avanzar en las pesquisas se reduzca por ahora, prácticamente, al testimonio de los hoyos ofondos de cabaña.

Lejos de aceptar que en todos los casos se trate de cubetas de chozas, son numerosos los trabajos recientes que destacan la polifuncionalidad de estas estructuras tan comunes a partir del Calcolítico en los yacimientos prehistóricos de la Meseta y de casi toda la Península Ibérica. En la mayoría de los casos, a los arqueólogos se nos ofrece la oportunidad de conocerlos ya amortizados, como basureros, llenos de desechos artefactuales y faunísticos sobre todo. Pero es evidente que en origen cumplieron otros cometidos distintos bien como hornos cerámicos, bien como cocinas, muladares, pozos fúnebres y de ofrendas o barreros (Bellido Blanco 1996; Márquez 2001 y 2006; Márquez y Jiménez-Jáimez 2010: 329362 ). En este sentido sigue siendo muy tentadora la idea de que fueran despensas y, más concretamente, silos para la conservación de semillas y otros productos vegetales, hecho que refrendarían multitud de paralelos etnográficos (Mauny 1979), ciertos testimonios de arqueología experimental (Reynolds 1979) y otros detalles menores, cabe la existencia más o menos común de revestimientos de arcilla y cestería para aislar el contenido (Rodríguez Marcos y Val Recio 1990). Algo similar parece deducirse de la presencia dentro de alguno de tales hoyos de grandes vasos asociados a pequeños recipientes o póculos, en ambos casos prácticamente enteros, como si los primeros fueran los pithoi que contenían el grano y los segundos la medida, menor, utilizada para extraerlo (Martín Benito y Jiménez González 1989; Passard, Piningre y Urlacher 1992: 21-212).
Los datos son concluyentes, en todo caso, en Moncín, primer yacimiento en el que se ha aplicado un protocolo específico para identificar restos carpológicos, con el resultado de que mayoritariamente sirvieron como silos de trigo (Harrison, Moreno y Legge 1987: 26). Y no otra cosa cabe señalar de algunos de los hoyos de El Pelambre, en León, aquí a partir del registro de concentraciones excepcionales de polen de ese mismo cereal (López Sáez, Merino y Pérez 2009). Por tanto ese cometido de silos, para conservar grano o bellotas, debió estar reservado a buena parte de los hoyos habilitados por las gentes cogotianas en los yacimientos del valle del Duero.

No es en absoluto gratuita, por tanto, la idea de que la agricultura de cereal jugó un papel destacado en la economía de las comunidades meseteñas de la prehistoria reciente ni la sospecha de que el grano fue clave en su alimentación. Esto último lo corroboran los análisis de dieta de las gentes calcolíticas del Valle Amblés (Fabián 2006: 439-440), y lo primero encuentra sanción en dos testimonios no menos convincentes. Por un lado, la relativa abundancia de trigo junto a los hogares del poblado del Cobre de Villardondiego, Zamora, reveladora probablemente de que el grano se torrefactaba como paso previo a su almacenamiento (Delibes 1995: 98). Y, por otro, el hallazgo de dentales de trillo - con fitolitos de trigo adheridos en uno de los casos - en el campo de hoyos ya mencionado de El Casetón de la Era que habla sin tapujos del procesado a gran escala de este cereal (Gibaja et al. 2011). ¿Tiraron ya de aquel primitivo tribulum de Matallana bueyes castrados como los documentados en contextos Protocogotas del valle del Manzanares (García y Liesau 2007)?

De la importancia de la actividad agrícola informan también la densidad y el elevado número de silos documentados tanto en las excavaciones como en los fotogramas aéreos. El hecho, al margen de que pudieran no haber funcionado todos simultáneamente ni al máximo de su capacidad, es indicativo en opinión de los excavadores de Moncín (Harrison et al. 1994: 92), de la existencia de unos volúmenes de excedente considerables, medidos en metros cúbicos, cuya trascendencia se multiplica si, como sospechan algunos investigadores, lo 
guardado pudo ser solo la reserva de simiente destinada a futuras siembras (Bellido Blanco 1996: 40). Demasiado también para no tratarse de un producto local; porque podría argüirse que, al igual que ciertos pastores nómadas de época histórica, la comunidad cogotiana se abasteció de grano por intercambio de sus excedentes de carne viva con pueblos agrícolas, estantes, que ocuparan el límite del territorio de sus devaneos (Goodenough 1970). Mas, por un lado, se nos antoja inverosímil en sociedades preestatales la imagen de unos intercambios regulares y a tan gran escala de bienes subsistenciales de primera necesidad (más comercio que intercambio) y, por otro, es justo reparar en que la periferia de nuestros presuntos pastores del valle medio del Duero no es sino ese cíngulo montañoso que rodea la cuenca - el Sistema Central, las cordilleras Ibérica y Cantábricadonde no faltan yacimientos igualmente cogotianos, pero en los que la densidad de silos es infinitamente inferior a la registrada, por apelar sólo a dos ejemplos, en Tierra de Campos o Tierra de Pinares. La idea de abastecerse en la poquedad de la periferia se nos antoja poco afortunada.

Cierta dosis de eso que los arqueólogos procesualistas denominan "teoría de alcance medio" también contribuye, pues, a sostener que las sociedades de la Edad del Bronce de la Meseta, al margen de dedicarse a la cría de ganado cosa que es evidente hicieron - vacuno, ovino, caballar y cerda están bien presentes en todas las muestras faunísticas-, fueron asimismo agricultoras y ello en un espacio como el nuestro, que sufre unas muy particulares condiciones climáticas, lleva implícito el reconocimiento de un grado de sedentarismo importante. Un refrán castellano reduce sabia y gráficamente el ciclo climático anual de estas tierras a "nueve meses de invierno y tres de infierno", en clara referencia a la larga duración y crudeza del primero, a la acusada aridez estival $\mathrm{y}$, tras ello, al registro en el sector central de la cuenca de un déficit o saldo negativo en el balance hídrico de cerca de dos meses y medio. De tal manera que, como ha sido apuntado, "el campesino que no logra llevar agua a sus predios [todos, probablemente, los de la etapa que analizamos] se ve obligado a acoplar la explotación al ciclo climático del año: lo hace con cultivos que puede sembrar en otoño, a favor de la humedad que proporcionan las primeras lluvias, y que los calores primeros del verano dejan en sazón" (Cabo 1987: 36). Un ciclo que se materializa, por tanto, en ocho, nueve o diez largos meses, entre los temperos de septiembre-octubre y el agostamiento de finales de junio, a lo largo de los cuales el campesino prehistórico debió verse obligado a permanecer a orilla de los campos, velando por sus inversiones. Razones no le faltaron, pues, para pasar la mayor parte del año en el mismo asentamiento, aunque también debamos preguntarnos, en el extremo contrario, por la posible necesidad de desplazarse a otros pagos para sobrellevar la aridez del verano, lo que de nuevo supondría plantearse la estacionalidad de los sitios.

\subsection{Los ganados esteparios ante el agostamiento estival}

Ya se ha hecho hincapié en como, en la etapa de los calores, la cuenca central de Castilla y León padece una extrema escasez de agua. Durante tres meses de fuerte evapotranspiración, en los que cesan por completo las precipitaciones, se produce un severo agostamiento, que resulta infinitamente superior al sufrido por los montes de la periferia. En estos, en realidad, el saldo negativo del régimen hídrico es muy pequeño cuando no inexistente, lo que asegura la lozanía entre junio y agosto de unos pastos de montaña que han sido bien aprovechados históricamente, en régimen trashumante, por los ganaderos del llano. La tentación a recurrir a este o similar comportamiento en la Prehistoria reciente para asegurar la supervivencia estival de los rebaños esteparios hubo de resultar casi invencible una vez las comunidades agropecuarias del más estricto somontano advirtieran la complementariedad de los ciclos de crecimiento vegetal de ambos biotopos y tomaran conciencia de su beneficio, lo cual debió suceder pronto, tal vez desde el IV milenio, a juzgar por la posición de determinados sepulcros megalíticos de la Cordillera Cantábrica en cotas muy elevadas, de nieves invernales permanentes (Díez Castillo 1997: 139). Pero tal vez el retraimiento para hacerlo fue mayor para las comunidades del centro de la cuenca sedimen- 
taria, para aquellas, por ejemplo, del interfluvio Duero-Pisuerga, al distar su posición de partida no menos de un centenar de kilómetros de los más próximos agostaderos.

En todo caso, aunque tales desplazamientos tuvieran lugar, ello no da derecho a deducir que la sedienta estepa central del Duero Medio se convirtiera durante el verano en un absoluto despoblado ni, en consecuencia, a reivindicar el carácter estacional de los hábitats de hoyos o su normal abandono, tras sólo unos meses de permanencia. En el borde más septentrional de la Meseta hasta hace poco más de medio siglo existían pueblos con una doble sede, de invierno y de verano, en los que todas sus gentes se trasladaban del valle a las cumbres y viceversa buscando el beneficio de los distintos ritmos de la naturaleza (Martín Galindo 1953: 84); se producía, pues, auténtico abandono de uno de los caseríos para ocuparse el otro, pero entre puntos en realidad muy próximos, pues se trataba de un movimiento en altitud, no en longitud y latitud. Nada que ver, pues, con los largos desplazamientos a los que se hubieran visto obligadas las poblaciones del centro de la cuenca del Duero.

No falta, además, algún pequeño indicio en contra de la interrupción ocupacional de los sitios. En las colecciones faunísticas de los yacimientos del Cobre y del Bronce de las llanuras centrales de cualquiera de las dos Submesetas, tiende a registrarse un predominio de ovicaprinos, siempre muy jaleado de cara a argumentar la movilidad pastoralista, pero también una cabaña de vacuno, "más sedentaria", y "otra sedentaria total que evidencia el porcino" (Morales y Liesau 1994: 245). Una referencia ésta que refuerza la tesis de un poblamiento continuo durante todo el ciclo anual y que, sin embargo, no es incompatible con que los rebaños de oveja se desplazaran a los veranaderos conducidos por sólo un pequeño segmento de la población, permaneciendo in situ el resto, como ha sido práctica común a lo largo de la historia y se sugiere, muy concretamente, en el caso de algunos yacimientos prehistóricos andaluces (Lizcano 1999: 267).

Pero, siendo ello una posible fórmula de conciliación entre sedentarismo y pastoralismo, nuestras miras se orientan más a sopesar la posibilidad de que el ganado de las llanuras de la época hubiera podido tener un carácter estante, esto es, hubiera dispuesto de pastos locales suficientes para mantenerse sobre el terreno, sin desplazarse, en el transcurso del año, en lo que habrían desempeñado un papel decisivo los espacios húmedos. La imagen actual de la llanura castellana, como ya se ha dicho, es la de un medio seco y desprovisto de agua, la de una estepa sedienta, pero en realidad es estampa que se contradice con la importancia que tiempos atrás han tenido los humedales de la región. "Paradójicamente - nos recuerda Ortega Valcárcel (1995: 55) — ésta es tierra de lagunas o mejor, para emplear un término de arraigo histórico indiscutible, de navas".

Navas, navazos, lavajos, bodones, mestas, paludes o salinas, son algunos de los nombres con los que popularmente se conoce a tales charcas, que se cuentan todavía por miles y que en el pasado proliferaron por doquier, aunque hoy sean poco más que un recuerdo toponímico tras la desecación que, a partir de época moderna, sufrieron por razones sanitarias. La concentración de yacimientos de la Edad del Bronce registrada en el entorno de algunos de estos puntos de agua suele ser extraordinaria - se conocen bien los casos de las lagunas de Villafáfila, en Zamora (Rodríguez, Larrén y García Rozas 1990), o del gran estero de La Nava, en Palencia (Rojo Guerra 1987); las primeras aún en funcionamiento, la última desecada a mediados de este siglo_-, lo que habla de su importancia. Pero todavía más interesante para nuestra argumentación es constatar que la actividad salinera en Villafáfila a fines del Calcolítico y en la Edad del Bronce (Abarquero et al. 2010a y 2010b) sólo era posible en el óptimo estival -único momento del año en el que cabía obtener mueras con buena ley de sal-, hecho que demuestra no se producía despoblamiento absoluto de estos espacios durante el verano.

Esta notable densidad de asentamientos en los humedales estratégicos, que tiene el mismo sentido que la ubicación bastante sistemática de los poblados de áreas fluviales en el mismo borde del lecho de inundación de los ríos, no en el cauce — nada excepcionalmente anegado en invierno y primavera - ni en lo más alto de las cuestas, no es, desde luego, una prueba definitiva pero sí constituye una invitación a con- 
siderar que el ganado encontró en aquellas casi ubicuas charcas el pasto requerido para capear esos tres meses de infierno castellano a los que se refiere el dicho popular. Y nos referimos, sobre todo, al ganado de labor, pues los ovicaprinos, más resistentes, pudieron conformarse con el ramoneo del monte y con los rastrojos, una vez producida la derrota de los campos. En los puntos de agua, incluso en verano - aunque las condiciones climáticas fueran, como parece, bastante más secas y cálidas que las actuales (Fabián, Blanco y López Sáez 2006) sobrevivirían praderas capaces de sostener modestos hatos. Entonces, si a los rebaños de épocas históricas no les quedó otro remedio que hacerse trashumantes, atribúyase la razón tanto a su desproporcionado tamaño como a la extensión alcanzada por los campos de cultivo, incompatible con otro aprovechamiento.

\subsection{Aquilatando la propuesta: un modelo de poblamiento semipermanente y una economía mixta}

El conjunto de los hechos y circunstancias hasta aquí examinados y sus implicaciones más directas contribuyen a diseñar una imagen, sumaria pero no poco convincente, del modelo de poblamiento y paleoeconómico de las comunidades de Cogotas I, a través de la cual nos parece intuir un comportamiento menos itinerante del tradicionalmente defendido. Los pastores de las llanuras del Duero simultanearon sus quehaceres ganaderos con prácticas agrícolas, fueron, pues, campesinos, y ello, sospechamos, coartó notablemente su movilidad. Pero dejemos constancia de nuestra propuesta a través de una lectura integradora y sinóptica de los datos.

a) El modelo de hábitat de campos de hoyos, que parece complementarse frecuentemente con asentamientos mayores, por lo general en alto, tiene un carácter predominante en el valle medio del Duero. Pese a la amplitud y el alto número de "hoyos" de muchos de ellos — los excavados en La Huelga, Palencia, llegan al centenar (Pérez Rodríguez et al. 1994)-, debió tratarse en la mayoría de los casos de reducidos poblados, tal vez de granjas habitadas por contadas familias, por más que su extensión sea a veces considerable de acuerdo con la dinámica de las "estratigrafías horizontales" que afecta normalmente a estos yacimientos. No se trata, además - la Arqueología Aérea lo corrobora- de campamentos de ocasión o de aduares improvisados: responden a proyectos previos y con frecuencia adquieren su definitiva configuración tras onerosas dotaciones en infraestructura, como esos fosos o zanjas que los circunvalan, a los que, a partir de ahora, parece necesario considerar consustanciales a este tipo de hábitats. Por último, creemos entrever un patrón de asentamiento bastante sistemático en el caso de estos poblados, siempre sobre suelo campiñés - en Valladolid, el desprecio por la paramera rotunda de Torozos es absoluto-y en el mismo límite de los lechos de inundación de los ríos o en los niveles de crecida de las charcas endorreicas tan características de este sector de la cuenca del Duero.

b) Los tradicionales pastores Cogotas I - que en parte lo fueron, sin duda, a juzgar por las colecciones faunísticas de los yacimientos- simultanearon la cría del ganado con el cultivo, con la caza y con otros aprovechamientos silvícolas. No faltan indicios de actividad agrícola, indirectos pero bastante concluyentes: los frutos del cultivo - cereal, pero también leguminosas según datos carpológicos de algún yacimiento de la campiña del Tajo-, los instrumentos para recogerlos y transformarlos - elementos de hoz y molinos, a veces numerosísimos - y los contenedores o silos para el almacenamiento. Una investigación reciente orientada al estudio de las posibilidades agronómicas del entorno de los yacimientos de la Prehistoria Reciente de las campiñas del sur del Duero insiste en la importancia porcentual de los suelos agrícolas, aunque en Cogotas I aquella se equilibre o incluso decrezca respecto a los de interés forestal y ganadero (Blanco González 2010).

c) El régimen de ocupación de los campos de hoyos difícilmente pudo ser sólo estacional. El clima meseteño determina - no ahora, con los modernos cereales tremesinos- un muy prolongado ciclo agrícola, de cerca de diez meses, a lo largo de los cuales la permanencia 
in situ de los cultivadores resultó obligada. La pregunta es si, de cara a la alimentación del ganado, el acusado agostamiento del verano forzó al éxodo entre julio y septiembre, al abandono de los poblados del llano en favor de otros de montaña, lo que no se termina de ver claro. De un lado, porque también esos meses habría que velar, si no por la cosecha en marcha, sí por los excedentes recién acopiados, y de otro por el reconocimiento entre los animales domésticos de unas piaras de porcino cuyo carácter sedentario no ofrece discusión. Añádase a ello el inconveniente de la gran distancia - nunca menos de un centenar de kilómetros desde el interfluvio Duero-Pisuerga - existente hasta los pastos de montaña.

d) Nos inclinamos, por tanto, a deducir que los hábitats seguían cumpliendo su función durante el estío, buscándose solución al problema del ganado bien a través de la encomienda de su desplazamiento a una pequeña fracción de la comunidad (los pastores), bien, lo que nos parece más probable, procediéndose a su concentración durante esos meses en los nada raros humedales del llano, de cuya importancia histórica da fe la decisión tomada por algunos municipios, en pleno siglo XVII, de reconvertir tierras de pan en prados, bien es cierto que con la intención de alimentar en ellos no tanto al ovino como al ganado de labor (Ojeda Nieto 2000: 121-125). Se accede de esta manera a la imagen de comunidades básicamente permanentes... aunque no por completo sedentarias. No se trata más que de una intuición, pero la duración o trayectoria de estos establecimientos bien pudo venir impuesta por el agotamiento de la tierra, por su rápida pérdida de fertilidad. Las ocupaciones, en este sentido, pudieron cubrir tres, cuatro, cinco temporadas, o algunas más si, desde el mismo poblado, existió la oportunidad de explotar, sin mayor mudanza, sucesivos terrazgos - la clave para que tal fuera posible es que cada grupo social ostentara el dominio de un extenso territorio-. Es difícil pensar en estancias más cortas siquiera por la necesidad de rentabilizar el ingente trabajo que hubo de suponer, sobre todo en los pesados suelos arcillosos, el desbrozamiento y la preparación de los campos, o la fuerte inversión realizada en infraestructuras en el pobla- do (los fosos); pero también por el previsible deseo de amortizar (?) los gastos nada desdeñables de ciertos ritos de fundación, como esos enterramientos de bóvidos - completos o selectivos (Palomino, Negredo y Abarquero 1999: 36; Blasco et al. 1985) — que se dan en tantos yacimientos y que nos resistimos a relacionar con muertes accidentales, de animales enfermos que nunca se hubieran inhumado en el interior del poblado.

e) Los campos de hoyos sufren comúnmente reocupaciones, que no suelen traducirse en potentes depósitos sedimentarios - hay excepciones, como la de Hoya de Pajaroncillo (Ulreich, Negrete y Puch 1994) — entre otras razones por el carácter perecedero de los materiales constructivos mayoritarios. Esa recurrencia a los mismos sitios nos consta gracias al hallazgo en los mismos yacimientos de materiales diacrónicos - en este sentido la evolución estilística de las cerámicas protoCogotas/ Cogotas I es más firme de lo que en ocasiones se ha pensado (Fernández-Posse 1998: 95)-, a las intersecciones documentadas en los silos $\mathrm{e}$, incluso, en ciertos casos, al reconocimiento de las trazas de los nuevos fosos delatoras de que la refundación de los poblados no se produce exactamente sobre los anteriores, sino más bien en sus márgenes, más o menos yuxtapuestos. Existe la costumbre, pues, de regresar a los mismos lugares, seguramente dictada por el atractivo económico del medio seleccionado previamente, y acaso la falta de coincidencia exacta en el emplazamiento de los nuevos hábitats - he ahí el origen de tantas "estratigrafías horizontales" - , lejos de ser casual, responda al interés de excavar en suelos limpios y perfectamente estabilizados esos almacenes subterráneos, "los hoyos", tan característicos de nuestros yacimientos.

¿Se producen estas reocupaciones, tras largas fases de abandono, atendiendo al ritmo de recuperación de la fertilidad de la tierra? ¿Tuvieron lugar cíclicamente? ¿Cuántos de los poblados de campos de hoyos de una misma comarca, dotados de idénticos fósiles-guía, no podrían corresponder a sucesivas posturas de un mismo grupo social en régimen de semipermanencia? Por lo tanto ¿en qué medida son objetivas y pueden considerarse auténticas las 

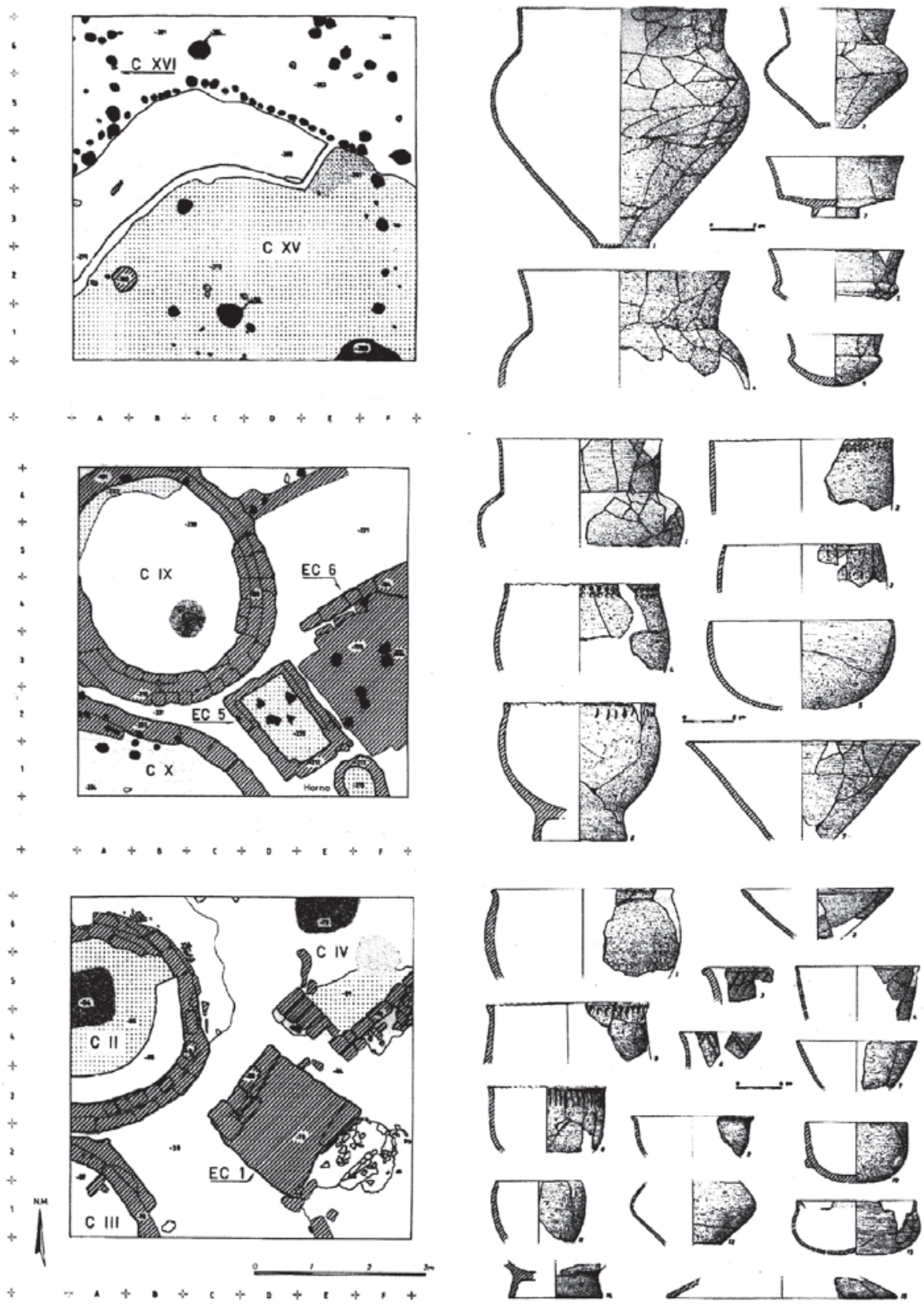

Figura 5.- El Soto de Medinilla (Valladolid), sondeo de 1989-90: plantas (izquierda) y cerámicas (derecha) de los niveles de hábitat undécimo (arriba), quinto (centro) y segundo (abajo) (Delibes, Romero y Ramírez 1995).

redes de poblamiento construidas por medio de la cartografía de todos los yacimientos que, grosso modo, se consideran de la misma fase arqueológica? Demasiadas dudas todavía por resolver, pero tras ellas cierta lógica de fondo: Dichas formas de vida sólo hubieron de resultar posibles en situaciones de baja densidad demográfica, de escasa competencia por la tierra, de economías agropecuarias muy extensivas en las que no debió existir una fuerte presión sobre el medio. Unas condiciones que, en opinión de Fernández-Posse (1998: 120-122), parecen adecuadas para el desenvolvimiento de sociedades sin grandes contrastes, pero que mucho nos tememos - icuál es el papel reservado, entonces, a algunos lujosos bienes de prestigio de carácter personal (joyas y armas) asimilables al complejo cogotiano? - no pudieron impedir que el feliz hombre natural acabara convertido en el ser miserable y depravado al que, según Rousseau, nos condena el desarrollo social. Pero eso son ya otros problemas. 


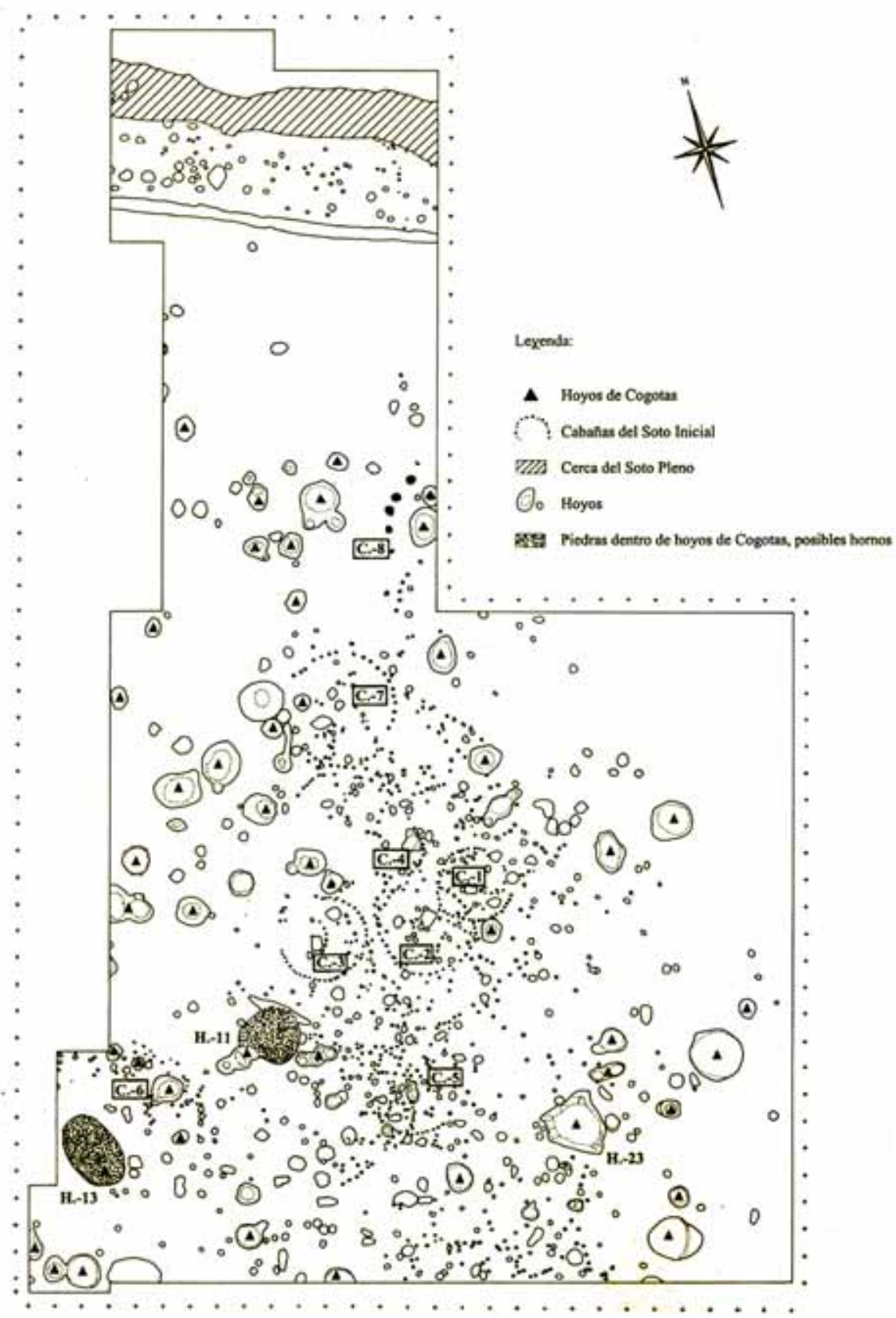

Figura 6.- Castro de Sacaojos (Santiago de la Valduerna, León). Sectores I y II, planta de las excavaciones (Misiego et al. 1999).

\section{EI Soto de Medinilla: la aparición de un hábitat definitivo}

En un trabajo relativamente reciente uno de nosotros ha señalado que, de tener que elegir una sola de entre las múltiples y diversas novedades que introduce la cultura del Soto, habría que decantarse, dada su importancia, por la revolución habida en el hábitat: "He ahí la verdadera esencia del cambio respecto a Cogotas I; la aparición por primera vez en la Meseta de un hábitat definitivo, por completo permanente, propio de comunidades incontestablemente sedentarias, lo que sin duda traduce también innovaciones en las actividades económicas de entonces" (Delibes y Fernández Manzano 2000: 115). Estas palabras, de las que como puede apreciarse hemos extraído las que titulan el presente epígrafe, reflejan puntualmente, por otro lado, cuanto queremos desarrollar en el mismo y queda fielmente reflejado en el registro arqueológico a través de una peculiar 

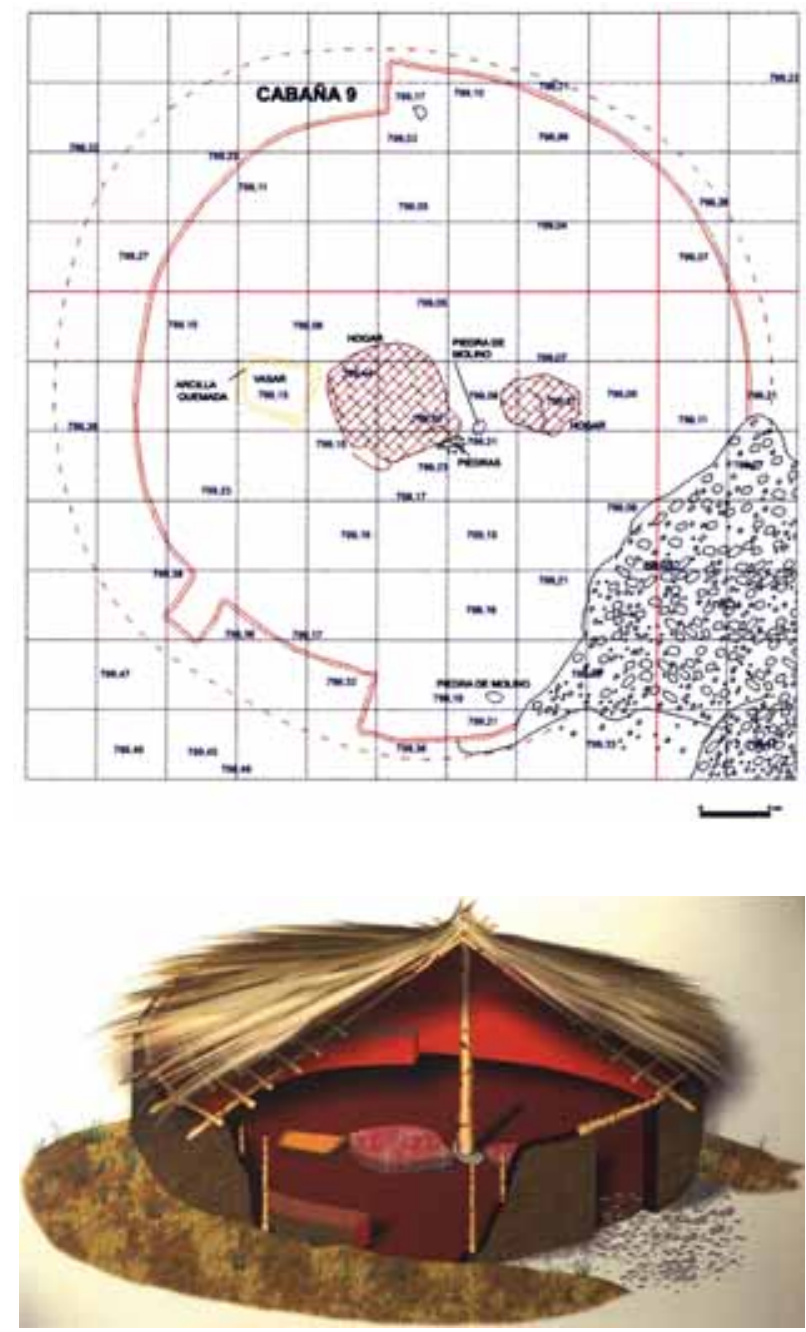

Figura 7.- Dessobriga (Osorno, Palencia/Melgar de Fernamental, Burgos): planta y reconstrucción hipotética de la cabaña 9 (Misiego et al. 2003).

arquitectura doméstica, y de las primeras trazas urbanas añadiremos ahora, y de esos característicos tells que, resultado de la destrucción de poblados sucesivos, denuncian la vocación de permanencia en los asentamientos.

\subsection{Las construcciones domésticas}

La peculiar planta circular de las viviendas de El Soto de Medinilla (Figs. 5 y 8 a 10), tachada en su momento de anomalía (Palol y Wattenberg 1974: 33), dado el carácter celta que como veíamos se atribuía al yacimiento, ha terminado por erigirse en un referente de la cultura pues, como se ha señalado en cierta ocasión: "la presencia de viviendas circulares de adobe en un poblado de la primera Edad del Hierro, del centro o el occidente de la cuenca del Duero, es un dato decisivo, aunque bien es verdad que no el único, para su adscripción cultural a la facies Soto" (Romero 1992: 206); una idea que hoy, cuando puede decirse que la arquitectura doméstica es uno de los aspectos soteños mejor conocidos, merece ser matizada al menos en dos sentidos.

Así, y en primer lugar, porque las viviendas de planta rectangular, cuya generalización se impone durante la segunda Edad del Hierro, se implantan tempranamente en poblados como el segoviano de Cuéllar o el vallisoletano de La Mota, en Medina del Campo. Después porque, tal como quedó intuido a raíz de las viejas excavaciones del mismo Soto de Medinilla y han confirmado las más recientes o evidencian hoy además otra serie de lugares, previamente a las características viviendas de adobes, que continúan siendo las más, se alzaron otras de materiales deleznables —o de cañas y barro como gusta decir María Luisa Ramírez (1999: 79)_, cuya detección sólo es posible a partir de la identificación de los hoyos de poste perimetrales. Dichas cabañas, que en su versión más sencilla nos son bastante bien conocidas en el castro de Sacaojos (Santiago de la Valduerna, León) (Fig. 6), donde se han excavado ocho, con diámetros de entre tres y cuatro metros y superficie media de cinco a nueve metros cuadrados, y restos de pavimentos de arcilla muy compactada y placas de hogar algunas de ellas (Misiego et al. 1999: 52-55),

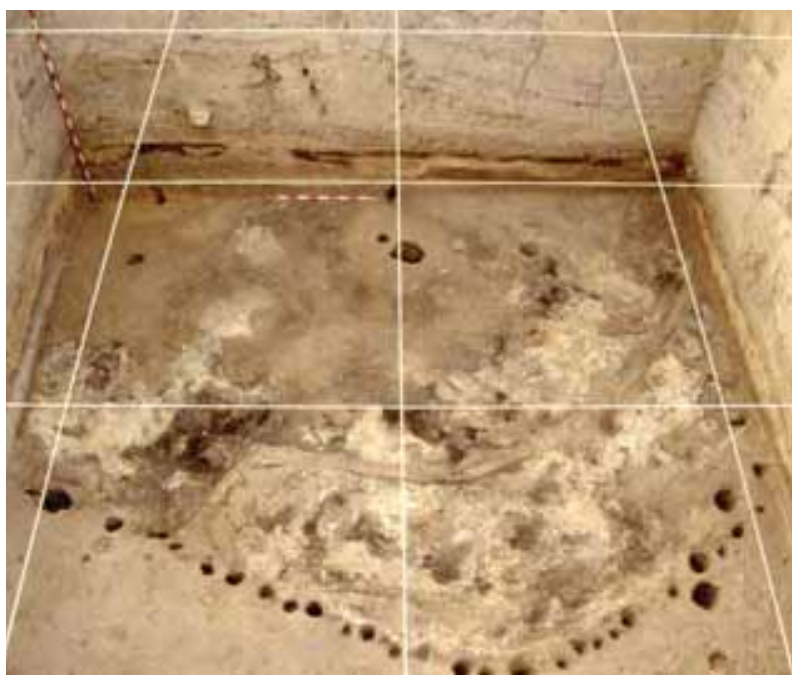

Figura 8.- El Soto de Medinilla (Valladolid), sondeo de 1989-90: cabaña construida con materiales perecederos del undécimo nivel de hábitat. 


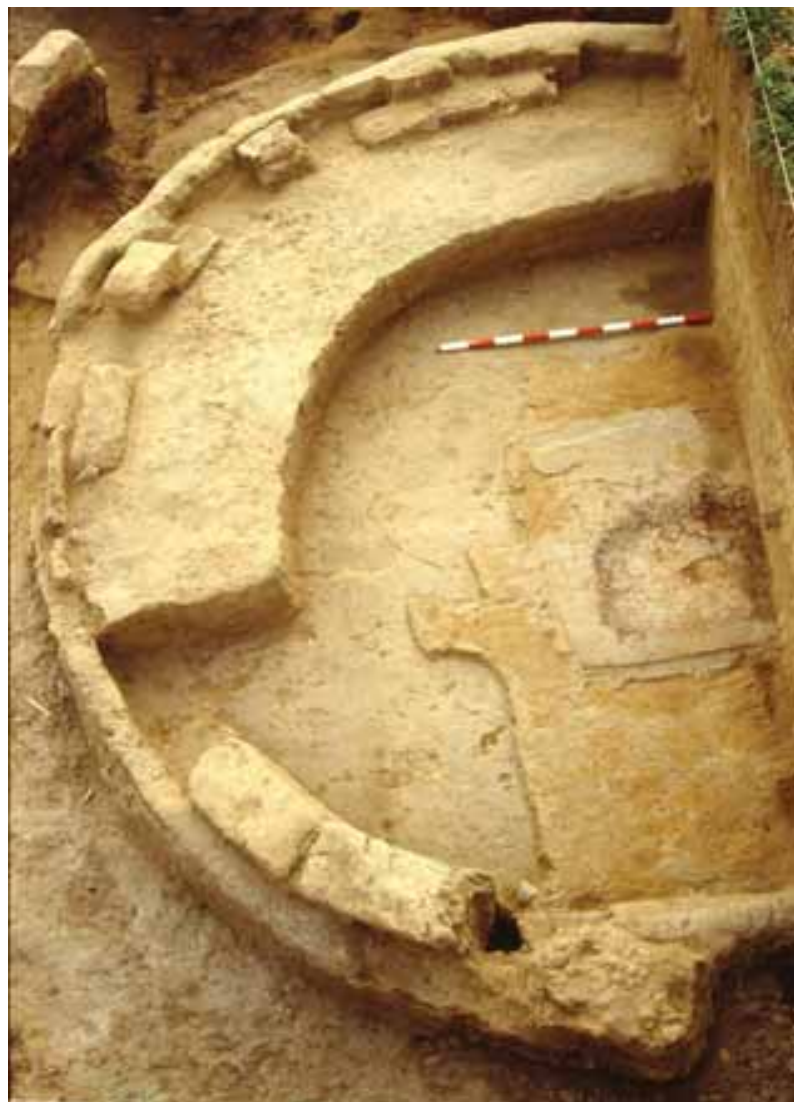

Figura 9.- El Soto de Medinilla (Valladolid), sondeo de 1989-90: vivienda circular de adobes del segundo nivel de hábitat.

ofrecen mayor complejidad en otras ocasiones, como ocurre en el caso de la denominada Casa XV de El Soto de Medinilla, exhumada en el inferior de los once niveles de hábitat identificados en el último sondeo estratigráfico (Fig. 8), pues, además de medir entre siete y ocho metros de diámetro y contar con piso y hogar como las anteriormente citadas, presenta un amplio banco corrido que, y he aquí lo más importante, estaba delimitado en su frente por un murete de adobes y había estado revocado (Delibes, Romero y Ramírez 1995: 154-156). Mención aparte merecen las de Guaya (Berrocalejo de Aragona, Ávila), pues en su mayor parte ofrecen planta rectangular con cabecera semicircular, sin que falten las circulares —cabañas I y II-; la vivienda propiamente dicha, circular u oval, estaría al fondo, en tanto que la superficie más extensa y próxima a la entrada, se dedicaría al almacenaje y tareas relacionadas con las actividades agropecuarias (Misiego et al. 2005: 211, figs. 1 y 2).

Con carácter general ya (Romero 1992; Ramírez 1999), hay que señalar que las casas so- teñas cuentan con un único espacio, en el que no se aprecian áreas de actividad o uso diferenciadas, y que estarían destinadas fundamentalmente a cumplir las funciones de protección, cocina y descanso. Con diámetros que oscilan entre los tres y los seis metros, rara vez supera su superficie los treinta metros cuadrados, situándose habitualmente por debajo de los doce. Sus alzados son, en el caso de las de cañas y barro a que nos referíamos con anterioridad, de postes, entre los que se disponía un entramado vegetal que después se mantearía con barro; las más consistentes, de adobes y más raramente de tapial, no suelen mostrar obras de cimentación, y de hacerlo estas son de piedra al igual que ciertos zócalos, pero se observan con alguna frecuencia tareas de regularización del terreno previamente a la erección de sus paredes que, conservadas únicamente en sus hiladas inferiores, contaban con entre una y tres hileras de adobes, dispuestos a soga regularmente, y podían reforzarse al exterior con pies derechos de madera. Su cubierta, que suponemos en ambos casos de materiales perecederos, sería cónica y se sustentaría en un poste central, de cuya existencia sabemos por el hoyo correspondiente. La entrada, rara vez identificada, se abre allí donde nos consta al Sur o Sureste, y se ve precedida, en casos aislados y muy tardíos, por un vestíbulo.

Ya en el interior, generalmente en el centro y sobre un suelo de arcilla apisonada, se sitúa el hogar; de dimensiones variables y planta redondeada o cuadrangular, suele ser de barro y presentar, aunque un tanto ocasionalmente, re-

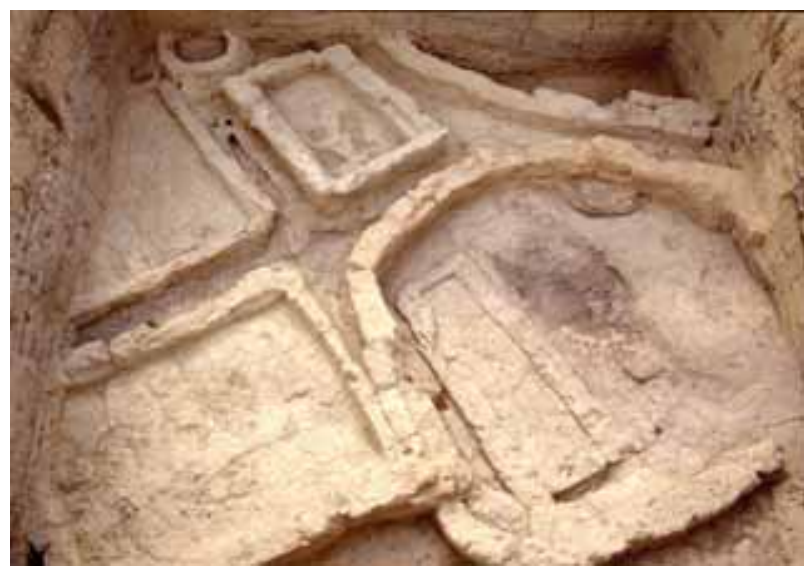

Figura 10.- El Soto de Medinilla (Valladolid), sondeo de 1989-90. Sexto nivel de hábitat: viviendas, graneros y, al fondo, horno doméstico. 


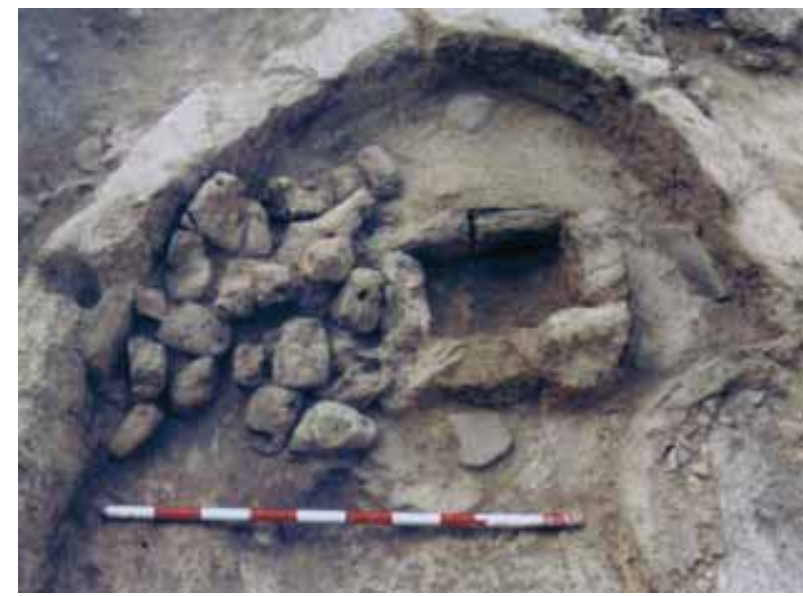

Figura 11.- El Soto de Medinilla (Valladolid), sondeo de 1989-90. Tercer nivel de hábitat, pormenor de la Casa V: hogar, estructura de combustión y pesas de telar.

bordes de este mismo material o de adobes, en todo o parte de su perímetro. Habituales son los bancos corridos adosados a los muros (Fig. 9) que, con entre veinte y setenta centímetros de ancho por diez a treinta de alto, se construyen con adobe o tapial y, al igual que las paredes, muestran revestimientos diversos y en ocasiones múltiples; destacan entre estos últimos los pintados, polícromos y de temas geométricos, de sendas casas de los poblados de Zorita de Valoria la Buena, en Valladolid, Los Cuestos de la Estación en Benavente, en Zamora, o de la Plaza de San Martín de Ledesma, en Salamanca.

Además de las viviendas, en los poblados se han venido identificando otras construcciones de carácter asimismo doméstico, construidas con adobes también y de planta circular o cuadrangular, que vienen considerándose anejos destinados a servicios complementarios; así, aquellas de reducidas dimensiones —con superficies inferiores a los cinco metros cuadrados por lo general-, las que carecen de los rasgos estructurales que, como el banco corrido y sobre todo el hogar, se consideran propiamente característicos de las casas o las que por sus rasgos específicos es forzoso vincular a una actividad determinada.

Es el caso, sin ir más lejos, de las que junto a las casas, y a otras estructuras que tendremos ocasión de comentar más adelante, se han excavado no hace mucho en La Corona/El Pesadero (Manganeses de la Polvorosa, Zamora); de planta circular u oval y muros de adobes, se suponen almacenes (Misiego et al. 1997: 22). Sobradamente conocidas son las rectangulares $\mathrm{y}$ de adobes, que en ocasiones tuvieron pisos de tablas o estaban compartimentadas, recuperadas en la práctica totalidad de los niveles de El Soto de Medinilla - particularmente en los anteriormente atribuidos al Soto II (Palol y Wattenberg 1974: 187-191) o en los niveles de hábitat sexto y séptimo del sondeo más reciente, en los que venían a ocupar la práctica totalidad de los casi cuarenta metros cuadrados de superficie excavada (Delibes, Romero y Ramírez 1995: 158-160)—; consideradas graneros en unos casos, por el hecho de que en su interior se hayan encontrado restos de cereales, se interpretan en otros como almacenes para guardar setas. Finalmente es preciso mencionar los hornos aparecidos en La Aldehuela, en la misma capital zamorana (Santos 1989: 175), o El Soto de Medinilla (Misiego et al. 1993); en uno y otro caso se consideran domésticos, apuntándose además en este último la posibilidad de que hubiera servido para cocer pan (Fig. 10).

\section{2. Ámbito doméstico, actividades artesa- nales y prácticas rituales}

Aunque, como queda dicho, todos los indicios avalan el carácter estrictamente doméstico de las viviendas descritas, no podemos dejar de mencionar la posibilidad de que en algunas

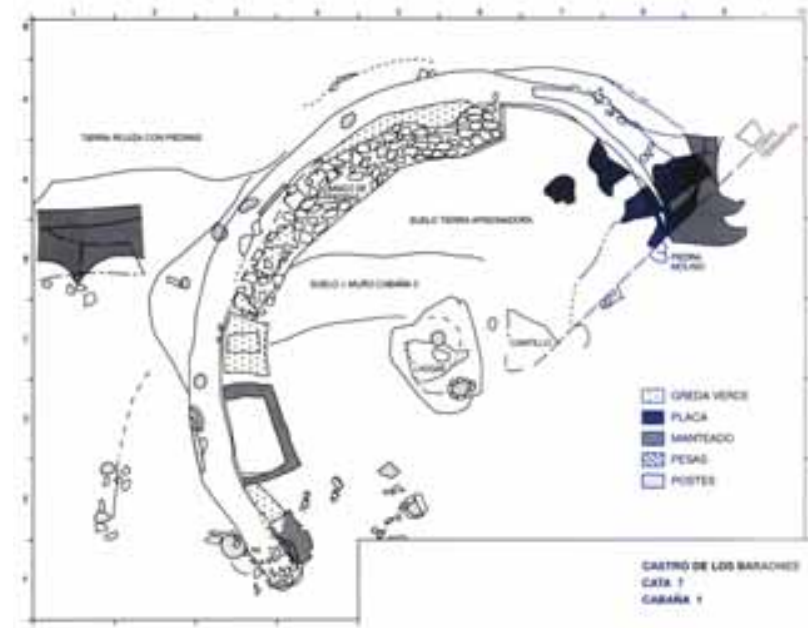

Figura 12.- Castro de Los Baraones (Valdegama, Palencia), planta de la cabaña 1 (Barril 1995). 


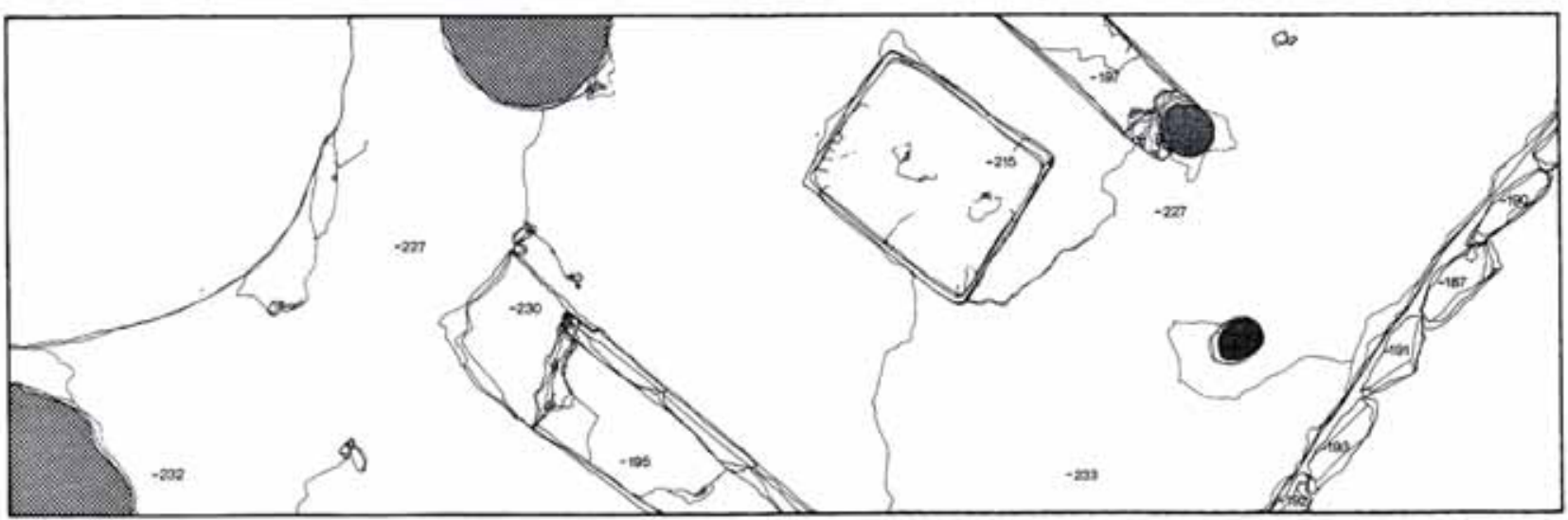

Figura 13.- Plaza del Castillo (Cuéllar, Segovia). Poblado II, posible santuario doméstico (Barrio 2002).

de ellas, bien es verdad que muy reducidas en número, se llevaran a cabo ciertas actividades que cabría calificar de especializadas o profesionales.

Caso de estas últimas pudieran ser las que tuvieran lugar en aquella del poblado vallisoletano de Zorita, antes mencionado, de la que procede un interesante lote de crisoles y que, por dicha razón, se viene identificando con la vivienda de un fundidor (Martín Valls y Delibes 1978); el hecho de que no fuera excavada impide confirmar si se trataba de tal - y de ser así si en su interior se reservaba un espacio para la actividad metalúrgica - o de un taller - y en dicho caso si contaba con un horno, aunque parece más probable que este se ubicara al exterior, visto que los domésticos y algunos de los que como veremos parecen destinados a cocer cerámicas, que no requerían alcanzar tan altas temperaturas, se sitúan fuera de las casas-. En cualquier caso, este testimonio y el hallazgo de numerosos crisoles y moldes de fundición en una larga lista de contextos habitacionales soteños (Delibes et al. 1995a: 70) parecen avalar que ciertos pasos de la cadena operativa metalúrgica, al menos aquellos subsiguientes a la obtención del metal, tuvieran lugar en el interior de los poblados, en tanto que otros, quizá por más tóxicos, caso de la reducción del mineral, se llevaran a cabo en áreas específicas fuera de los mismos (Delibes et al. 1995b: 152).

Actividad textil sugieren, por otro lado, los indicios de sendas viviendas de El Soto de Medinilla, La Mota y el castro de Los Baraones (Valdegama, Palencia). En el primero de ellos, en el sector meridional de la Casa V, junto a un hogar y a una estructura rectangular de ado- bes destinada a la combustión, que se entiende fuera un brasero, se localizaron treinta pesas de telar de arcilla (Fig. 11), lo que ha dado pie a identificarla con la casa-taller de un tejedor (Delibes, Romero y Ramírez 1995: 164-165 y 171). En La Mota, junto al castillo medinense del mismo nombre, una docena de pesas y un morillo aparecieron al lado de dos hogares y una cubeta de adobe y tapial que contenía una fina capa de fibra vegetal o animal prensada con adobes (Seco y Treceño 1993: 136). Por último, en Los Baraones, y en una de las cabañas exhumadas en su ladera occidental, se recuperaron diez pesas de telar, troncopiramidales y de barro, próximas a un hoyo enmarcado por piedras que se piensa estuviera destinado a cobijar una de las patas del telar (Barril 1995: 404-405); y aún cabría preguntarse en este caso si no habría de relacionarse con dicha actividad textil, visto lo dicho acerca del anterior y pese a que dentro del mismo figuren en esta ocasión dos piedras de molino barquiforme, un receptáculo rectangular de barro semicocido que en sus proximidades se adosaba al muro de la vivienda (Fig. 12).

Con actividades artesanales, no siempre bien determinadas, se han relacionado asimismo ciertas estructuras anejas y algunos hornos. Es el caso entre las primeras de las rectangulares de adobes de Los Cuestos de la Estación (Celis 1993: 101-104): una de ellas, correspondiente a la fase 5 , se ha supuesto tal al detectarse en su exterior un apilamiento de troncos leñosos calcinados; la segunda, que contaba con un fogón y cuya finalidad no se precisa, fue recuperada en el nivel correspondiente a la fase 6. Al mismo yacimiento y a la fase citada 


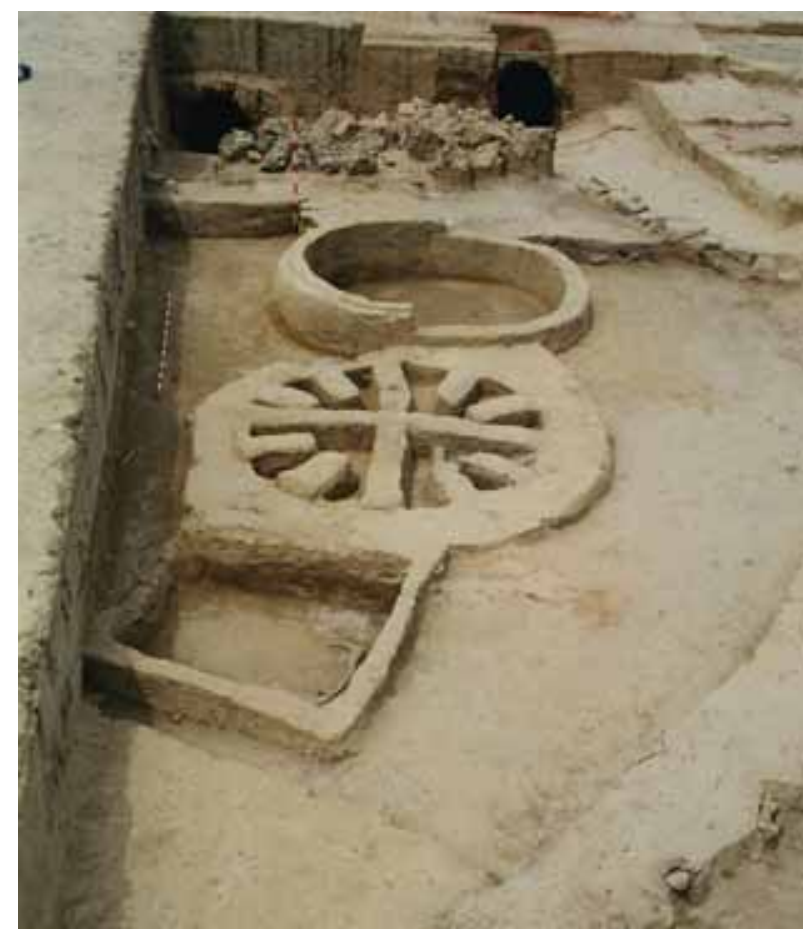

Figura 14.- La Corona/El Pesadero (Manganeses de la Polvorosa, Zamora). Manganeses I, estructuras cultuales (Misiego et al. 2006).

en último lugar pertenece también una estructura circular de adobe, de dos metros y medio de diámetro, interpretada como un horno destinado a cocer cerámicas; y a la cocción de pesas de telar, cuando menos, pues más de cuarenta crudas aparecieron junto a él, debió estar orientado el que se situaba en el interior de una casa rectangular de La Mota (García Alonso y Urteaga 1985: 80 y 129). El hallazgo de hornos en el interior de algunas de las estructuras - cabañas V, VIII y XII- del yacimiento abulense de Guaya ha permitido presumir que las mismas estuvieran destinadas exclusivamente a la fundición metalúrgica y a la cocción de cerámicas (Misiego et al. 2005: 211-212).

A las viviendas se asocian también las escasas referencias con que contamos sobre el mundo de las creencias de las gentes del Soto. Este sería el caso de la habitación, tenida por posible santuario, de una vivienda del poblado II localizado bajo la Plaza del Castillo de Cuéllar (Segovia) (Fig. 13); cuadrangular y con las paredes pintadas de rojo, presenta en el centro un hogar flanqueado por dos poyetes, interpretados como bando y repisa; entre los abundantes materiales cerámicos recuperados en su interior, merecen destacarse, amén de los vasos con decoración a peine o los importados hechos a torno, una clepsidra, (Barrio 2002). Poco puede decirse de momento acerca de ciertas estructuras de adobe que, junto a las casas y a aquellas construcciones anejas tenidas por almacenes, a que nos referimos con anterioridad, han sido identificadas en el poblado zamorano de La Corona/El Pesadero (Fig. 14); circulares, de reducido diámetro, poca altura y con adobes dispuestos en diferentes combinaciones geométricas en su interior, se relacionan con cerámicas y restos óseos animales que, en la medida que se tienen por ofrendas, permiten contemplarlas como rituales (Misiego et al. 2006: 121). Idéntica interpretación se sugería no hace mucho también para ciertos hogares de Los Cuestos de la Estación y La Mota, habida cuenta lo decorado de sus placas (Ramírez 1999: 73).

Mucho mejor documentadas están, por el contrario, las inhumaciones infantiles bajo los pisos de las viviendas, pues no en vano son bien conocidas a lo largo de la Edad del Hierro en numerosos lugares peninsulares, del ámbito mediterráneo sobre todo, y del sureste de Francia (Gusi y Muriel 2008: 257-287) y se atestiguan ya en media docena de estaciones soteñas; no puede decirse otro tanto, sin embargo, acerca de su valoración, pues son varias las interpretaciones esgrimidas al respecto, entre las que destacan las que se inclinan por su carácter funerario o sacrificial-propiciatorio (Delibes et al. 1995a: 78-79; Ramírez 1999: 75-78; Gusi y Muriel 2008: 288-302). Para quienes defienden su carácter funerario, a los niños fallecidos antes de una determinada edad, aquella en la que alcanzarían el reconocimiento social y quedarían integrados como miembros de pleno derecho en la comunidad, se les otorgaría un trato funerario distinto, tanto en lo que se refiere al ritual - la inhumación, frente, en nuestro caso, la incineración, cuando se suponía que esta sería la práctica normativa al relacionarse la cultura del Soto con la de los Campos de Urnas del Noreste peninsular, u otro rito desconocido que no dejaría huella arqueológica, como se sugiere hoy ante la desesperanza de encontrar alguna tumba- como al lugar de enterramiento - el espacio doméstico, frente a la necrópolis u otro que no alcanzamos a suponer-, diferente al recibido por la comu- 
nidad en general. Frente a ellos se sitúan quienes consideran que se trata de auténticos sacrificios, ligados muy probablemente a ritos de fundación, pues no hay que olvidar que en ocasiones en lugar de tales inhumaciones encontramos depósitos de ovicaprinos - como ocurre en la base misma del reciente sondeo estratigráfico llevado a cabo en El Soto de Medinilla (Delibes, Romero y Ramírez 1995: 154)—, que se entienden como víctimas sustitutorias.

Sea como fuere, es preciso reconocer que el número de inhumaciones y depósitos no es lo suficientemente importante como para otorgar a una u otra práctica carta de naturaleza, pues, de tratarse de auténticos enterramientos, denunciarían una mortandad infantil muy inferior a la que cabría esperar y, si son sacrificios fundacionales, cómo explicar que no aparezcan bajo todas las casas o que, como parece ocurrir en nuestro ámbito en La Corona/El Pesadero, sean varios los localizados en una sola (Caro y López 2001). A la vista de tal aleatoriedad y ausencia normativa parece obligado concluir que, sea cual sea la explicación que quiera dárseles, tales rituales sólo se practicaran en circunstancias concretas, y por ello seguramente especiales, de la vida de quienes habitaran la correspondiente vivienda.

\subsection{Las primeras trazas urbanas}

Uno de los aspectos más desconocidos de esta arquitectura, polémico se ha señalado en relación con la cultura castreña del Noroeste (Romero Masiá 1976: 99-100), es el de la existencia o no de urbanismo en los poblados, pues no en vano la planta circular de sus viviendas se supone poco apta para tal tipo de organización; máxime ello si añadimos en nuestro caso que no son muchos los poblados excavados hasta la fecha y tenemos en cuenta además lo generalmente reducido de las superficies excavadas. De ahí que, prescindiendo por el momento de la sin duda "precipitada" presunción de un posible urbanismo en Guaya (Misiego et al. 2005: 209), sea de obligada necesidad traer a colación aquí y ahora lo que, en este sentido, han aportado excavaciones recientes al pie de la antigua Dessobriga, en el límite entre Osorno (Palencia) y Melgar de Fernamental (Burgos), y en La Corona/El Pesadero de Manganeses de la Polvorosa, un yacimiento zamorano afectado por el trazado de la Autovía de las Rías Baja, poblados ambos que han podido ser conocidos en extensión.

La intervención en el yacimiento palentinoburgalés (Misiego et al. 2003: 47, 54-55 y 80, figs. pp. 54, 56-57 y 85) ha permitido identificar dos calles (Fig. 15): de la primera de ellas, que se relaciona con las cabañas 4 y 5 , se conserva un empedrado de pequeños cantos de cuarcita de entre dos y cuatro metros de ancho; la segunda, mucho más desdibujada, pues los tramos conservados vienen a coincidir con los pavimentos - de características análogas a la calle anteriormente descrita- de entrada a las cabañas 8,9 y 11, pudiera relacionarse asimismo con otras varias que abren sus puertas a ella.

Por su parte, el complejo arqueológico zamorano, formado por el cerro de La Corona y la llanura que conocida como El Pesadero se extiende a sus pies por el mediodía, se sitúa en el espigón fluvial que forman los ríos Eria y Or-

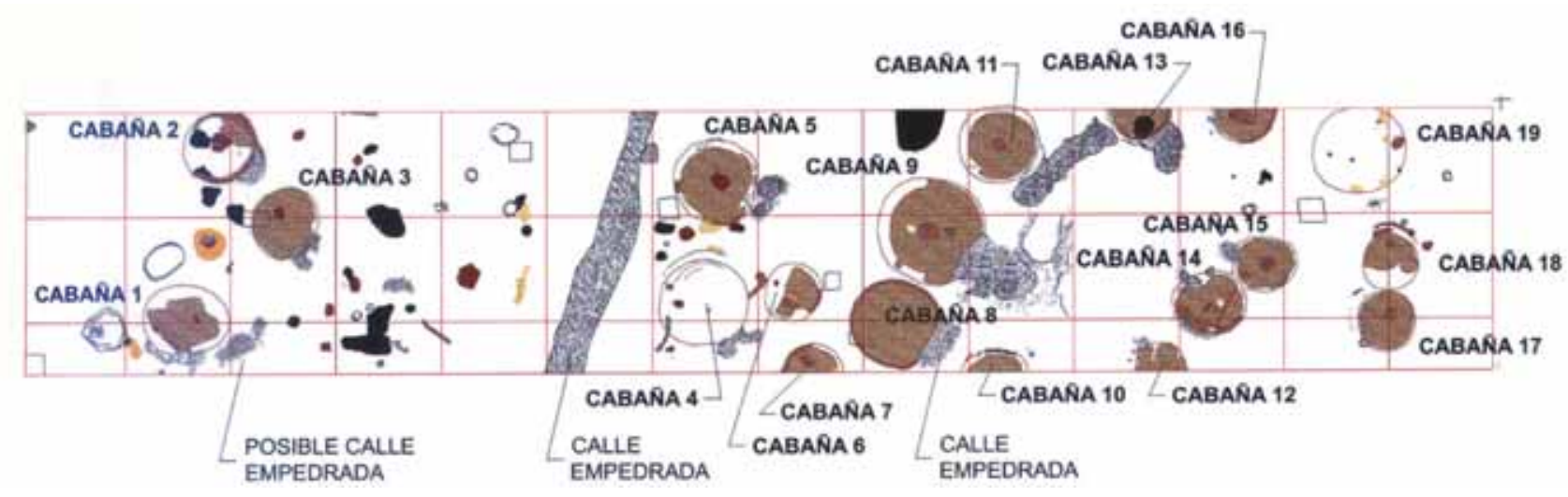

Figura 15.- Dessobriga (Osorno, Palencia/Melgar de Fernamental, Burgos). Planta del Sector VI con la distribución de las cabañas y las calles (Misiego et al. 2003). 
bigo, por un lado, y el arroyo y afluente de este último también llamado El Pesadero, por otro. La mencionada intervención (Misiego et al. 1997, 1998 y 2006: 114-133), llevada a cabo lógicamente en la extensa planicie, permitió conocer, a partir de los sondeos iniciales, una dilatada y diversa ocupación del solar e identificar, por lo que aquí interesa, cuatro fases correspondientes a la primera Edad del Hierro; abordada con posterioridad su excavación en extensión, ésta alcanzó exclusivamente a las dos más modernas: Ic y Id.

Corresponde la primera de ellas a un poblado de unas dos hectáreas y media de extensión, cuyas construcciones circulares u ovales, siempre de adobe y tapial pero de funcionalidad diversa como veremos, se disponen a uno y otro lado de una serie de callejas, de entre tres y tres metros y medio de anchura, que se orientan de Noreste a Suroeste. Entre cinco y siete metros de diámetro tienen las consideradas viviendas, cuyas características en nada difieren de las generales antes contempladas, a no ser por el hecho de que han podido identificarse aquí los accesos, pavimentados con pequeños cantos y abiertos a las calles; junto a dichas casas se sitúan en ocasiones otras de dimensiones menores identificadas como anejo vivienda, y como almacenes se interpretan, ya lo hemos visto, unas terceras construcciones carentes de aquellos elementos que, como los hogares o los bancos corridos, se entienden típicamente domésticos; carácter ritual se ha atribuido, por último, tal y como hemos tenido ocasión de comentar también, a ciertas estructuras planas, de planta circular y adobe asimismo aunque de reducidas dimensiones, a las que se asocian cerámicas y restos animales interpretados como ofrendas. El poblado, que mantiene los rasgos descritos durante la fase siguiente, la Id, se dota sin embargo en dicho momento de una muralla; dicha obra se localiza en el extremo occidental y viene a cerrar el espacio que media entre el arroyo El Pesadero y La Corona.

Dos cosas merecen destacarse en este punto a partir de lo dicho hasta aquí: en primer lugar, la articulación de las construcciones, siquiera sea incipiente, en torno a una serie de calles longitudinales y paralelas; por otro lado, la agrupación, cercada incluso según se señala en alguna ocasión, de los diferentes tipos de estructuras arquitectónicas detectados — casa principal, anejo vivienda, almacén, estructura cultual-, bien sea en parte o en su totalidad. Uno y otro aspecto se perfeccionan y consolidan a lo largo de la segunda Edad del Hierro, momento en que el poblado viene a alcanzar, con sus once hectáreas de superficie, su máxima extensión. Sería interesante entrar en ello, máxime cuando entre las dos fases identificadas en Manganeses II se aprecian además transformaciones importantes, pero no es éste un problema que desde el punto de vista cronológico afecte al presente trabajo; conviene recordar, en cualquier caso, que ambos, y en particular el segundo, quedan prefigurados aquí durante la primera Edad del Hierro y en contexto Soto. En efecto, agrupaciones constructivas como las comentadas, que cabe considerar unidades familiares de ocupación, nos eran conocidas en La Corona de Corporales y El Castrelín de San Juan de Paluezas, ambos en León, durante el siglo I a.C. (Fernández-Posse y Sánchez-Palencia 1992); queda por saber ahora si tal sistema organizativo es común al mundo Soto o específico del territorio, luego histórico, de los astures trasmontanos.

Nada conocemos de Manganeses Ia y b, ocupaciones detectadas únicamente en ciertos sondeos, por lo que es imposible saber si esta, siquiera incipiente, ordenación urbana se previó ya desde un principio; claro parece, sin embargo, que no estuvo entre las preocupaciones de sus iniciales habitantes la de dotar al poblado de sistema defensivo alguno, pues, como queda dicho, la muralla que lo cierra por occidente - una construcción de cuatro metros y medio de ancho, con basamento externo de piedra y paramentos de adobes dispuestos a soga, entre los que se encuentran otros sin ordenación aparente - se levantó a finales de la primera Edad del Hierro, en un momento que se sitúa en el primer cuarto del siglo V a.C. Esa misma impresión se desprende de otros casos bien conocidos.

Así, en El Soto de Medinilla, donde dicha obra, identificada a lo largo de veinticinco metros en su flanco noroccidental, se construyó y mantuvo en pie coincidiendo con el segundo de los poblados inicialmente identificados, el Soto I-2, al que hoy sabemos precedieron, cuando menos, además del Soto I-1 otros tres de casas 
de materiales lígneos. Esta estructura está formada por un muro de adobes de dos metros de ancho, embutido en algunos tramos en una zanja de cimentación que alcanza las gravas de base, y una serie de líneas de empalizada por el interior, la primera de las cuales apoya directamente en él y las siguientes, hasta un máximo de cinco, se sitúan a distancias entre medio y un metro (Palol y Wattenberg 1974:182-185).

A un momento de plenitud del Primer Hierro se atribuye también la muralla del castro de Sacaojos, pues parece fosilizar cabañas de postes del tipo de las localizadas en el Sector II, ya comentadas, y asociarse a otras de adobes; localizada curiosamente en su vertiente mejor protegida, la que se asoma al valle del Duerna, ha sido excavada en trece metros de su recorrido (Misiego et al. 1999: 56-59). Aquí, y previa nivelación del terreno, se dispuso un potente muro terrero de tapial muy endurecido, de entre poco más de un metro y casi dos de ancho, por delante del cual, y al interior del poblado como ocurría en El Soto de Medinilla, corren dos alineaciones de hoyos de postes, a uno y dos metros respectivamente, $\mathrm{y}$, algo más alejada, una trinchera que debió servir para drenar las aguas del poblado y proteger así la estructura.

Mencionaremos finalmente, por la doble razón de corresponder a un área geográfica diferente y haberse construido con piedra, la muralla del castro de Los Baraones; con paramentos ataludados de mampostería en seco, presenta en su base una anchura de cuatro metros, que queda reducida a la mitad a la altura conservada de metro y medio. Corresponde a la fase más moderna de las detectadas en el sector occidental del poblado, cuyo flanco delimita, y, por tanto, a un momento avanzado del Primer Hierro (Barril 1995: 403-404 y 407-408).

Más novedosa es la detección de fosos en este mundo, tal y como ha acontecido en Roa de Duero (Burgos) y La Mota. En la primera de las localidades citadas ello tuvo lugar en el curso de una intervención de urgencia en el número 5 de la Calle de la Escuela, pudiendo advertirse que este debió de tener una anchura próxima a los siete metros y entre cinco y seis metros de profundidad; su rápida colmatación habría tenido lugar en los momentos finales de la cultura del Soto (Sacristán 1994: 254-

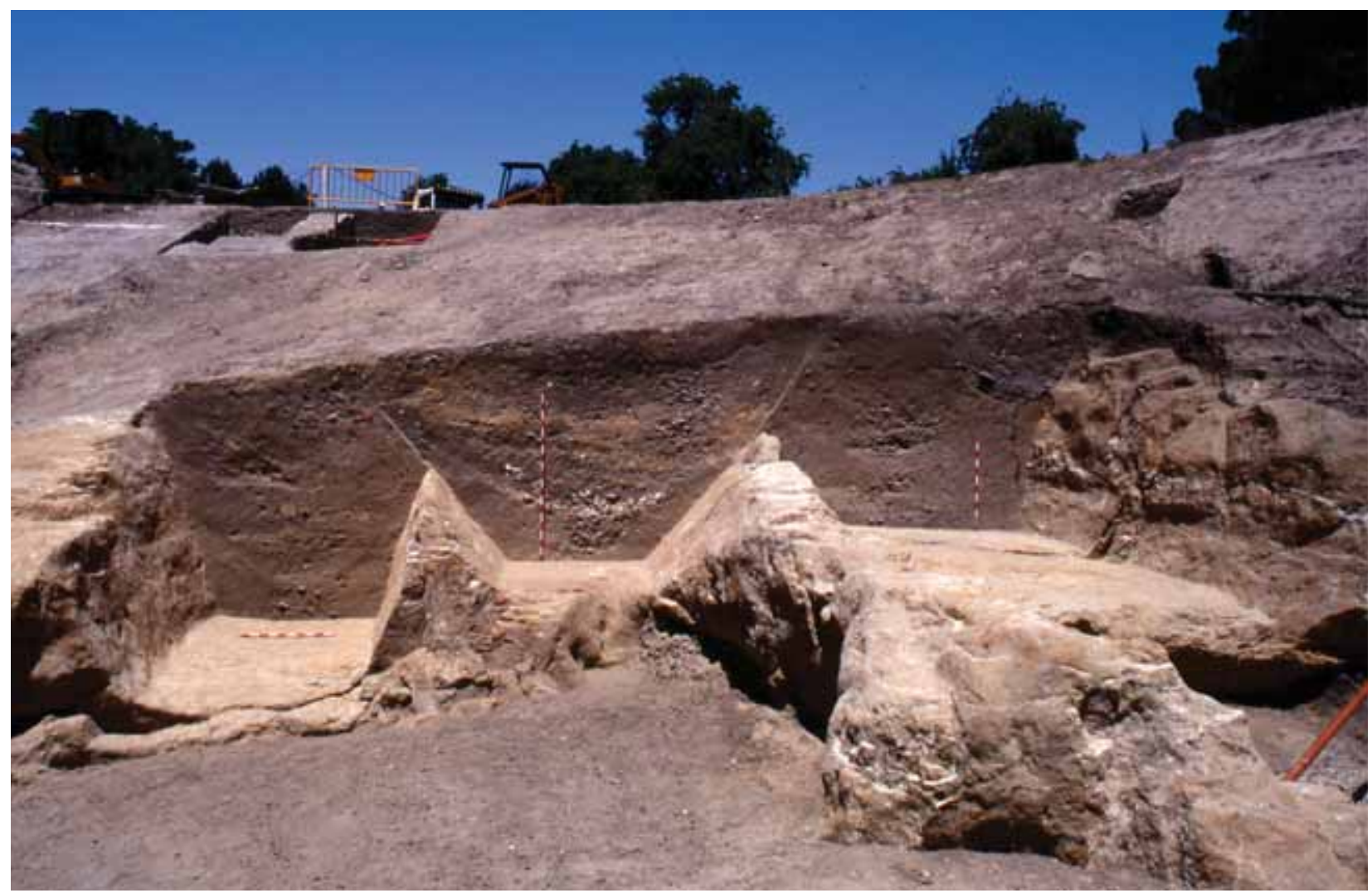

Figura 16.- La Mota (Medina del Campo, Valladolid). Doble foso del Primer Hierro cortado por el de la época de los Reyes Católicos (Blanco y Retuerce 2010). 
255). Los trabajos de restauración llevados a cabo en los últimos años en el castillo de La Mota de Medina del Campo (Fig. 16) han permitido exhumar parte del foso del poblado soteño allí asentado; se trata, según se considere, de un foso de dos senos entre los que se sitúa una plataforma, que quedó demolida al excavarse el foso del castillo en época de los Reyes Católicos, o de doble foso (Blanco y Retuerce 2010: 77-78).

Recordaremos, por otro lado, que las prospecciones llevadas a cabo en el interfluvio Duero-Pisuerga y el concurso de la fotografía aérea han detectado medio centenar de yacimientos soteños, de los cuales aproximadamente la mitad pudieron contar con muralla o foso - y sólo dos con ambos_-, si bien la presencia de la primera pudiera asegurarse únicamente en media docena de lugares, entre los que se encuentra, por mencionar uno bien conocido, el Cerro de San Andrés de Medina de Rioseco (Valladolid). Los autores de dichos trabajos (San Miguel 1993; Olmo y San Miguel 1993) destacan, en cualquier caso, que la mayoría de los poblados no se fortificaron y llaman la atención sobre la dificultad de atribuir tales obras, en caso de que efectivamente lo fueran, al momento que estudiamos, dado que muchos de esos lugares se mantuvieron ocupados durante la segunda Edad del Hierro y volvieron a habitarse en la Alta Edad Media.

Puede afirmarse, en definitiva, que la erección de murallas no es consustancial a los asentamientos soteños y, lo que parece igualmente importante, que en caso de contar con ellas su construcción no fue programada de inicio. Ello explica el que, por más que algunos de estos poblados se asienten en lugares naturalmente bien defendidos o les identifique como castros la toponimia - lo que haría difícil su diferenciación de los con toda propiedad así considerados de la orla montañosa de la Submeseta Norte (Almagro-Gorbea 1994: 40-41) — , no sean tenidos como tales; es más, todo aconseja, incluso en dichos casos y por más que la cultura del Soto sea el referente obligado, una prudencia como la mantenida por Ángel Esparza (1986) al estudiar el foco castreño de Zamora noroccidental.

Por otro lado, la no generalización y circunstancialidad de dichas obras obliga a elu- dir su justificación militar, psicológica y aun cultural, y a pensar mejor en su necesidad ante una situación dada y difícilmente evaluable, como pudiera ser la de proteger el poblado de posibles inundaciones. Tal se ha señalado, entre otras, pudiera ser la explicación para la de Manganeses de la Polvorosa (Misiego et al. 1997: 23) y se nos antoja igualmente plausible para la de El Soto de Medinilla. Baste recordar que esta última fue identificada en el extremo noroccidental del poblado - allí donde este se abre a la amplia llanura de inundación del meandro del Pisuerga en cuyo cerrado cuello se asienta-, y que el río corría entonces algunos metros por encima de su actual nivel y llevaba un caudal mayor, amén de que el poblado ocuparía una cota inferior a la que contemplamos hoy, datos estos últimos que permiten suponer que estuviera sometido a periódicas avenidas de agua (Delibes et al. 1995b: 148); esta justificación podría explicar además el hecho de que andando el tiempo, cuando el poblado se situaba ya por encima del nivel del Soto I-2, en tiempos del Soto II-2, sobre la antigua muralla se levantara simplemente un muro de contención, del que son testigos numerosos hoyos de poste (Palol y Wattenberg 1974: 184).

\subsection{A propósito de esas largas secuencias es- tratigráficas}

Si la adopción, en lo que a las construcciones domésticas se refiere, de la arquitectura en duro, de adobes, frente a la, más frágil y vulnerable, de cañas y barro, ha merecido una lectura en clave económica, según la cual, mientras que estas últimas pudieran relacionarse con una primera toma de contacto con el territorio - en tanto los habitantes de los respectivos poblados tanteaban sus potenciales recursos económicos-, las primeras reflejarían el grado de estabilidad conseguido a resultas del éxito logrado en su explotación económica (Romero 1992: 210), qué duda cabe que ello permite ser leído, asimismo, en el sentido de que las gentes soteñas tuvieran en mente desde un principio, una vez buscado y elegido el emplazamiento deseado, instalarse definitivamente en él. Por buena prueba de esa, llamémosle vocación de permanencia, se tienen hoy, desechada la idea 
de que sean el resultado de la práctica de una agricultura itinerante (Delibes et al. 1995a: 73-74), las superposiciones de poblados documentadas en diversos yacimientos que, en ambientes geográficos diferentes, han terminado por poblar el paisaje con esos tan característicos, y ya comentados, tells. No cabe pasar por alto, con todo, que cuanto queda dicho, y por más que buena parte de los enclaves excavados en los últimos años muestren una dilatada secuencia, no deja de ser una simplificación; pero permítasenos incidir sobre este punto antes de formular las objeciones pertinentes, y al objeto de hacerlas mejor entendibles.

Desde el momento mismo de su excavación, El Soto de Medinilla, con sus cinco poblados superpuestos, se erigía en paradigma de lo que se acabaría considerando un típico asentamiento soteño. Pues bien, excavaciones recientes no parecen sino venir a confirmar mucho de cuanto allí quedaba visto; es el caso, por ejemplo y entre las ya mencionadas por diversas razones, de las llevadas a cabo en Sacaojos, Manganeses de la Polvorosa o Los Baraones, pero también de las practicadas en yacimientos como el salmantino de Ledesma, bajo cuya Plaza de San Martín se han excavado cuatro ocupaciones soteñas (Benet, Jiménez y Rodríguez 1991), Cuéllar, en cuya Plaza del Castillo se exhumaron cinco poblados (Barrio 1993), El Castro (Villacelama, León), donde se cuentan asimismo un mínimo de cinco fases de ocupación (Celis 1996: 4647), La Mota, en el que una cata realizada en el actual cementerio de la villa medinense permitió identificar seis niveles (Seco y Treceño 1993), Benavente, con sus diez poblados superpuestos (Celis 1993), o el propio Soto de Medinilla, donde el sondeo estratigráfico varias veces aludido, llevado a cabo en los años 1989-1990, permitió detectar once niveles de hábitat (Delibes, Romero y Ramírez 1995; Delibes et al. 1995b: 146-148). Pero también ofrecen, muchos de ellos, una singular novedad: por debajo de los niveles con las prototípicas viviendas circulares de adobes se registran otros con esas cabañas de materiales perecederos; un dato, que intuido en su día en el yacimiento citado en último término (Palol y Wattenberg 1974: 186), ha quedado plenamente confirmado en el reciente sondeo, ya que de los once niveles exhumados los tres más antiguos presentan restos de tales cabañas.
Ocurre así que la secuencia de El Soto de Medinilla, la nueva ahora, sigue siendo la más completa de las conocidas y, por ello, una vez más, punto poco menos que obligado de referencia; y que, de nuevo y en virtud de ello, aunque de forma mucho más matizada ahora, pues no podemos perder de vista hoy los datos aportados por excavaciones como las mencionadas, $\mathrm{u}$ otras menos espectaculares, ni la documentación proporcionada por las prospecciones - el numero de yacimientos soteños ha aumentado de forma considerable (Martín Valls 1986-87: fig. 3; González-Tablas 1989: fig. 4), superando ampliamente el centenar los localizados, simplemente, en la provincia de Valladolid (Quintana y Cruz 1996: tabla 2, fig. 9)-, vuelve a ser determinante a la hora de precisar la evolución y secuencia de la cultura.

Esas abundantes, pero por lo general monótonas y pobremente decoradas, cerámicas a que aludíamos páginas atrás —análogas por otra parte, como pone a todas luces de manifiesto una de esas composiciones gráficas a que nos tiene acostumbrados Gonzalo Ruiz Zapatero (1995: fig. 6), a las de otras culturas contemporáneas del interior peninsular-, han dejado de tener el valor diagnóstico que otrora se les atribuyera; y si escaso lo tienen, y por ello suscitan una particular atención, aunque en otro orden de cosas, especies como las decoradas a peine o las primeras producciones a torno pintadas. Ello no es de extrañar si tenemos en cuenta que las diferentes estratigrafías muestran que la vida de los respectivos poblados se sucedió sin solución de continuidad; máxime además cuando el hecho de que en las mas recientes de El Soto de Medinilla no se haya detectado el nivel de incendio que permitió en su día hablar de un Soto I y un Soto II viene a invalidar tal distinción y parece obligar a contemplarlos como un todo. Entretanto, y al margen de que ciertos vasitos carenados mantengan su protagonismo durante los momentos iniciales del Soto, otros aspectos, caso de la arquitectura doméstica o la metalurgia, se presentan hoy tanto o más significativos en relación con lo que comentamos. No es cuestión de volver sobre el primero de ellos, pues de cuanto queda dicho parece claro que va tomando cuerpo la idea de que a las típicas viviendas circulares de adobes precedieron otras de idéntica planta 
pero más frágiles. Contemporánea de estas últimas sería, por otro lado y en relación con el segundo de los aspectos citados, una variada serie de piezas metálicas de bronce asimilable a la metalurgia atlántica del Bronce Final IIIb, y más concretamente a la de tipo Baiões-Vénat, en tanto que se imponen con posterioridad las fíbulas de doble resorte y los cuchillos de hierro de hoja curva (Delibes et al. 1995a: 6972, y 2001).

Contamos, finalmente, con una relativamente buena colección de dataciones radiocarbónicas, mereciendo destacarse, una vez más, la coherente serie obtenida para El Soto de Medinilla tras el último sondeo, que permite fijar la vida del poblado entre finales del siglo $\mathrm{X}$ y el último cuarto del VI cal a.C. (Delibes et al. 1995b: 153-156). Dado que la fecha más antigua de dicha serie es también la más vieja de las conocidas para la cultura hay que pensar en el siglo $X$ cal a.C. para el nacimiento de la misma; su final ha de situarse en el declinar del siglo V o los inicios del IV a.C., momento en que una nueva serie de transformaciones de todo tipo nos permite hablar de la segunda Edad del Hierro e identificar a sus protagonistas, partiendo de la primera documentación histórica, con sus correspondientes nombres étnicos.

Es así como hoy se habla ya de una fase inicial o formativa de la cultura del Soto, que vendría a coincidir aproximadamente en el tiempo con el tradicional Bronce Final IIIb entendiéndose además que éste formara parte ya del Primer Hierro (Delibes et al. 1999 y 2001), contrariamente a la idea otro tiempo mantenida de que el Soto hubiera iniciado su andadura en las postrimerías de la Edad del Bronce-, y de otra, plena o de madurez, en la que quedan incluidos el Soto I y II de $\mathrm{Pa}$ lol, desarrollada a partir del 700 a.C. en fechas convencionales, y desde aproximadamente un siglo antes de ser calibradas (Delibes et al. 1995a: 83-88).

Pero cerremos ya este largo paréntesis y volvamos al principio. Decíamos entonces que tanto las superposiciones de los poblados como la incorporación de la arquitectura de adobe se nos antojan prueba de la voluntad que manifiestan las gentes del Soto de permanecer en los enclaves elegidos; y señalábamos que ello constituía en parte una simplificación. Es preciso reconocer, para empezar, que desconocemos cuál fue la vida de cada uno de los poblados identificados; y así, en tanto que parece que los cuatro de Ledesma apenas si llegaron a sumar medio siglo (Benet, Jiménez y Rodríguez 1991: 135-136), los once de El Soto de Medinilla, de tener presentes las dataciones radiocarbónicas a que aludíamos líneas arriba, cubrirían casi medio milenio.

Es cierto, por otro lado, y buena prueba de ello son los testimonios aducidos, que la mayor parte de los yacimientos excavados mueven a sospechar ese deseo de instalación definitiva, pero no lo es menos que son muchos más, y más cada día, aquellos de los que nada o casi nada sabemos, al tener constancia poco más que de su existencia. Y es precisamente en relación con este último punto con el que merece la pena traer a colación las prospecciones llevadas a cabo para la realización del Inventario Arqueológico de Valladolid; dichos trabajos, que, hasta donde disponemos de información, han afectado a algo más del sesenta por ciento de la superficie provincial y a la totalidad de los ambientes geográficos de la misma, han permitido identificar, como ya se dijo, casi un centenar y medio de yacimientos soteños (Quintana y Cruz 1996: 41-51, tabla $2)$. Una cuarta parte de ellos parecen ocupados durante la fase formativa del Soto, cifra que podría elevarse a casi la mitad del total de tener en cuenta otros posibles, y, lo que parece más importante, una treintena de estos establecimientos pudiera asegurarse que sólo lo estuvo en dicha fase y, por tanto, en algún momento de los algo menos de dos siglos iniciales de la cultura; es más, tales asentamientos se localizan en los valles del Duero y sus principales afluentes hasta la altura de Tordesillas y en el sector oriental de las Campiñas Meridionales vallisoletanas, comarca esta última en la que se localiza el de Almenara de Adaja, único de los de este grupo excavado (Balado 1989). Estos yacimientos dan pie a comentarios de diversa índole, y algunos de ellos irán surgiendo en las páginas que siguen; de momento nos limitaremos a relacionarlos con esa apuntada toma de contacto con el territorio de las primeras gentes soteñas, lo que de alguna manera nos obligaría a contemplar- 
los como intentos frustrados en la búsqueda del hogar definitivo.

Según esas mismas prospecciones el número de yacimientos vallisoletanos adscribibles al Soto pleno sería de algo más de ochenta, elevándose la lista ligeramente por encima del centenar de tener en cuenta, asimismo, otros posibles; puede decirse además, ahora, que, salvo las campiñas suroccidentales, todo el territorio provincial pareció atractivo a los soteños, lo que ha dado pie a hablar de un "movimiento migratorio" o "colonización" de la Tierra de Campos y la Campiña de Villalar. Sin embargo, y por más que se considere que responde a una situación real, un dato resulta curioso: sólo puede afirmarse que media docena de estos yacimientos hubiera iniciado su andadura en la fase anterior; ahora bien, ¿quién puede asegurar que en las arcillas de las campiñas noroccidentales los niveles del Soto pleno no sean el sudario de una ocupación formativa? En respuesta a tal interrogante cabría recordar cómo los asentamientos parecen mostrar - como no podía ser menos, por otro lado, dada su arquitectura y si, como suponemos, no sufrieron abandonos y reocupaciones periódicas - una intensa actividad constructiva, y buenas evidencias de ello serían las diferentes secuencias registradas, en puntos a veces muy próximos entre sí, en Sacaojos, La Mota o el mismo Soto de Medinilla; de no ser porque los tres han sido excavados en diferentes momentos y lugares nuestra visión de los mismos sería todavía más parcial de la que aún hoy, sin duda, tenemos. Y aún podría traerse a colación un nuevo ejemplo, más claro aún si cabe, el del núcleo urbano de Simancas (Valladolid), donde de tener en consideración las intervenciones practicadas en la Plaza Mayor y calle Atrio de la Iglesia habría que pensar que estuvo ocupado en el clásico Soto II, mientras que de saber de la más reciente en la calle de la Esperanza cabe presumir lo fuera ya en el Soto formativo (Quintana 1993).

En definitiva que, en tanto parece admisible que algunos yacimientos correspondan exclusivamente a la fase más antigua, es difícil poder asegurar, y las excavaciones así parecen indicarlo, que aquellos que sabemos habitados en la de madurez no lo estuvieran también con anterioridad.

\subsection{Asentarse para siempre, sí... pero dónde}

Una rápida respuesta a este nuevo interrogante podría partir de una, igualmente rápida, mirada a cualquiera de los más recientes mapas de dispersión de yacimientos Soto publicados, y ya citados con anterioridad: las gentes del Soto se distribuyeron, de manera más o menos regular, por todo el valle medio del Duero, en general por los valles de sus afluentes $\mathrm{y}$, muy particularmente, a lo largo del curso de los de su margen derecha. De volver al marco vallisoletano, el mejor conocido hoy por hoy, y obviar la objeción antes planteada, cabe detenerse en dos cuestiones. El pretendido "movimiento migratorio" hacia la llanura de Villalar y Tierra de Campos en el tránsito del Soto formativo al pleno no vendría sino a avalar la idea de la "difusión del grupo céltico" hacia el Noroeste que, formulada en su momento (Palol y Wattenberg 1974: 33-34), ha venido siendo asumida por la bibliografía posterior a la vista de la cartografía general. En segundo lugar, la coincidencia en la ocupación de los cursos bajos del Pisuerga y el Esgueva, del sector oriental del Duero y de la campiña pinariega suroriental tanto por parte de las gentes de Cogotas I avanzado como, y ya tuvimos ocasión de comentarlo, por las de los inicios del Soto (Quintana y Cruz 1996: tabla 2, fig. 8); ante lo cual parece obligado preguntarse acerca de la posible continuidad de las ocupaciones y aún de las mismas gentes.

Superada hace tiempo la diversa apropiación del territorio a nivel macroespacial por parte de Cogotas I y el Soto, la de la diferencia en lo que a los modelos de ocupación del territorio se refiere constituye uno de los argumentos de la visión básicamente rupturista con la que la gran mayoría de los autores contempla hoy, tal y como tuvimos ocasión de comentar en el primer epígrafe de este capítulo, el cambio cultural Cogotas I-Soto. No es cuestión de entrar ahora en los variados razonamientos esgrimidos al propósito (Romero y Ramírez 2001; Romero, Sanz y Álvarez-Sanchís 2008: 252-257), pero, ciñéndonos a lo que por el momento nos ocupa, diremos que se aduce, en dicho sentido y para empezar, que rara vez un poblado soteño se asienta sobre otro cogotiano, lo que equivale a decir que aquellos son, en la gran mayoría de los casos, asentamientos de nueva planta; y 
se recuerda, a renglón seguido, que en aquellos lugares en que se atestiguan materiales de ambas culturas - las respectivas y características cerámicas por lo general-, ello no permite hablar de una ocupación continuada (Delibes et al. 1995a: 62 y 80).

Así, en tratándose de excavaciones - como ha podido apreciarse por una o varias razones en Almenara de Adaja, Ledesma o La Mota, por citar yacimientos ya conocidos-, bien porque los materiales estén revueltos, lo que impide identificar el correspondiente nivel de ocupación, o sean poco menos que testimoniales, lo que suele ocurrir en el caso de los de Cogotas I; bien porque la diferencia cronológica entre unos y otros sea lo suficientemente explícita como para impedir establecer la conexión entre las respectivas comunidades. En relación con las prospecciones cabe recordar, en idéntico sentido, cómo en las llevadas a cabo en la palentina Cuenca de la Nava (Rojo Guerra 1987) sólo dos de los veintiocho yacimientos soteños presentaban indicios de una ocupación Cogotas I, o cómo en las practicadas en el interfluvio DueroPisuerga (San Miguel 1993: 24-31) dicha situación se daba en media docena de lugares sobre cuarenta y seis. La cuestión se presenta más matizada en el caso de las tantas veces reseñadas del Inventario Arqueológico de Valladolid, al contar en esta ocasión con referencias sobre las fases identificadas de cada cultura; el resultado, pese a todo, no es mucho más halagüeño $\mathrm{y}$, en cualquier caso, no lo suficiente como para poder afirmar que quiebra uno de los argumentos favoritos en pro de la ruptura Cogotas I-Soto, pues, aunque es cierto que la coincidencia de ocupaciones de uno y otro signo está lejos de ser una excepción - en el más generoso de los recuentos, de las ciento treinta y ocho estaciones soteñas veintidós ofrecen materiales de Cogotas-, la verdad es que sólo cinco lugares cuentan, con seguridad y al tiempo, con restos de Cogotas I avanzado y el Soto formativo, un número que, de acudir nuevamente a la generosidad, pudiera elevarse a ocho.

Y ello nos lleva directamente a hablar de los emplazamientos y a reconocer, una vez más y en primer lugar, que el modelo que en su día significó El Soto de Medinilla, y que a buen seguro propició en principio el hallazgo de otros asentamientos de características análogas, hace tiempo que ha dejado de serlo. Prescindiendo de aquellos que, como los del noroeste zamorano (Esparza 1986), cabe incluir entre los típicamente castreños, razón por la cual han merecido atención particular en otro trabajo de este mismo volumen, recordaremos las enseñanzas que en relación con este punto han ofrecido las últimamente comentadas prospecciones en la Cuenca de la Nava y el interfluvio Duero-Pisuerga. Se diferencian entre los yacimientos de la primera, regularmente distribuidos y no siempre vinculados a cursos de agua, dos tipos de emplazamientos, ambos de carácter defensivo: por un lado, los tells que en el llano, y a alturas mínimas de $750 \mathrm{~m}$, ocupan los accidentes orográficos más sobresalientes, y, por otro, aquellos que, por encima siempre de los $800 \mathrm{~m}$, se localizan en los bordes de los páramos de su orla periférica occidental. En el interfluvio Duero-Pisuerga se destacan, por encima de la diversidad ambiental, tres tipos de emplazamientos: a orillas de los ríos, en cerros aislados y en el borde de los páramos; en su indistinta elección parecen haberse valorado siempre la proximidad a humedales y vías pecuarias, la intervisibilidad y las mejores condiciones de habitabilidad y seguridad.

Los poblados del ámbito geográfico comentado en último lugar presentan extensiones comprendidas entre una y cinco hectáreas - valores que se dan asimismo entre los que jalonan los principales cursos fluviales en las tierras sedimentarias leonesas (Celis 1996: 46) -, aglutinándose generalmente la población en un único núcleo en torno al cual, y en un radio aproximado de medio kilómetro, suelen localizarse áreas especializadas, tales como basureros o zonas de actividad artesanal; en algún caso — media docena de lugares en el territorio que comentamos - han llegado a reconocerse dos y hasta tres recintos, explicándose su existencia en virtud de la diferente funcionalidad o el aumento demográfico.

\section{Las bases económicas de la sedentarización}

Quizá no esté de más recordar de inicio la crisis ecológica a la que —durante cerca de un siglo, 850 a 760 cal a.C., en el tránsito entre los periodos climáticos Subboreal y Subatlántico- estuvo sometida la región y que supuso el paso, 
repentino y abrupto, de un ambiente muy seco y cálido a otro húmedo y más frío, pues, entre las principales consecuencias del estrés ambiental de ella derivado, se ha señalado el origen de las comunidades campesinas (López-Sáez et al. 2009).

Con todo y con ello, retomando la frase en que apoyábamos el inicio del epígrafe anterior, recordaremos igualmente cómo se vinculaba la aparición de los hábitats permanentes de la cultura del Soto con innovaciones en las actividades económicas del momento; innovaciones, añadiremos ahora, que, como la práctica del barbecho o el abonado animal y, tal vez, la rotación de cultígenos, habrían permitido superar "el obstáculo de la fertilidad finita de la tierra" (Delibes y Fernández Manzano 2000: 115-117). Y en idéntico sentido, en el de asociar la estabilidad de los asentamientos con los cambios acontecidos en las prácticas agropecuarias entre Cogotas I y el Soto, se manifestaba no mucho antes María Luisa Ruiz-Gálvez (1998: 228-229), si bien, para ella, la base de dichas transformaciones habría residido en "la capacidad de esta última [la cultura del Soto] para desarrollar una agricultura de subsistencia lo bastante eficaz como para permitir la especialización ganadera". Dos posturas que para alcanzar idéntico objetivo otorgan la primacía a una u otra actividad económica, lo cual, aunque pudiera parecer contradictorio, es, en la medida que complementario, perfectamente conciliable.

Con tal fin recordaremos cómo, frente a la idea tradicional de que la economía de las gentes del Soto descansaba fundamentalmente en el cultivo de las gramíneas (Palol y Wattenberg 1974: 32), se viene insistiendo en los últimos años en el carácter mixto, agrícola y ganadero, de dicha economía (Romero y Jimeno 1993: 197-198; Delibes et al. 1995a: 73-77); carácter que no han venido sino a confirmar los estudios paleoambientales derivados de excavaciones en poblados vallisoletanos (Delibes et al. 1995c: 564-582; Romero y Ramírez 1999). Veamos, en definitiva, que es lo que nos dicen todos ellos.

Así, y en relación con la agricultura (Mariscal, Cubero y Uzquiano 1995; Romero y Cubero 1999), podría hablarse de un monocultivo cerealista, de trigo común/duro, dado, por un lado, que el 90 por 100 de las semi- llas recuperadas corresponde a Triticum aestivum/durum y teniendo en cuenta, por otro, que tanto las dos especies vestidas de trigo, escanda y esprilla, como Hordeum vulgare y su variedad desnuda aparecen siempre en proporciones muy limitadas - lo que pudiera deberse, al menos en el caso de las cebadas $\mathrm{y}$ de pensar que no estuvieran destinadas al consumo humano, a un almacenaje diferencial y quizá al margen del hábitat (Cubero 1995: 387) - y con carácter puramente testimonial en ciertas ocasiones, cosa que ocurre también con la avena, que pudiera incluso ser silvestre; además, en tanto Triticum aestivum/ durum y Hordeum vulgare están presentes a lo largo de toda la secuencia de El Soto de Medinilla, las especies restantes lo hacen, en este y otros lugares, tardíamente y en momentos que cabe asimilar al clásico Soto II. En cualquier caso, y pese a que lo más lógico es suponer que ello obedezca a simples causas accidentales, la presencia en ciertas muestras de semillas de algunas de dichas especies permite preguntarse, por un lado, sobre el posible cultivo simultáneo de las mismas en ciertos campos - lo que a su vez lleva a plantear si con ello no se trataría de asegurar la cosecha de, al menos, una de ellas - o sobre su almacenamiento conjunto, y sospechar, en otro orden de cosas, si tales muestras - dado que en ocasiones integran también semillas de malas hierbas y plantas ruderales - no reflejarían un estadio inicial en el procesamiento, previo al almacenaje, de dichos cereales.

Hay que suponer, por otro lado, cosechas anuales con siembras en otoño-invierno y recolecciones en primavera-verano, pues los distintos cereales mencionados son de ciclo largo. Asimismo, que su cultivo tuviera lugar en campos dispersos, aunque no muy alejados de los poblados, y de reducidas dimensiones, unas 0,2 hectáreas, lo que permitiría que fueran trabajados en un día por un hombre y una pareja de animales. Descartada hoy, por otra parte, como vimos, la práctica de una agricultura itinerante, parece igualmente poco probable la de aquella intensiva que, con el cultivo continuado de los cereales, condujera al agotamiento de los campos, de ahí la presunción de que una adecuada gestión de los mismos, con vistas a garantizar su regeneración y por 
tanto su fertilidad prolongada, incluyera el barbecho y, quizá, la rotación de cultivos. Cabe contemplar, así, en el caso del primero la modalidad de año y vez, según la cual a un año de cultivo cerealista seguiría otro de descanso en el que el campo permanecería labrado aunque sin cultivar; y aun otras de barbecho más prolongado, lo que comportaría seguramente una gestión extensiva de las tierras de cultivo, con roturaciones poco menos que continuadas. Las rotaciones de cultivos, por su parte, implicarían la alternancia bienal de cereales y leguminosas, algo posible desde el momento en que el cultivo de estas últimas se ha sugerido en La Era Alta (Melgar de Abajo, Valladolid) a partir de la información palinológica (Yll 1995: 363) y nos consta la recuperación de Vicia faba en uno de los graneros del poblado Soto II-1 excavado por Palol (Hopf 1973: 140-141); tales datos, con todo, habida cuenta lo anecdótico de los testimonios, no permiten asegurar que se hubiera estabilizado la alternancia de los cultivos y emplazan, por lo demás, a un momento del Soto pleno, posiblemente avanzado incluso.

Esa eficaz gestión de los campos de cultivo a que nos referíamos requiere pensar además en una mínima ganadería; de ella nos hablan, como veremos, las colecciones faunísticas procedentes de las últimas excavaciones, poniendo de manifiesto la explotación de significativas cabañas ganaderas, de bóvidos y ovicaprinos fundamentalmente, pero también equinas en ciertos casos. Bóvidos y équidos aportarían, por un lado, el necesario estiércol para el abonado de los campos, contribuyendo así a aumentar su fertilidad y a su permanente explotación; además, de la detección de patologías relacionadas con las sobrecargas y esfuerzos en los huesos apendiculares del vacuno y de la presencia en esta misma cabaña y en la equina de individuos castrados, cabe deducir la participación de unos y otros en las tareas agrícolas y que vivían en régimen de semilibertad —en Guaya se han podido identificar, a partir de los hoyos de los postes, cercados en torno a las viviendas, cuya extensión hace presumible el encierro del ganado (Misiego et al. 2005: 210)-, como se deriva del hecho de que no presenten las deformaciones u osteopatías características del ganado estabulado.
De lo dicho hasta aquí se desprende el carácter especializado - cerealista, de ciclo anual y centrada en el cultivo del trigo común/duro - y de tipo probablemente extensivo que debió tener la agricultura entre las gentes soteñas del centro mismo de la cuenca del Duero; cabe preguntarse ahora si descansaría en ella la economía de dichas gentes o, lo que sería igual, si esta fue su principal fuente de riqueza. Para empezar, y al objeto de dar cumplida respuesta a tal cuestión, cabría invocar lo pobre e incluso raquítico de las muestras carpológicas recuperadas en las excavaciones más recientes, auque podría argumentarse igualmente que, de no perecer carbonizadas, las semillas se hubieran puesto a buen recaudo ante las eventuales, y hay que pensar que frecuentes, remodelaciones arquitectónicas sufridas por los poblados, eludiéndose así la posibilidad de que llegaran a nosotros en sus contenedores originales, en los que, como mucho, habrían quedado restos despreciables; en cualquier caso, nada que ver con esas grandes vasijas de provisiones llenas de trigo y cebada encontradas por $\mathrm{Pa}$ lol en las viejas excavaciones de El Soto de Medinilla, en el poblado Soto II-3, que le dieron la impresión de "un momento de cierta prosperidad" (Palol y Wattenberg 1974: 190191), y que hoy podemos relacionar con el elevado porcentaje de gramíneas cultivadas apreciado en la última zona de un palinograma del yacimiento (Mariscal 1995: 345). Otros estudios palinológicos denuncian, por su parte y en general, niveles siempre continuos y estables de Cerealia, lo que lleva a pensar en una agricultura cerealista constante; ahora bien, dichos porcentajes son lo suficientemente bajos como para impedir otorgar una importancia excesiva a dicha actividad y llevan a calificarla de subsidiaria (Y11 1995: 367-369).

La importancia, frente a cuanto queda dicho, de las colecciones arqueofaunísticas recuperadas en las intervenciones a que nos venimos refiriendo (Morales y Liesau 1995), y muy particularmente en las de El Soto de Medinilla (Liesau 1998), pero también en las llevadas a cabo en otros yacimientos soteños (Driesch y Boessneck 1980; Sacristán 1986: 68-69), ha permitido otorgar a la ganadería un 
papel básico, y seguramente preponderante, entre esas mismas gentes (Romero y Ramírez 1999: 460). De ahí que, paralelamente, debamos tener presente cuanto ellas nos dicen.

Así, y de tomar como referencia el peso de los restos óseos, se comprueba cómo la fauna doméstica supera, en los más de los casos e incluso ampliamente, el 90 por 100 y cómo la mayor parte del porcentaje restante corresponde a Cervus elaphus, de donde se deduce el alto valor cinegético de esta especie salvaje, cuya biomasa supera o va pareja a la de los ovicaprinos, respectivamente, en El Soto de Medinilla y Roa. De atenernos a las especies domésticas, que son las que de verdad interesan en relación con cuanto comentamos, se advierte la relevancia que tuvo el ganado vacuno, ya que, de acuerdo con el parámetro citado, representa en la mayoría de los yacimientos entre el 40 y el 60 por 100 del total de la muestra, en tanto que a los ovicaprinos, segunda cabaña en importancia por lo general, corresponde entre un 10 y un 30 por 100; las pautas de sacrificio de unos y otros son análogas, deduciéndose del predominio de individuos adultos la optimización en su aprovechamiento que, en el caso de los primeros, añadiría, al de la carne y los productos secundarios, su empleo como bestias de carga y tiro. En idéntico sentido hablan los restos de caballo, cuyos elevados porcentajes en algún caso - entre el 19 y el 25 por 100 en Melgar de Abajo, Roa y El Soto de Medinilla, en orden de interés - remiten sobre todo a garañones y cuyo consumo parece asegurado en el yacimiento citado en último lugar, pues muestran en él huellas de manipulación similares a las constatadas en el vacuno, así como en Guaya (Misiego et al. 2005: 217). El cerdo, finalmente, debió tener escaso significado en la dieta y la economía, pues en los lugares en que se detecta sus restos alcanzan porcentajes reducidos, entre el 5 y el 6 por 100 , y tan sólo en Roa consigue, con un 17 por 100, superar al de los ovicaprinos.

A la vista de los cuantiosos restos óseos exhumados en El Soto de Medinilla - tan sólo en el sondeo, tantas veces mencionado, y en dos excavaciones practicadas en el espacio por el que, al exterior del meandro donde se asienta el poblado primitivo, se expandió el caserío durante la segunda Edad del Hierro, ocupando una extensión de entre diez y doce hectáreas, se han recuperado más de 31.000 restos, lo que permite calificar tal colección como una de las más ricas y variadas de la Península Ibérica (Liesau 1998: 76-77)— los arqueozoólogos han podido afirmar, refiriéndose al Soto pleno y en la misma línea que permitían en otro tiempo como veíamos los abundantes conjuntos de semillas de cereal, que "con un sacrificio de animales jóvenes (incluso infantiles), abundancia de fauna cinegética y consumo sistemático de una especie (el caballo) antes de poder rentabilizarla alternativamente, evidencia una sociedad opulenta que no resulta comparable ni tan siquiera con la situación constatada en el mismo poblado durante la fase celtibérica" (Morales y Liesau 1995: 506-507). El presumible carácter excedentario de la cabaña equina, cuyo control condujo al destino culinario de los machos adultos jóvenes, ha llevado a suponer su cría con vistas a la comercialización y aún cabría plantearse si, de la misma manera que se sugiere en relación con ciertos objetos exóticos y de procedencia fundamentalmente meridional hallados en contextos soteños (Romero y Ramírez 1996), no pudieran haber sido objeto de intercambio por otras mercancías o, en una política de alianzas destinada a consolidar relaciones, regalos entre las élites y, por qué no, dotes femeninas (Delibes 1995: 126-129). Esto último implicaría la existencia de unas élites locales - bajo cuyo control, y posible posesión, estarían las cabañas ganaderas - de las que, por desgracia, nada nos dice la arqueología; poco cabe deducir en este sentido a partir de la arquitectura doméstica, por más que en ciertas ocasiones mayor tamaño y pintura mural, aspectos que pudieran valorarse como signo de riqueza y status social, aparezcan asociados, y otro tanto puede decirse sobre la presencia o no en la misma de esos objetos foráneos de lujo a que antes nos referíamos, pues fíbulas de doble resorte o cuchillos de hierro de hoja curva, por citar los más evidentes, aparecen indistintamente en unas u otras viviendas (Ramírez 1999: 75).

Sea como fuere, tampoco debemos llamarnos a engaño en este caso, pues de todo cuanto queda dicho no puede aventurarse el papel 
jugado por la ganadería en la economía de las gentes del Soto. Hay que partir del hecho de que los huesos que han llegado hasta nosotros - por importantes y espectaculares que puedan parecernos las colecciones arqueofaunísticas comparadas con las de cualquier otro tipo de restos - corresponden a los animales sacrificados o cazados $\mathrm{y}$, por tanto, que los cómputos mencionados no refieren otra cosa que los porcentajes relativos a su consumo, por lo que constituyen indicadores de dieta; pero nada nos dicen, lógicamente, sobre las prácticas pecuarias $\mathrm{y}$, mucho menos, respecto de la importancia real de cada una de las cabañas o sobre la posible comercialización de ciertas especies, entre las que podríamos poner por caso, una vez más, el ejemplo de los caballos, por más que quepa deducir de su consumo, siquiera sea hipotéticamente, que fueran excedentarios (Morales y Liesau 1995: 501-503). En definitiva, las cuantificaciones enunciadas tampoco nos permiten señalar hasta qué punto la ganadería fue el principal factor de la economía soteña y, aun de ser así, cuál era el nivel que ella representaba en relación con la agricultura cerealista antes comentada.

Ello nos lleva a sugerir la existencia de un equilibrio agropecuario, en el sentido de que ninguna de las prácticas comentadas quedara ahogada por la sobreexplotación de la otra; es decir, el cultivo extensivo de los campos no habría alcanzado nunca a poner en peligro las necesidades de pastos y, en recíproca correspondencia, las respectivas cabañas ganaderas habrían mantenido, en particular las de bóvidos y équidos, el número mínimo de individuos para proporcionar el estiércol necesario para el abonado de los campos de cultivo. Ello garantizaría a su vez el cereal, la carne y los productos secundarios requeridos para el mantenimiento de la comunidad, proveyendo seguramente el excedente necesario para hacer frente a años de sequía o inundaciones que dieran al traste con las cosechas o a las enfermedades y mortandad en el ganado, y no excluye la posibilidad, en tanto se mantuviera el equilibrio, de producir excedentes mayores con vistas a la comercialización, incluso con el riesgo, y volvemos al caso de los caballos, de tener que echar mano a su consumo para controlar tales superproducciones.
Es detrás de dicho equilibrio, que en la rica variedad de nichos ecológicos del amplio espacio geográfico ocupado por la cultura del Soto se adecuaría en cada caso a los recursos potenciales, donde hay que buscar la estabilidad de los poblados reflejada por los tells; del éxito del modelo de explotación del territorio hablan igualmente esos niveles de "prosperidad" y "opulencia" a que, como hemos comentado, se refieren ciertos autores, y es igualmente lógico presumir que del mismo se derivara un aumento poblacional que, al objeto de perpetuarlo, condujera a la creación de nuevos poblados en los que, por idénticas razones y con las pertinentes adaptaciones, se mantendría el sistema.

Cuanto queda dicho pudiera parecer obvio en exceso, pero no es menos cierto que lo obvio, en cuanto tal, suele ser, valga la expresión, habitualmente obviado. Y precisamente por ello un nuevo interrogante se cierne sobre lo sugerido: ¿por qué este mundo, al que otro autor ha calificado de "pujante" (Esparza 1995: 142), quiebra en un momento, difícilmente precisable, pero que en el centro de la cuenca del Duero, allí de donde procede la mayor parte de la información que viene dando pie a estos comentarios, pudiera situarse entre finales del siglo $\mathrm{V}$ e inicios del IV a.C.? Una nueva pregunta cuya respuesta sobrepasa los límites propuestos en el presente trabajo.

Permítasenos, eso sí, para concluir, contemplar - siquiera sea a través de lo que los mencionados trabajos paleoambientales han permitido recrear a partir de la documentación proporcionada por las excavaciones, insistimos una vez más, de varios yacimientos vallisoletanos (Delibes, Romero y Morales 1995) - el paisaje en que debió de desenvolverse la vida de nuestros protagonistas. Partiremos para ello del hecho de que las gentes del Soto debieron soportar un clima muy similar al actual en lo que a temperaturas y régimen de lluvias se refiere; un clima que, definido como Mediterráneo-frío, rige en el valle medio del Duero, desde los comienzos del período climático Subatlántico, cuyos inicios, como tuvimos ocasión de comentar con anterioridad, vienen a coincidir, grosso modo, con los de la cultura. Habremos de situarnos, en segundo lugar, en las inmediaciones de un destacado río o cualquier otro acuífero - lagunas o, lo que por la tierra llaman, lavajos y bodones-, pues 
como hemos visto los poblados soteños se asentaron en espacios de alta disponibilidad hídrica; tendremos que recordar, además, que dichos cursos fluviales debían discurrir por entonces varios metros por encima de su actual nivel y que su caudal sería mayor y más irregular que el presente; $\mathrm{y}$, no habremos de olvidar, finalmente, que, al menos en aquellos casos en que la ocupación del lugar fue prolongada, el asiento primitivo se situaba algunos metros por debajo de la actual superficie del yacimiento. Todo ello unido nos sugiere la posibilidad de que los poblados, o sus entornos, se vieran amenazados por posibles y periódicas inundaciones, al estar mucho más expuestos al régimen de crecidas de las aguas, y, en general, nos da idea de un ambiente más húmedo que el que contemplamos hoy. Es más, la recuperación de restos de castor, nutria, galápago, pigargo, salmón y moluscos fluviales, aunque meramente testimonial, no viene sino a abundar en la idea, ya comentada, de que nuestros ríos fueran durante la primera Edad del Hierro más caudalosos, apunta hacia lo frío, limpio y bien oxigenado de sus aguas e incide en la importancia de la cobertera arbórea de sus márgenes.

El último aspecto citado encuentra su confirmación en los resultados de los análisis polínicos que nos describen ambientes no excesivamente boscosos - los porcentajes de pólenes de taxones arbóreos son siempre inferiores al 50 por 100 , y por lo general al 30 por 100 -, con predominio de espacios abiertos y cubiertos de herbáceas silvestres y cultivadas. En efecto, dichos análisis detectan un predominio de taxones hidrófilos, herbáceos en particular, propios de ambientes ripícolas; así, juncos, helechos, musgos, narcisos o campánulas $\mathrm{y}$, elevándose sobre ellos, olmos, alisos o abedules, poblarían las riberas de los ríos. Chopos, sauces, álamos y fresnos salpicarían igualmente el paisaje en las proximidades de charcas y lavajos, que serían temporalmente frecuentados por aves migratorias como las grullas y las garzas. En torno a los poblados predominarían los espacios abiertos y cubiertos de herbáceas silvestres, artemisias y acederas, adecuados para la práctica del pastoreo y la cría del ganado - de bóvidos, cuya elevada talla en algún caso podría derivarse de la bondad de los pastos, y ovicaprinos, esencialmente, y aun de caballos en ciertos lugares-, y, junto a ellos, los campos de cultivo en los que, además de las gramíneas, crecerían las malas hierbas y las plantas ruderales. En las inmediaciones, más o menos alejadas y dispersas, se distribuirían manchas boscosas, de Pinus y Quercus principalmente, que cobijarían y permitirían el mantenimiento de una variada y rica gama de especies cinegéticas - ciervos, jabalíes, conejos y liebres, sobre todo-, y aun el pastoreo en aquéllas más abiertas y entreveradas de arbustos y matorrales. Junto a las dominantes especies mencionadas se atestigua la presencia de avellanos, nogales y enebros, e incluso en los espacios más protegidos de castaños y olivos, seguramente silvestres estos últimos en la época que nos ocupa. Especies de las que, como atestiguan los estudios carpológicos y antracológicos, fueron aprovechados los frutos, en ciertos casos, y cuya madera, en otros, se empleó en la construcción y como combustible.

\section{Reflexión final}

Hasta llegar aquí hemos trazado la imagen de dos horizontes prehistóricos consecutivos, no opuestos pero si muy distintos, y nos hemos atrevido a sugerir que, siendo las novedades que caracterizan al segundo de ellos, la cultura del Soto, numerosísimas y de la más diversa índole - por ejemplo, tecnológicas, artefactuales, funerarias o artísticas-, seguramente la de mayor calado y la que podría estar en el origen de todas las restantes fué la implantación de un régimen de vida plenamente sedentario, en estrecha relación con un nuevo concepto de la actividad agropecuaria. Fueran o no así las cosas, una de las cuestiones clave, a juzgar por la atención historiográfica que ha merecido, es determinar quiénes fueron los artífices de tan acusados cambios, si las propias gentes indígenas urgidas por las contradicciones de su economía o un pueblo foráneo familizarizado de antemano con artes agrícolas más desarrolladas. Un manido dilema este del cambio cultural en la continuidad o en la ruptura que, en el caso concreto del Soto, se ha saldado tradicionalmente apelando a un nada velado proceso de colonización protagonizado, según las ideas de Palol, por efectivos de una etnia europea, 
de ascendencia céltica, de nunca bien precisado origen.

La opinión que seamos capaces de verter ahora sobre el particular sigue siendo tan poco concluyente como las publicadas con anterioridad. Al igual que ha ocurrido otras veces, podemos hartarnos de apilar argumentos alusivos a la disimetría arqueológica existente entre Cogotas I y el Soto, pero sin lograr por ello librarnos por completo del fantasma de la continuidad étnica; y, al revés, hechizados por el paradigma dominante, tampoco será difícil sucumbir a los argumentos —más subjetivos- que esgrimen los defensores de lo contrario. Aquilatar el valor de unos y otros: he ahí la cuestión. Pero mucho nos tememos que el debate tardará en cerrarse y en alcanzar la fluidez necesaria mientras la invisibilidad de las necrópolis soteñas siga obstaculizando la comparación del material bioantropológico de las poblaciones de uno y otro momento.

Los aquí firmantes no pueden ocultar que en otras ocasiones se han mostrado proclives a las tesis de la discontinuidad, aún evitando el empleo de términos tan contundentes como el de suplantación étnica, pero no por ello dejan de ser conscientes de que en buena parte el trasfondo de la transición Cogotas I-Soto se reduce a un problema económico: la búsqueda de mayores rendimientos por unidad de espacio. La explotación extensiva del suelo en Cogotas I, condicionada por la rapidez con que las tierras en un régimen de cultivo arcaico "se estragan y quedan escoradas y degolladas", según palabras de un erudito del siglo XVII, Miguel Caxa de Leruela (Anes 1970: 123), habría dado paso a otra en la que, aplicando otro tratamiento al terrazgo - el propio Caxa se hace eco, por ejemplo, de que "las heredades de pan han menester la huella del ganado -el abono- para que fructifiquen", lo que es tentador relacionar con el avance de la cabaña de vacuno atestiguada en el Soto-, se logra intensificar la producción. ¿Es demasiado ingenuo dar crédito a la idea de que tamaña revolución, que entre otros beneficios, habría hecho posible cubrir las necesidades alimentarias de una población más amplia, se gestó de forma autónoma e independiente en el seno de la cultura de Cogotas I? ¿Hicieron falta tantas revoluciones de este tipo como grupos culturales de la Edad del Bronce conocemos en Europa, para llegar a los mismos o muy parecidos resultados? ¿No se limitarían las poblaciones indígenas de la Meseta a adoptar de otros, sin mayor trastorno poblacional, esas innovaciones agronómicas que entrevemos en el origen del resto de los cambios? Todavía, como se ve, muchas más preguntas que respuestas y no todas las últimas apuntando precisamente hacia la misma solución.

No espere el lector a estas alturas mayores milagros de nosotros; antes al contrario, lejos de aligerar la discusión, vamos a poner punto y final a nuestro escrito añadiendo un nuevo elemento para la reflexión, esta vez de la mano de un texto de Eloy Terrón, de marcado sesgo antropológico, que tiene la virtud de recordarnos la renuencia del agricultor a cualquier cambio y, por tanto, la excepcionalidad de que estos lleguen a producirse de no mediar alguna circunstancia excepcional: "A fin de asegurarse los resultados más favorables [...] había que seguir con rigor las normas garantizadas por la experiencia del grupo. En otras palabras, la actividad agropecuaria no era propensa a la experimentación ni a la innovación; los campesinos no podían permitirse el lujo de hacer ensayos pues ponían en peligro la misma subsistencia del grupo. Esta es la explicación de por qué la agricultura fue tan conservadora, así como del hecho de que los campesinos buscasen tozudamente la seguridad de los resultados" (Terrón 1981: 18). La sombra del influjo externo vuelve a sobrevolarnos.

\section{REFERENCIAS BIBLIOGRÁFICAS}

Abarquero Moras, F.J. (2005): Cogotas I. La difusión de un tipo cerámico durante la Edad del Bronce. Arqueología en Castilla y León, Monografías 4. Junta de Castilla y León, Valladolid.

Abarquero, J.; Guerra, E.; Delibes, G.; Palomino, A.; Val, J. del (2010a): Cuarenta siglos de explotación de sal en las lagunas de Villafáfila, Zamora (2500 A.C.-1500 D.C). Plan Pahis-Junta de Castilla y León, Valladolid. 
Abarquero, J.; Guerra, E.; Delibes, G.; Palomino, A.; Val, J. del (2010b): Excavaciones en los "cocederos de sal" prehistóricos de Molino Sanchón II y Santioste (Villafáfila, Zamora). Los yacimientos de Villafáfila en el marco de las explotaciones salineras de la prehistoria europea (J. Abarquero, E. Guerra, coords.), Colección Actas, Junta de Castilla y León, Valladolid: 119-156.

Almagro Basch, M. (1939): La cerámica excisa de la Primera Edad del Hierro de la Península Ibérica. Ampurias, I: 141-154.

Almagro-Gorbea, M. (1986): Bronce Final y Edad del Hierro. La formación de las etnias y culturas prerromanas. Historia de España. 1. Prehistoria (F. Jordá, M. Pellicer, P. Acosta, M. Almagro-Gorbea, eds.), Gredos, Madrid: 351-532.

Almagro-Gorbea, M. (1986-87): Los Campos de Urnas en la Meseta. Zephyrus, XXXIX-XL: 31-47.

Almagro-Gorbea, M. (1994): Urbanismo de la Hispania "céltica". Castros y Oppida del centro y occidente de la Península Ibérica. Castros y Oppida en Extremadura (M. Almagro-Gorbea, A.Mª Martín, eds.), Complutum Extra, 4. Madrid: 13-75.

Anes Alvarez, G. (1970): Las crisis agrarias en la España Moderna. Taurus Ediciones, Madrid.

Arnold, B. (1992): Villages du Bronze Final sur les rives du lac de Neuchâtel. L'habitat et l'occupation du sol a l'Age du Bronze en Europe (C. Mordant, A. Richard, eds.), Actes du Colloque International de Lons-le-Saunier, Paris: 303-312.

Balado Pachón, A. (1989): Excavaciones en Almenara de Adaja: el poblamiento prehistórico. Diputación Provincial de Valladolid, Valladolid.

Barril Vicente, M. (1995): El Castro de "Los Baraones" (Valdegama, Palencia): un poblado en el alto valle del Pisuerga. Poblamiento Celtibérico. III Simposio sobre los Celtíberos (F. Burillo Mozota, coord.), Institución "Fernando El Católico", Zaragoza: 399-408.

Barrio Martín, J. (1993): Estratigrafía y desarrollo poblacional en el yacimiento prerromano de la Plaza del Castillo (Cuéllar, Segovia). Arqueología vaccea. Estudios sobre el mundo prerromano en la cuenca media del Duero (F. Romero, C. Sanz, Z. Escudero, eds.), Junta de Castilla y León, Valladolid: 173-212.

Barrio Martín, J. (2002): El santuario de culto doméstico del poblado prerromano de Cuéllar (Segovia). Un análisis del contexto arqueológico y de los elementos rituales. Madrider Mitteilungen, 43: 79-122.

Bellido Blanco, A. (1996): Los campos de hoyos. Inicios de la economía agrícola en la Submeseta Norte. Studia Archaeologica, 85, Valladolid.

Benet, N.; Jiménez, M.C.; Rodríguez, M.B. (1991): Arqueología en Ledesma, una aproximación: La excavación en la Plaza de San Martín. Del Paleolítico a la Historia (M. Santonja, coord.), Junta de Castilla y León y Museo de Salamanca, Salamanca: 117-136.

Blanco García, J.F.; Retuerce Velasco, M. (2010). Últimas intervenciones arqueológicas en el cerro de La Mota (Medina del Campo, Valladolid). Vaccea Anuario 2009 (C. Sanz, F. Romero, dirs.), Centro de Estudios Vacceos "Federico Wattenberg”, Universidad de Valladolid, Valladolid: 77-79.

Blanco González, A. (2010): 'Arqueología de la población' entre la Edad del Bronce y el Primer Hierro (1800-400 AC): sobre procesos migratorios y colonizadores en la Submeseta Norte. Arqueología de la Población, Arqueología Espacial, 28: 361-379.

Blancquaert, G.; Bostyn, F.; Desfossés, Y.; Lanchon, Y.; Talon, Y. (eds.) (2000): Habitats et necropoles à l'Âge du Bronze sur le Transmanche et le T.G.V. Nor. Travaux de la Société Préhistorique Française, 1, París.

Blasco, M.C.; Sanchez Capilla, M.L.; Caprile, P.; Valle, J. (1985): Depósito votivo en un yacimiento de la Edad del Bronce en el valle del Manzanares (Perales del Río, Madrid). Homenaje al Profesor Gratiniano Nieto, Cuadernos de Prehistoria y Arqueología, 11-12: 69-83.

Bosch Gimpera, P. (1942): Two Celtic Waves in Spain. Proceedings of the British Academy, 26: 1-126.

BRADLEy, R. (1984): The social foundations of Prehistoric Britain. Longman, Londres.

Cabré Aguiló, J. (1930): Excavaciones en Las Cogotas. Cardeñosa (Avila). I. El Castro. Memorias de la Junta Superior de Excavaciones y Antigüedades, 110. Madrid.

Cabo Alonso, A. (1987): Los fundamentos de la unidad regional. Geografía de Castilla y León. 1. Unidady diversidad del territorio (A. Cabo, F. Manero, dirs.), Ámbito, Valladolid: 12-149. 
Caro Dobón, L.; López Martínez, B. (2001): Estudio antropológico de las inhumaciones del poblado de la Edad del Hierro "La Corona / El Pesadero" (Manganeses de la Polvorosa, Zamora). Anuario del Instituto de Estudios Zamoranos Florián de Ocampo, 18: 13-23.

Celis Sánchez, J. (1993): La secuencia del poblado de la Primera Edad del Hierro de 'Los Cuestos de la Estación', Benavente (Zamora). Arqueología vaccea. Estudios sobre el mundo prerromano en la cuenca media del Duero (F. Romero, C. Sanz, Z. Escudero, eds.), Junta de Castilla y León, Valladolid: 93-132.

Celis SÁnchez, J. (1996): Origen, desarrollo y cambio en la Edad del Hierro de tierras leonesas. ArqueoLeón. Historia de León a través de la Arqueología, Junta de Castilla y León y Diputación Provincial de León, León: 41-67

CRUZ, P.J. (1997): Nuevos puñales de remaches de bronce de La Mesa de Carpio (Villagonzalo de Tormes, Salamanca). Zephyrus, L: 263-272.

Cubero Corpas, C. (1995): Estudio paleocarpológico de yacimientos del valle medio del Duero. Arqueología y medio ambiente. El primer milenio a.C. en el Duero Medio (G. Delibes, F. Romero, A. Morales, eds.), Junta de Castilla y León, Valladolid: 371-394.

David-El Biali, M. (1992): L'habitat a l'Age du Bronze en Suisse. Tentative de synthèse. L'habitat et l'occupation du sol à l'Age du Bronze en Europe (C. Mordant, A. Richard, eds.), Actes du Colloque International de Lons-le-Saunier, Paris: 359-376.

Delibes de Castro, G. (1995): El amanecer de la Historia. Historia de una cultura. Castilla y León en la Historia de España (A. García Simón, ed.), Junta de Castilla y León, Valladolid: 71-131.

Delibes de Castro, G. (2001): Del Bronce al Hierro en el valle medio del Duero: una valoración del límite Cogotas I-Soto de Medinilla a partir de las manifestaciones de culto. Zephyrus, 53-54: 293-309.

Delibes de Castro, G.; Fernández Manzano, J. (1981): El castro protohistórico de "La Plaza" en Cogeces del Monte (Valladolid). Reflexiones sobre el origen de la fase Cogotas I. Boletín del Seminario de Arte y Arqueología, XLVII: 51-70.

Delibes de Castro, G.; Fernández Manzano, J. (2000): La trayectoria cultural de la Prehistoria Reciente (6400-2500 BP) en la Submeseta Norte española: principales hitos de un proceso. Pré-história recente da Península Ibérica (V.O. Jorge, coord.), Actas do $3 .^{\circ}$ Congresso de Arqueologia Peninsular, IV Associação para o Desenvolvimento da Cooperação em Arqueologia Peninsular, Porto: 95-122.

Delibes de Castro, G.; Romero Carnicero, F. (1992): El último milenio a.C. en la Cuenca del Duero. Reflexiones sobre la secuencia cultural. Paleoetnología de la Península Ibérica (M. Almagro-Gorbea, G. Ruiz Zapatero, eds.), Complutum, 2-3: 233-258.

Delibes de CAstro, G.; Zapatero Magdaleno, P. (1996): De lugar de habitación a sepulcro monumental: una reflexión sobre la trayectoria del yacimiento neolítico de La Velilla, en Osorno (Palencia). Actes del I Congrés del Neolític a la Península Ibèrica. Formació i implantació de les comunitats agrícoles, vol. 1. Rubricatum, 1: 337-345.

Delibes de Castro, G.; Fernández Manzano, J.; Herrán, J.I. (2007): Los bronces de Valdevimbre y la metalurgia Cogotas I. El hallazgo leonés de Valdevimbre y los depósitos del Bronce Final Atlántico en la Península Ibérica (J. Celis, G. Delibes, J. Fernández-Manzano, L. Grau, eds.), Estudios y Catálogos 17, Junta de Castilla y León, Valladolid: 106-131.

Delibes de Castro, G.; Fernández Manzano, J.; Rodríguez Marcos, J.A. (1990): Cerámica de la plenitud Cogotas I: El yacimiento de San Román de Hornija (Valladolid). Boletín del Seminario de Arte y Arqueología, LVI: 64-105.

Delibes de Castro, G.; Olmo Martín, J. del; Santiago Pardo, J. (2000): El hábitat de la Edad del Bronce en el valle medio del Duero: un proyecto de Arqueología Aérea. Boletín del Seminario de Arte y Arqueología, LXVI.

Delibes de Castro, G.; Romero Carnicero, F.; Morales Muñiz, A. (eds.) (1995): Arqueología y medio ambiente: El primer milenio a.C. en el Duero Medio. Junta de Castilla y León, Valladolid.

Delibes de Castro, G.; Romero Carnicero, F.; Ramírez Ramírez, M.L. (1995): El poblado “céltico" de El Soto de Medinilla (Valladolid). Sondeo estratigráfico de 1989-90. Arqueología y medio ambiente. El primer milenio a.C. en el Duero Medio (G. Delibes, F. Romero, A. Morales, eds.), Junta de Castilla y León, Valladolid: 149-177. 
Delibes de Castro, G.; Romero Carnicero, F.; Sanz Mínguez, C.; Escudero Navarro, Z.; San Miguel Maté, L.C. (1995a): Panorama arqueológico de la Edad del Hierro en el Duero medio. Arqueología y medio ambiente. El primer milenio a.C. en el Duero Medio (G. Delibes, F. Romero, A. Morales, eds.), Junta de Castilla y León, Valladolid: 49-146.

Delibes de Castro, G.; Romero Carnicero, F.; Fernández Manzano, J.; Ramírez Ramírez, M.L.; Misiego Tejeda, J.C.; Marcos Contreras, G.J. (1995b): El tránsito Bronce Final-Primer Hierro en el Duero Medio. A propósito de las nuevas excavaciones en El Soto de Medinilla (Valladolid). Homenaje a la Dra. Ana María Muñoz Amilibia, Verdolay, 7: 145-158.

Delibes de Castro, G.; Romero Carnicero, F.; Escudero Navarro, Z.; Sanz Mínguez, C.; San Miguel Maté, L.C.; Mariscal Alvarez, B.; Cubero Corpas, C.; Uzquiano Ollero, P.; Morales Muñiz, A.M.; Liesau von Lettow-Vorbeck, C.; Calonge Cano, G. (1995c): El medio ambiente durante el primer milenio a.C. en el valle medio del Duero. Consideraciones finales. Arqueología y medio ambiente. El primer milenio a.C. en el Duero Medio (G. Delibes, F. Romero, A. Morales, eds.), Junta de Castilla y León, Valladolid: 543-582.

Delibes de Castro, G.; Romero Carnicero, F.; Fernández Manzano, J.; Ramírez Ramírez, M.L.; Herrán Martínez, J.I.; Abarquero Moras, F.J. (1999): Datations au radiocarbone concernant la transition entre l'Âge du Bronze et l'Âge du Fer dans la Péninsule Ibérique. ${ }^{14} \mathrm{C}$ et Archéologie. $3^{\text {ème }}$ Congrès Internacional (J. Evin, Ch. Oberlin, J.-P. Daugas, J.-F. Salles, dirs.), Mémoires de la Société Préhistorique Française, XXVI, Supplément 1999 de la Revue d'Archéométrie, Paris-Rennes, 1999: 193-197.

Delibes de Castro, G.; Fernández Manzano, J.; Romero Carnicero, F.; Herrán Martínez, J.I.; Ramírez Ramírez, M.L. (2001): Metal production at the end of the Late Bronze Age in the Central Iberian Peninsula. Journal of Iberian Archaeology, 3: 73-95.

DíAz deL Río, P. (2001): La formación del paisaje agrario. Madrid en el III y II milenios BC. Arqueología, Paleontología y Etnografía, 9, Comunidad de Madrid, Madrid.

Díez Castillo, A. (1997): Utilización de los recursos en la Marina y Montaña cantábricas: una prehistoria ecológica de los valles del Deva y Nansa. Illunzar, 3, Gernika.

Driesch, A. von DEN; Boessneck, J. (1980): Tierknochenfunde aus Sacaojos bei La Bañeza (Provinz León). Studien über frühe Tierknochenfunde von der Iberischen Halbinsen, 7. München: 122-159.

Esparza Arroyo, A. (1986): Los castros de la Edad del Hierro del noroeste de Zamora. Instituto de Estudios Zamoranos Florián de Ocampo y Diputación de Zamora, Zamora.

Esparza Arroyo, A. (1990): Sobre el ritual funerario de Cogotas I. Boletín del Seminario de Arte y Arqueología, LVI: 106-143.

Esparza Arroyo, A. (1995): La Primera Edad del Hierro. Historia de Zamora. I. De los orígenes al final de Medioevo (J.C. Alba López, coord.), Diputación de Zamora, Instituto de Estudios Zamoranos "Florián de Ocampo" y Caja España, Zamora: 103-149.

Fabián García, J. F. (2006): El IV y III Milenio AC en el Valle Amblés (Ávila). Arqueología en Castilla y León, Monografías 5, Junta de Castilla y León, Valladolid.

Fabián García, J.F.; Blanco González, A.; López SÁez, J.A. (2006): La transición Calcolítico-Bronce Antiguo desde una perspectiva arqueológica y ambiental: el Valle Amblés (Ávila) como referencia. Arqueología Espacial: Espacios Agrarios (A. Orejas, coord.), Arqueología Espacial, 26: 37-56.

Fernández-Posse, Ma .D. (1998): La investigación protohistórica en la Meseta y Galicia. Síntesis, Madrid.

Fernández-Posse, Ma.D.; SÁnchez-Palencia, F.J. (1992): Organización y estructura de los asentamientos castreños en la Asturia interior. Arquitectura popular en Castilla y León. Bases para un estudio (J.M. Báez Mezquita, coord.), Universidad de Valladolid, Valladolid: 153-174.

Fernández Rodríguez, C. (2009): Los restos faunísticos de la Edad del Bronce de "El Pelambre". "El Pelambre", Villaornate, León. El horizonte Cogotas I de la Edad del Bronce y el periodo tardoantiguo en el valle medio del Esla (M.L. González Fernández, coord.), Tragsa, León: 215-255.

García, J.; Liesau, C. (2007): Los restos faunísticos. El Bronce Medio y Final en la región de Madrid. El poblado de la Fábrica de Ladrillos (Getafe, Madrid) (C. Blasco, J.F. Blanco, C. Liesau, E. Carrión, J. García., S. Quero, M.J. Rodríguez, eds.), Estudios de Prehistoria y Arqueología Madrileñas, 14-15, Madrid: 171-182. 
García Alonso, M.; Urteaga Artigas, M. (1985): La villa medieval y el poblado de la Edad del Hierro en La Mota (Medina del Campo, Valladolid). Noticiario Arqueológico Hispánico, 23: 61-140.

García Fernández, J. (1968): La Meseta. Submeseta Septentrional. Castilla la Vieja y León. Geografía regional de España (M. Terán, L. Solé Sabarís, coords.), Ariel, Barcelona: 100-154.

Gibaja, J.; Crespo, M.; Delibes, G.; Fernández, J.; Fraile, C.; Herrán, J.I.; Rodríguez Marcos, J.A. (2011): El uso de trillos durante la Edad del Cobre en la Meseta española. Análisis traceológico de una colección de denticulados de sílex procedentes del "recinto de fosos" de El Casetón de la Era (Villalba de los Alcores, Valladolid), Trabajos de Prehistoria en prensa.

González-Tablas Sastre, F.J. (1989): Los niveles superiores de Sanchorreja. La primera Edad del Hierro en el borde meridional de la Meseta. Trabajos de Prehistoria, 46: 117-128.

Goodenough, W. (1970): The evolution of pastoralism and Indoeuropean origins. Indoeuropean and indoeuropeans (G. Cardona, H.M. Köenigswald, A. Senn, eds.), Philadelphia: 253-266.

Gusi, F.; Muriel, S. (2008): Panorama actual de la investigación de las inhumaciones infantiles en la Protohistoria del sudoeste mediterráneo europeo. Nasciturus, infans, puerulus vobis mater terra: la muerte en la infancia (F. Gusi, S. Muriel, C. Olària, eds.), Diputació de Castelló, Servei d’Investigacions Arqueològiques i Prehistòriques, Castelló: 257-329.

Harrison, R.J.; Moreno, G; Legge, A.J. (1987): Moncín: un poblado prehistórico de la Edad del Bronce. Noticiario Arqueológico Hispánico, 29: 7-102.

Harrison, R.J.; Moreno, G.; Legge, A.J. (1994): Moncín: un poblado de la Edad del Bronce (Borja, Zaragoza). Institución "Fernando El Católico", Zaragoza.

Hopf, M. (1973): Pflanzenfunde aus Nordspanien. Cortes de Navarra-El Soto de Medinilla. Madrider Mitteilungen, 14: 133-142.

Hopfner, H. (1954): La evolución de los bosques de Castilla la Vieja en tiempos históricos. Estudios Geográficos, 56: 415-430.

Jones, M.U.; Bond, D. (1980): Later Bronze Age settlement at Mucking, Essex. Settlement and society in the British Later Bronze Age (J.C. Barret, R. Bradley, eds.), British Archaeological Reports, British Series, 83, Oxford: 471-482.

Jorge, S.O. (1998): Debate. Existe uma Idade do Bronze Atlântico? (S.O. Jorge, ed.), Trabalhos de Arqueologia, 10, Lisboa: 248-249.

Kristiansen, K. (1989): Transformaciones sociales en el Neolítico Final de la Europa Templada (4000-2000 a.C.). Trabajos de Prehistoria, 46: 65-74.

Liesau von Lettow-Vorbeck, C. (1998): El Soto de Medinilla: Faunas de mamíferos de la Edad del Hierro en el Valle del Duero (Valladolid, España). Archaeofauna, 7: 11-210.

Lizcano Prestel, R. (1999): El Polideportivo de Martos (Jaén): Un yacimiento neolítico del IV Milenio A.C. Nuevos datos para la reconstrucción del Proceso Histórico en el Alto Guadalquivir. Publicaciones Cajasur, Córdoba.

López SÁez, J.A.; López Merino, L.; Pérez Díaz, S. (2009): Estudio arqueopolínico de cuatro hoyos de la Edad del Bronce de "El Pelambre". "El Pelambre", Villaornate, León. El horizonte Cogotas I de la Edad del Bronce y el periodo tardoantiguo en el valle medio del Esla (M. L. González Fernández, coord.), Tragsa, León: 258-265.

López-Sáez, J.A.; Blanco-González, A.; López-Merino, L.; Ruiz-Zapata, M.B.; Dorado-Valiño, M.; PéReZ-Díaz, S.; Valdeolmillos, A.; BuRJachs, F. (2009): Landscape and climatic changes during the end of the Late Prehistory in the Amblés Valley (Ávila, central Spain), from 1200 to $400 \mathrm{cal} \mathrm{BC}$. Rhythms and causalities of the anthropisation dynamics in Europe between 8500 and 2500 cal BP: Sociocultural and/ or climatic assumptions (D. Galop, L. Carroza, M. Magny, G. Gilaine, eds.), Quaternary International, 200: 90-101.

MaluQuer de Motes, J. (1954): El yacimiento hallstáttico de Cortes de Navarra. Estudio crítico I. Excavaciones en Navarra, IV, Pamplona.

MaluQuer de Motes, J. (1956): La técnica de incrustación de Boquique y la dualidad de tradiciones cerámicas en la Meseta durante la Edad del Hierro. Zephyrus, VII: 179-200. 
Maluquer de Motes, J. (1958a): Excavaciones arqueológicas en el Cerro del Berrueco (Salamanca). Acta Salmanticensia, XIV-1, Salamanca.

Maluquer de Motes, J. (1958b): El yacimiento hallstáttico de Cortes de Navarra. Estudio crítico II. Excavaciones en Navarra, VI, Pamplona.

Mariscal Alvarez, B. (1995): Análisis polínico de los yacimientos de la Edad del Hierro de El Soto de Medinilla (campaña de 1989-1990) y El Cerro de La Mota en Medina del Campo, Valladolid. Arqueología y medio ambiente. El primer milenio a.C. en el Duero Medio (G. Delibes, F. Romero, A. Morales, eds.), Junta de Castilla y León, Valladolid: 337-350.

Mariscal, B.; Cubero, C.; UzQuiano, P. (1995): Paisaje y recursos del valle del Duero durante el primer milenio antes de Cristo a través de la Paleoetnobotánica. Arqueología y medio ambiente. El primer milenio a.C. en el Duero Medio (G. Delibes, F. Romero, A. Morales, eds.), Junta de Castilla y León, Valladolid: 416-454.

Martín BentTo, J.I.; JimÉnez GonzÁlez, M.C. (1989): En torno a una estructura constructiva en un "campo de hoyos" de la Edad del Bronce de la Meseta española (Forfoleda, Salamanca). Zephyrus, XLI-XLII: 263-281.

Martín Galindo, J.L. (1953): Los cultivos sobre cenizas en la provincia de León. Archivos Leoneses, VII: 79-95.

MÁrqueZ, J.E. (2001): De los campos de silos a los agujeros negros: sobre fosas, recintos y zanjas en la Prehistoria Reciente del Sur de la Península Ibérica. SPAL, 10: 207-220.

MÁrquez, J.E. (2006): Sobre los depósitos estructurados de animales en yacimientos con fosos del sur de la Península Ibérica. Animais na Pré-historia e Arqueologia da Península Ibérica (N. Ferreira Bicho, ed.), Actas do IV Congresso de Arqueologia Peninsular, Promontoria Monográfica, 03, Universidade do Algarve, Faro: 15-25.

MÁrquez, J.E.; JimÉnez-JÁImez, V. (2010): Recintos de fosos. Genealogía y significado de una tradición en la prehistoria del suroeste de la Península Ibérica (IV-III Milenios AC). Universidad de Málaga, Málaga.

Martín Valls, R. (1986-87): La segunda Edad del Hierro: consideraciones sobre su periodización. Zephyrus, XXXIX-XL: 59-86.

Martín Valls, R.; Delibes de Castro, G. (1978): Die Hallstatt-zeitliche Siedlung von Zorita bei Valoria la Buena (Prov. Valladolid). Madrider Mitteilungen, 19: 219-230.

MAUNY, R. (1979): Contribution a l'étude des fosse ovoïdes et silos. Les techniques de conservation de grains à long terme. Leur rôle dans la dynamique des systèmes des cultures et des sociétés, CNRS, Paris: 48-52.

Misiego Tejeda, J.C.; Marcos Contreras, G.J.: Sarabia Herrero, F.J.; Martín Gil, J.; Martín Gil, F.J. (1993): Un horno doméstico de la Primera Edad del Hierro de "El Soto de Medinilla" (Valladolid) y su análisis por ATD. Boletín del Seminario de Arte y Arqueología, LIX: 89-111.

Misiego Tejeda, J.C.; Martín Carbajo, M.A.; Marcos Contreras, G.J.; Sanz García, F.J. (1997): Excavaciones arqueológicas en el yacimiento de 'La Corona/El Pesadero', en Manganeses de la Polvorosa (Zamora). Anuario del Instituto de Estudios Zamoranos "Florián de Ocampo": 17-41.

Misiego Tejeda, J.C.; Martín Carbajo, M.A.; Sanz García, F.J.; Marcos Contreras, G.J.; Larrén IzQuierDo, H. (1998): Arqueología en territorio astur. La Corona/El Pesadero (Zamora). Revista de Arqueología, 208: 24-35.

Misiego Tejeda, J.C.; Sanz García, F.J.; Marcos Contreras, G.J.; Martín Carbajo, M.A. (1999): Excavaciones arqueológicas en el castro de Sacaojos (Santiago de la Valduerna, León). Numantia. Arqueología en Castilla y León, 7: 43-65.

Misiego Tejeda, J.C.; Martín Carbajo, M.A.; Marcos Contreras, G.J.; Sanz García, F.J.; Redondo Martínez, R.; Doval Martínez, M.; García Rivero, P.F.; García Martínez, M.I. (2003): Excavación arqueológica en el poblado protohistórico de Dessobriga (Osorno, Palencia/Melgar de Fernamental, Burgos). Actuaciones arqueológicas en la autovía del Camino de Santiago (A-231, León-Burgos). Provincia de Burgos (2000-2003) (J.C. Misiego Tejeda, C. Etxeberría Zarranz, coords.), Junta de Castilla y LeónGical, León: 31-91.

Misiego Tejeda, J.C.; Marcos Contreras, G.J.; Martín Carbajo, M.A.; Sanz García F.J.; Villanueva MarTín, L.A. (2005): Guaya (Berrocalejo de Aragona, Ávila): reconstrucción de la vida y economía de un poblado en los albores de la Edad del Hierro. Bronce Final y Edad del Hierro en la Península Ibérica (A. Blanco, C. Cancelo, A. Esparza, eds.), Encuentro de Jóvenes Investigadores, Universidad de Salamanca, Salamanca: 207-228. 
Misiego Tejeda, J.C.; Marcos Contreras, G.J.; Martín Carbajo, M.A.; Sanz García F.J. (2006): Últimas investigaciones de la Edad del Hierro en la provincia de Zamora: El yacimiento de "La Corona/El Pesadero" en Manganeses de la Polvorosa. Segundo Congreso de Historia de Zamora, Actas I. Instituto de Estudios Zamoranos "Florián de Ocampo", Zamora: 103-141.

Molina González, F. (1978): Definición y sistematización del Bronce Tardío y Final en el Sudeste de la Península Ibérica. Cuadernos de Prehistoria de la Universidad de Granada, 3: 159-232.

Morales Muñiz, A.; Liesau von LetTow-Vorbeck, C. (1994): Arqueozoología del Calcolítico en Madrid: ensayo crítico de síntesis. El horizonte campaniforme en la región de Madrid en el centenario de Ciempozuelos (M.C. Blasco, ed.), Patrimonio Arqueológico del Bajo Manzanares, 2. Madrid: 227-247.

Morales Muñíz, A.; Liesau von Lettow-Vorbeck, C. (1995): Análisis comparado de las faunas arqueológicas en el valle Medio del Duero (prov. Valladolid) durante la Edad del Hierro. Arqueología y medio ambiente. El primer milenio a.C. en el Duero Medio (G. Delibes, F. Romero, A. Morales, eds.), Junta de Castilla y León, Valladolid: 455-514.

Needham, S.P. (1992): The structure of settlement and ritual in the Late Bronze Age of South-East Britain. L'habitat et l'occupation du sol a l'Age du Bronze en Europe (C. Mordant, A. Richard, eds.), Actes du Colloque International de Lons-le-Saunier, París: 49-69.

OJeda Nieto, J. (2000): Alaejos. Los pueblos de Castilla en el siglo XVII. Diputación Provincial de Valladolid, Valladolid.

Olmo Martín, J. Del; San Miguel Maté, L.C. (1993): Arqueología aérea en asentamientos vacceos. Arqueología vaccea. Estudios sobre el mundo prerromano en la cuenca media del Duero (F. Romero, C. Sanz, Z. Escudero, eds.), Junta de Castilla y León, Valladolid: 507-528.

Ortega Valcarcel, J. (1995): El espacio físico en Castilla y León. Historia de una Cultura. I. Castilla y León en la Historia de España (A. García Simón, ed.), Junta de Castilla y León, Valladolid: 19-74.

Palol, P. DE (1963): Notas para la sistematización de la Primera Edad del Hierro en Castilla la Vieja. Los silos del Barrio de San Pedro Regalado de Valladolid. A Pedro Bosch Gimpera en el septuagésimo aniversario de su nacimiento, México: 135-150.

Palol, P. DE (1974): Alava y la Meseta Superior durante el Bronce Final y Primer Hierro. Estudios de Arqueología Alavesa, VI: 91-100.

Palol, P. DE; Wattenberg, F. (1974): Carta Arqueológica de España. Valladolid. Diputación Provincial de Valladolid, Valladolid.

Palomino Lázaro, A.L.; Negredo García, M.J.; Abarquero Moras, F.J. (1999): Cabañas, basureros, silos y tumbas en el yacimiento de El Cerro, La Horra (Burgos): A vueltas sobre el significado de un campo de hoyos en la Edad del Bronce de la Meseta. Nvmantia. Arqueología en Castilla y León, 7: 21-41.

Passard, F.; Piningre, J.F.; URlacher, J.P. (1992): L'habitat et l'occupation du sol des plateaux du Jura Central et du bassin supérieur de la Saône. L'habitat et l'occupation du sol a l'Age du Bronze en Europe (C. Mordant, A. Richard, eds.), Actes du Colloque International de Lons-le-Saunier, Paris: 195-226.

PéReZ de BARRAdAS, J. (1924): Introducción al estudio de la Prehistoria madrileña. Revista de la Biblioteca, Archivo y Museo del Ayuntamiento de Madrid, I: 13-35.

Pérez Rodríguez, F.J.; Misiego Tejeda, J.C.; Sanz García, F.J.; Marcos Contrearas G.J.; Martín Carbajo, M.A.; FernÁNDEZ GimÉNEZ, J.M. (1994): "La Huelga". Un interesante yacimiento de la Edad del Bronce en el centro de la Cuenca del Duero (Dueñas, Palencia). Nvmantia. Arqueología en Castilla y León, 5: 11-32.

Quintana López, J. (1993): Sobre la secuencia de la Edad del Hierro en Simancas. Arqueología vaccea. Estudios sobre el mundo prerromano en la cuenca media del Duero (F. Romero, C. Sanz, Z. Escudero, eds.), Junta de Castilla y León, Valladolid: 67-91.

Quintana López, J.; Cruz Sánchez, P.J. (1996): Del Bronce al Hierro en el centro de la Submeseta Norte (Consideraciones desde el Inventario Arqueológico de Valladolid). Boletín del Seminario de Arte y Arqueología, LXII: 9-78.

Ramírez Ramírez, Ma .L. (1999): La casa circular durante la primera Edad del Hierro en el Valle del Duero. Numantia. Arqueología en Castilla y León, 7: 67-94.

Reynolds, P.J. (1979): Iron Age Farm: The Butsir Experiment. British Museum, London. 
Rodríguez, E.; Larrén, H.; García Rozas, R. (1990): Carta Arqueológica de Villafáfila. Anuario del Instituto de Estudios Zamoranos "Florián de Ocampo": 33-76.

Rodríguez Marcos, J.A. (1993): El Carrizal (Cogeces del Monte, Valladolid): un nuevo yacimiento de facies Proto/Cogotas I, Numantia. Arqueología en Castilla y León, 4: 61-74.

Rodríguez Marcos, J.A.; Moral del Hoyo, S. (2007): Algunos ejemplos de ingeniería prehistórica poco conocidos: tres poblados amurallados del Bronce medio de la sub-Mesesta norte. Actas del Quinto Congreso Nacional de Historia de la Construcción, 2 (M. Arenillas Parra, C. Segura Graíño, F. Bueno Hernández, S. Huerta Fernández, coords.), Instituto Juan de Herrera, Madrid: 775-780.

Rodríguez Marcos, J.A.; Val Recio, J. del (1990): Nuevos datos para la interpretación de los "Hoyos" de Cogotas I. Un silo de Barcial del Barco. Actas del Primer Congreso de Historia de Zamora. II. Prehistoria e Historia Antigua, Instituto de Estudios Zamoranos "Florián de Ocampo", Zamora: 201-209.

Rojo Guerra, M. (1987): Asentamientos prehistóricos en la Cuenca de la Nava: Estudio de sus relaciones. Actas del Primer Congreso de Historia de Palencia. I. Arte, Arqueología y Edad Antigua, Diputación Provincial de Palencia, Palencia: 409-422.

Romero CARnicero, F. (1980): Notas sobre la cerámica de la primera Edad del Hierro en la cuenca media del Duero. Boletín del Seminario de Arte y Arqueología, XLVI: 137-153.

Romero Carnicero, F. (1992): Los antecedentes protohistóricos. Arquitectura de piedra y barro durante la primera Edad del Hierro. Arquitectura popular en Castilla y León. Bases para un estudio (J.M. Báez Mezquita, coord.), Universidad de Valladolid, Valladolid: 175-211.

Romero Carnicero, F.; Cubero Corpas, C. (1999): Agricultura y recolección en la cultura del Soto (Primera Edad del Hierro en el valle medio del Duero). Els productes alimentaris d'origen vegetal a l'edat del Ferro de l'Europa Occidental: de la producció al consum (R. Buxó, E. Pons, dirs.), Actes del XXII Colloqui Internacional per a l'Estudi de l'Edat del Ferro, Museu d'Arqueologia de Catalunya-Girona, Sèrie Monogràfica, 18, Girona: 169-187.

Romero Carnicero, F.; Jimeno Martínez, A. (1993): El valle del Duero en la antesala de la Historia. Los grupos del Bronce Medio-Final y Primer Hierro. Los Celtas: Hispania y Europa (M. Almagro-Gorbea, G. Ruiz Zapatero, eds.), Actas de El Escorial, Madrid: 175-222.

Romero Carnicero, F.; Ramírez Ramírez, M.L. (1996): La cultura del Soto. Reflexiones sobre los contactos entre el Duero Medio y las tierras del sur peninsular durante la primera Edad del Hierro. Homenaje al Profesor Manuel Fernández-Miranda (M.A. Querol, T. Chapa, eds.), Complutum Extra, 6 (I): 313-326.

Romero Carnicero, F.; Ramírez Ramírez, M.L. (1999): Estrategias de subsistencia en la cuenca media del Duero durante la Edad del Hierro. Economía. IV Simposio sobre los Celtíberos (F. Burillo Mozota, coord.), Institución "Fernando El Católico", Zaragoza: 453-465.

Romero Carnicero, F.; Ramírez Ramírez, M.L. (2001): Sobre el "celtismo" de la "cultura" del Soto. Boletín del Seminario de Arte y Arqueología, LXVII: 40-80.

Romero, Carnicero, F; Sanz Minguez, C.; Álvarez-Sanchïs, J. (2008): El primer milenio a. C. en las tierras del interior peninsular. De Iberia a Hispania. (F. Gracia Alonso, coord.), Ariel, Barcelona: 694-731.

Romero Masiá, A. (1976): El hábitat castreño. Asentamientos y arquitectura de los castros del N. O. peninsular. Publicacions do Colexio de Arquitectos de Galicia, Santiago de Compostela.

Ruiz-Gálvez Priego, M. (1998): La Europa atlántica en la Edad del Bronce. Un viaje a las raíces de la Europa occidental. Crítica, Barcelona.

Ruiz Zapatero, G. (1995): El substrato de la Celtiberia Citerior. El problema de las invasiones. Poblamiento Celtibérico (F. Burillo Mozota, coord.), III Simposio sobre los Celtíberos. Institución "Fernando El Católico", Zaragoza: 25-40.

Sacristán de Lama, J.D. (1986): La Edad del Hierro en el valle medio del Duero. Rauda (Roa, Burgos). Junta de Castilla y León y Universidad de Valladolid, Valladolid.

Sacristán de Lama, J.D. (1994): Burgos. Numantia. Arqueología en Castilla y León, 5: 247-260.

San Miguel Maté, L.C. (1993): El poblamiento de la Edad del Hierro al occidente del valle medio del Duero. Arqueología vaccea. Estudios sobre el mundo prerromano en la cuenca media del Duero (F. Romero, C. Sanz, Z. Escudero, eds.), Junta de Castilla y León, Valladolid: 21-65. 
SAntos Villaseñor, J. (1989): "La Aldehuela", Zamora. Resumen de la tercera campaña de excavación 1989. Anuario del Instituto de Estudios Zamoranos "Florián de Ocampo": 171-180.

Seco Villar, M.; Treceño Losada, F. (1993): La temprana "iberización" de las tierras del sur del Duero a través de la secuencia de "La Mota", Medina del Campo (Valladolid). Arqueología vaccea. Estudios sobre el mundo prerromano en la cuenca media del Duero (F. Romero, C. Sanz, Z. Escudero, eds.), Junta de Castilla y León, Valladolid: 133-171.

SolÉ SABARís, L. (1966): Sobre el concepto de Meseta española y su descubrimiento. Homenaje al Excmo. Sr. D. Amando Melón y Ruiz de Gordejuela, Instituto de Estudios Pirenaicos, Zaragoza: 15-45.

TERrón, E. (1981): La experiencia de la práctica agropecuaria, base de todo conocimiento. Agricultura General (edición crítica de E. Terrón) (G. Alonso de Herrera, ed.), Servicio de Publicaciones del Ministerio de Agricultura y Pesca, Madrid: 3-37.

Ulreich, H.; Negrete Martínez, M.A.; Puch Ramírez, E. (1994): Cerámica decorada de Hoyas del Castillo (Pajaroncillo, Cuenca), Corte 4. Boletín del Seminario Arte y Arqueología, LX: 105-137.

Vergés, J.M.; Allué, E.; Angelucci, D.E.; Cebriá, A.; Dóez, C.; Fontanal, M.; Manyanos, A.; Montero, S.; Moral, S.; Vaquero, M.; Zaragoza, J. (2002): La Sierra de Atapuerca durante el Holoceno: datos preliminares de la Edad del Bronce en la cueva de El Mirador (Ibeas de Juarros, Burgos). Trabajos de Prehistoria, 59: 107-126.

YlL, R. (1995): Análisis polínico de los yacimientos de la Edad del Hierro de Soto de Medinilla, La Era Alta y La Mota (Valladolid). Arqueología y medio ambiente. El primer milenio a.C. en el Duero Medio (G. Delibes, F. Romero, A. Morales, eds.), Junta de Castilla y León, Valladolid: 357-370. 